\title{
Addition of Fluorine and a Late-Stage Functionalization (LSF) of the Oral SERD AZD9833.
}

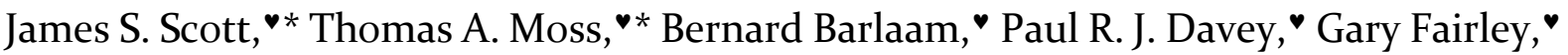 \\ Eric T. Gangl,* Ryan D. R. Greenwood," Holia Hatoum-Mokdad,* Andrew S. Lister," \\ David Longmire, $`$ Radoslaw Polanski,` Stephen Stokes, ${ }^{\vee}$ Michael J. Tucker, $`$ Jeffrey G. \\ Varnes,* Bin Yang.* \\ •Oncology R\&D, AstraZeneca, Cambridge CB4 oWG, United Kingdom. \\ *Oncology R\&D, AstraZeneca, R\&D Boston, 35 Gatehouse Drive, Waltham, Massachusetts 02451, United \\ States. \\ • Discovery Sciences, AstraZeneca, Cambridge CB4 oWG, United Kingdom.
}

Table of Contents:

Synthesis of intermediates and final compounds:

Biochemical and in vitro cell assays:

PAINS screening:

Molecular Formula Strings:
S2

S29

S32

S32

\section{EXPERIMENTAL SECTION}

General Procedures: All solvents and chemicals used were reagent grade. Anhydrous solvents THF, DCM, and DMF were purchased from Aldrich. Solutions were dried over anhydrous magnesium sulfate or sodium sulfate, and solvent was removed by rotary evaporation under reduced pressure. Microwave reactions were run in a Biotage 'Initiator Robot 60' (100-120/220-240 V, 50-60 Hz, 100 VA). Flash column chromatography was carried out using prepacked silica cartridges (from $4 \mathrm{~g}$ up to $330 \mathrm{~g})$ from Grace, Redisep or Silicycle and eluted using an Isco Companion system. The purity of compounds submitted for screening was $>95 \%$ as determined by UV analysis of liquid chromatography-mass spectroscopy (LCMS) chromatograms at $254 \mathrm{nM}$ and substantiated using the TAC (Total Absorption Chromatogram). Further support for the purity statement was provided using the MS TIC (Total lon Current) trace in ESI +ve and -ve ion modes, HRMS and NMR analysis. NMR spectra were recorded on Bruker Avance Neo $500 \mathrm{MHz}$ or Bruker Avance DPX400 and were determined in $\mathrm{CDCl}_{3}, \mathrm{DMSO}-d_{6}$, or $\mathrm{MeOH}-d_{4}$. Chemical shifts are reported as ? in ppm relative to TMS $(0.00 \mathrm{ppm})$ or solvent peaks as the internal reference. Splitting patterns are indicated as follows: $s$, singlet; $d$, doublet; $t$, triplet; $m$, multiplet; br, broad peak. Analytical LCMS was carried out using a suitable system, such as a Waters 2790/95 LC system with a 2996 PDA and a 2000 amu ZQ single quadrupole mass spectrometer, or a UPLC system utilising a Waters Aquity Binary pump with sample manager, Aquity PDA and SQD Mass spectrometer. Accurate mass and MSMS fragmentation data were obtained using a Thermo Scientific hybrid LTQ-FT Mass Spectrometer with an Agilent 1100 Quaternary pump with PDA and Autosampler; $5 \mu \mathrm{L}$ of sample dissolved in 50:50 acetonitrile:water $0.1 \%$ formic acid was injected onto a Thermo Scientific Hypersil Gold 50 × $2.1 \mathrm{~mm} 5 \mu \mathrm{m}$ particle LC 
Column and eluted with a gradient of 5 to $100 \%$ B over 17 min with 3 min re-equilibration time at $5 \%$ B. The flow rate was $0.5 \mathrm{~mL} / \mathrm{min}$ with A being $0.1 \%$ formic acid in water and $B 0.1 \%$ formic acid in acetonitrile. The MS and MSMS spectra were obtained in ESI +ve mode in both the ion trap and lon Cyclotron Resonance (ICR) cell using helium as the collision gas at a normalised collision energy of 35 $\mathrm{eV}$. The ICR cell was run at resolution settings of 25000 in MS mode and 12500 in MSMS mode.

All IC ${ }_{50}$ data are quoted as geometric mean values, and statistical analysis is available in the Supporting Information.

All experimental activities involving animals were carried out in accordance with AstraZeneca animal welfare protocols which are consistent with The American Chemical Society Publications rules and ethical guidelines.

\section{Scheme 1}

\section{Preparation of 5-bromo-2-(dimethoxymethyl)pyridine (13)}<smiles>COC(OC)c1ccc(Br)cn1</smiles>

Indium trifluoromethanesulfonate $(0.151 \mathrm{~g}, 0.27 \mathrm{mmol})$ was added to 5 -bromopicolinaldehyde $(5.00$ $\mathrm{g}, 26.9 \mathrm{mmol})$ and trimethyl orthoformate $(5.94 \mathrm{~mL}, 53.8 \mathrm{mmol})$ in DCM $(50 \mathrm{~mL})$ under nitrogen. The resulting solution was stirred at $40{ }^{\circ} \mathrm{C}$ for 24 hours. The reaction mixture was concentrated under reduced pressure. The residue was purified by flash silica chromatography, elution gradient 0 to $20 \%$ EtOAc in heptane to afford 5-bromo-2-(dimethoxymethyl)pyridine $(4.43 \mathrm{~g}, 71 \%)$ as a colourless oil. ${ }^{1} \mathrm{H}$ $\operatorname{NMR}\left(500 \mathrm{MHz}, \mathrm{CDCl}_{3}, 27^{\circ} \mathrm{C}\right) 3.33(6 \mathrm{H}, \mathrm{s}), 5.27(1 \mathrm{H}, \mathrm{s}), 7.39(1 \mathrm{H}, \mathrm{dt}), 7.75-7.83(1 \mathrm{H}, \mathrm{m}), 8.61(1 \mathrm{H}, \mathrm{dd})$.

\section{Preparation of 3-bromo-6-(dimethoxymethyl)-2-fluoropyridine (14)}<smiles>COC(OC)c1ccc(Br)c(F)n1</smiles>

Silver(II) fluoride $(2.83 \mathrm{~g}, 19.39 \mathrm{mmol})$ was added in one portion to 5-bromo-2(dimethoxymethyl)pyridine $13(1.50 \mathrm{~g}, 6.46 \mathrm{mmol})$ in acetonitrile $(26 \mathrm{~mL})$ under nitrogen. The resulting solution was stirred at room temperature for 18 hours. The reaction was filtered through a plug of silica and washed with MeCN. The filtrate was then concentrated under reduced pressure, then the crude product was purified by flash silica chromatography, elution gradient 0 to $10 \%$ EtOAc in heptane to afford 3-bromo-6-(dimethoxymethyl)-2-fluoropyridine 14 (0.941 g, 58\%) as a colourless oil. ${ }^{1} \mathrm{H}$ NMR $\left(500 \mathrm{MHz}, \mathrm{CDCl}_{3}, 27^{\circ} \mathrm{C}\right) 3.33(6 \mathrm{H}, \mathrm{s}), 5.18(1 \mathrm{H}, \mathrm{s}), 7.29(1 \mathrm{H}, \mathrm{ddd}), 7.87-7.98(1 \mathrm{H}, \mathrm{m}) ;{ }^{19} \mathrm{~F} \mathrm{NMR}(471$ $\left.\mathrm{MHz}, \mathrm{CDCl}_{3}, 27^{\circ} \mathrm{C}\right)-64.51$.

\section{Preparation of 5-bromo-6-fluoropicolinaldehyde (15)}<smiles>O=Cc1ccc(Br)c(F)n1</smiles>

Aqueous $\mathrm{HCl}(2 \mathrm{~N}, 10 \mathrm{~mL}$ ) was added to a solution of 3-bromo-6-(dimethoxymethyl)-2-fluoropyridine 14 (900 mg, $3.60 \mathrm{mmol})$ in THF $(10 \mathrm{~mL})$. The resulting solution was stirred at room temperature for 1 hour. The reaction was neutralised by addition of $2 \mathrm{~N}$ aqueous $\mathrm{Na}_{2} \mathrm{CO}_{3}$ solution and extracted with EtOAc. The organic phase was dried over $\mathrm{Na}_{2} \mathrm{SO}_{4}$, filtered and evaporated to afford 5-bromo-6fluoropicolinaldehyde 15 (702 mg, 96\%) as a colourless solid, which was used directly. ${ }^{1} \mathrm{H}$ NMR (500 $\left.\mathrm{MHz}, \mathrm{CDCl}_{3}, 27^{\circ} \mathrm{C}\right) 7.75(1 \mathrm{H}, \mathrm{dd}), 8.18(1 \mathrm{H}, \mathrm{td}), 9.92(1 \mathrm{H}, \mathrm{d})$. 


\section{Preparation of tert-butyl $(R)-(1-(1 H$-indazol-4-yl)propan-2-yl)carbamate}<smiles>C[C@H](Cc1cccc2[nH]ncc12)NC(=O)OC(C)(C)C</smiles>

$n$-Butyllithium in hexane $(2.5 \mathrm{M} ; 96 \mathrm{~mL}, 241 \mathrm{mmol})$ was added to a solution of 4-bromo- $1 \mathrm{H}$-indazole $(24.8 \mathrm{~g}, 126 \mathrm{mmol})$ in THF $(200 \mathrm{~mL})$ at $-78^{\circ} \mathrm{C}$ over 20 minutes, and the mixture was stirred at $-78{ }^{\circ} \mathrm{C}$ for 7 hours. Tert-butyl (R)-4-methyl-1,2,3-oxathiazolidine-3-carboxylate 2,2-dioxide $(26.0 \mathrm{~g}, 110$ mmol) was added, and the resultant mixture was stirred at $-78{ }^{\circ} \mathrm{C}$ for 15 minutes. The cooling bath was removed, and the mixture was stirred under these conditions for 18 hours. Aqueous citric acid $(1 \mathrm{~N} ; 130 \mathrm{~mL}$ ) was added and stirring was continued for 30 minutes. The mixture was extracted with hexanes, and the organic layer was washed with saturated aqueous sodium carbonate, dried over sodium sulfate, filtered and concentrated under reduced pressure. The resulting residue was purified by flash silica chromatography, eluting with 0 to $60 \%$ EtOAc in hexanes, to afford tert-butyl $(R)-(1-(1 H-$ indazol-4-yl)propan-2-yl)carbamate $(17.3 \mathrm{~g}, 57 \%)$ as a white solid. ${ }^{1} \mathrm{H} \mathrm{NMR}\left(300 \mathrm{MHz}\right.$, DMSO- $\left.d_{6}, 27^{\circ} \mathrm{C}\right)$ $1.02(3 \mathrm{H}, \mathrm{br} \mathrm{d}), 1.34(9 \mathrm{H}, \mathrm{s}), 2.82(1 \mathrm{H}, \mathrm{br} \mathrm{dd}), 3.09(1 \mathrm{H}, \mathrm{br} \mathrm{dd}), 3.82(1 \mathrm{H}, \mathrm{dt}), 6.82(1 \mathrm{H}, \mathrm{br} \mathrm{d}), 6.88(1 \mathrm{H}$, d), $7.24(1 \mathrm{H}, \mathrm{dd}), 7.35(1 \mathrm{H}, \mathrm{br} d), 8.18(1 \mathrm{H}, \mathrm{s}), 12.97(1 \mathrm{H}, \mathrm{s}) ; \mathrm{m} / \mathrm{z}$ : $\mathrm{ESI}+$ calcd $\mathrm{C}_{15} \mathrm{H}_{21} \mathrm{~N}_{3} \mathrm{O}_{2}[\mathrm{M}+\mathrm{H}]+:$ : 276; observed 276.

\section{Preparation of $(R)-1-(1 H$-indazol-4-yl)propan-2-amine dihydrochloride}

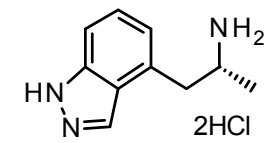

$\mathrm{HCl}$ in dioxane $(4 \mathrm{M}, 100 \mathrm{~mL}, 400 \mathrm{mmol})$ was added to a suspension of tert-butyl $(R)-(1-(1 \mathrm{H}$-indazol-4yl)propan-2-yl)carbamate $(17.3 \mathrm{~g}, 62.7 \mathrm{mmol})$ in DCM $(200 \mathrm{~mL})$ at room temperature over 10 minutes. The resulting slurry was stirred overnight and then concentrated under reduced pressure to afford (R)-1-(1H-indazol-4-yl)propan-2-amine $(15.9 \mathrm{~g}, 100 \%)$ as white solid. ${ }^{1} \mathrm{H}$ NMR (300 MHz, DMSO- $d_{6}, 27$ $\left.{ }^{\circ} \mathrm{C}\right) 1.14(3 \mathrm{H}, \mathrm{d}), 2.97(1 \mathrm{H}, \mathrm{dd}), 3.40(1 \mathrm{H}, \mathrm{dd}), 3.45-3.62(1 \mathrm{H}, \mathrm{m}), 6.96(1 \mathrm{H}, \mathrm{d}), 7.29(1 \mathrm{H}, \mathrm{dd}), 7.45(1 \mathrm{H}$, d), $7.97-8.27(3 \mathrm{H}, \mathrm{br} \mathrm{s}), 8.29(1 \mathrm{H}, \mathrm{d}) ; \mathrm{m} / \mathrm{z}$ : ESI+ calcd $\mathrm{C}_{10} \mathrm{H}_{13} \mathrm{~N}_{3}[\mathrm{M}+\mathrm{H}]+:$ 176; observed 176.

\section{Preparation of $(R)-1-(1 H$-indazol-4-yl)-N-(2,2,2-trifluoroethyl)propan-2-amine (16)}<smiles>C[C@H](Cc1cccc2[nH]ncc12)NCC(F)(F)F</smiles>

Potassium carbonate $(4.75 \mathrm{~g}, 34.3 \mathrm{mmol})$ was added to a stirred suspension of $(R)$-1-(1H-indazol-4yl)propan-2-amine dihydrochloride salt $(2.13 \mathrm{~g}, 8.58 \mathrm{mmol})$ in acetonitrile $(25 \mathrm{~mL})$ then 2,2,2trifluoroethyl trifluoromethanesulfonate $(2.19 \mathrm{~g}, 9.44 \mathrm{mmol})$ in DCM $(12.6 \mathrm{~mL})$ was added dropwise. The mixture was stirred at room temperature for 1.5 days. Additional 2,2,2-trifluoroethyl trifluoromethanesulfonate $(398 \mathrm{mg})$ in DCM $(0.30 \mathrm{~mL})$ was added. The resulting solution was stirred at $60{ }^{\circ} \mathrm{C}$ and after 3 hours, the reaction was cooled to room temperature and a further portion of 2,2,2-trifluoroethyl trifluoromethanesulfonate (398 $\mathrm{mg}$ ) was added as a solution in DCM $(0.30 \mathrm{~mL})$. After 18 hours, the reaction was concentrated under reduced pressure and then diluted with DCM. The mixture was washed with water, and the organic layer was dried over sodium sulfate, filtered and concentrated under reduced pressure. The resulting residue was purified by flash silica chromatography, elution gradient 0 to $60 \%$ ethyl acetate in hexanes to afford $(R)-1$ - $(1 \mathrm{H}$-indazol-4-yl)$\mathrm{N}$-(2,2,2-trifluoroethyl)propan-2-amine 16 (2.06 g, 93\%) as a gum. $\left.{ }^{1} \mathrm{H} \mathrm{NMR} \mathrm{(500} \mathrm{MHz,} \mathrm{CDCl}_{3}, 27^{\circ} \mathrm{C}\right) 1.12$ 
$(3 \mathrm{H}, \mathrm{d}), 2.96(1 \mathrm{H}, \mathrm{dd}), 3.08(1 \mathrm{H}, \mathrm{dd}), 3.13-3.30(3 \mathrm{H}, \mathrm{m}), 6.98(1 \mathrm{H}, \mathrm{dd}), 7.33(1 \mathrm{H}, \mathrm{dd}), 7.39(1 \mathrm{H}, \mathrm{d}), 8.12$ $(1 \mathrm{H}, \mathrm{d}), 10.26(1 \mathrm{H}, \mathrm{s}) ;{ }^{19} \mathrm{~F} \mathrm{NMR}\left(471 \mathrm{MHz}, \mathrm{CDCl}_{3}, 27^{\circ} \mathrm{C}\right)-71.85(\mathrm{~J}=9.4) ; \mathrm{m} / \mathrm{z}$ : ESI+ calcd $\mathrm{C}_{12} \mathrm{H}_{14} \mathrm{~F}_{3} \mathrm{~N}_{3}$ $[\mathrm{M}+\mathrm{H}]+$ : 258; observed 258.

Preparation of (6S,8R)-6-(5-bromo-6-fluoropyridin-2-yl)-8-methyl-7-(2,2,2-trifluoroethyl)-6,7,8,9tetrahydro-3H-pyrazolo[4,3-f]isoquinoline (17)<smiles>C[C@H]1Cc2c(ccc3[nH]ncc23)C(c2ccc(Br)c(F)n2)N1CC(F)(F)F</smiles>

Trifluoroacetic acid (1.69 $\mathrm{mL})$ was added to a solution of $(R)-1$-(1H-indazol-4-yl)-N-(2,2,2trifluoroethyl)propan-2-amine $(1.83 \mathrm{~g}, 7.11 \mathrm{mmol})$ and 5-bromo-6-fluoropicolinaldehyde $(1.45 \mathrm{~g}, 7.11$ $\mathrm{mmol})$ in toluene $(33.8 \mathrm{~mL})$. The resulting solution was stirred at $90^{\circ} \mathrm{C}$ overnight. The reaction mixture was cooled to room temperature, diluted with EtOAc $(50 \mathrm{~mL})$ and washed with aqueous $\mathrm{NaHCO}_{3}$ solution $(50 \mathrm{~mL})$. The organic layer was dried over $\mathrm{Na}_{2} \mathrm{SO}_{4}$, filtered and evaporated. The crude product was purified by flash silica chromatography, elution gradient 0 to $50 \%$ EtOAc in heptane. Pure fractions were evaporated to dryness to afford (6S,8R)-6-(5-bromo-6-fluoropyridin-2-yl)-8-methyl-7-(2,2,2trifluoroethyl)-6,7,8,9-tetrahydro-3H-pyrazolo[4,3-f] isoquinoline 17 as a white solid (2.09 g, 62\%). ${ }^{1} \mathrm{H}$ NMR $\left(300 \mathrm{MHz}\right.$, DMSO- $\left.d_{6}\right) 1.12(3 \mathrm{H}, \mathrm{d}), 2.81-2.92(1 \mathrm{H}, \mathrm{m}), 2.94-3.11(2 \mathrm{H}, \mathrm{m}), 3.32-3.45(1 \mathrm{H}, \mathrm{m})$, $3.51-3.72(1 \mathrm{H}, \mathrm{m}), 5.08(1 \mathrm{H}, \mathrm{s}), 6.97(1 \mathrm{H}, \mathrm{d}), 7.30(2 \mathrm{H}, \mathrm{dt}), 8.07(1 \mathrm{H}, \mathrm{s}), 8.24(1 \mathrm{H}, \mathrm{dd}), 13.02(1 \mathrm{H}, \mathrm{s}) ;{ }^{19} \mathrm{~F}$ NMR (471 MHz, CDCl3, 27 $\left.{ }^{\circ} \mathrm{C}\right)-70.90(\mathrm{~J}=9.3),-65.61(\mathrm{~J}=8.7) ; \mathrm{m} / \mathrm{z}$ : $\mathrm{ESI}+$ calcd $\mathrm{C}_{18} \mathrm{H}_{15} \mathrm{BrF}_{4} \mathrm{~N}_{4}[\mathrm{M}+\mathrm{H}]+$ : 443; observed 443.

Preparation of $(6 S, 8 R)$-6-(5-bromo-3-fluoropyridin-2-yl)-8-methyl-7-(2,2,2-trifluoroethyl)-6,7,8,9tetrahydro-3H-pyrazolo[4,3-flisoquinoline (18)<smiles>C[C@H]1Cc2c(ccc3[nH]ncc23)[C@@H](c2cncc(Br)c2)N1CC(F)(F)F</smiles>

Trifluoroacetic acid $(0.050 \mathrm{~mL})$ was added to a solution of $(R)-1-(1 \mathrm{H}$-indazol-4-yl)- $N-(2,2,2-$ trifluoroethyl)propan-2-amine $(38.0 \mathrm{mg}, 0.15 \mathrm{mmol})$ and 5-bromo-3-fluoropicolinaldehyde $(30.1 \mathrm{mg}$, $0.15 \mathrm{mmol}$ ) in toluene $(1.0 \mathrm{~mL})$. The resulting solutionwas stirred at $100^{\circ} \mathrm{C}$ for 30 minutes. The reaction mixture was concentrated under reduced pressure. The residue was partitioned between DCM $(2.00$ $\mathrm{mL}$ ) and $2 \mathrm{M} \mathrm{NaOH}(2.00 \mathrm{~mL})$. The organic phase was dried over $\mathrm{Na}_{2} \mathrm{SO}_{4}$, filtered and evaporated. The crude product was purified by flash silica chromatography, elution gradient 0 to $50 \%$ EtOAc in heptane to afford (6S,8R)-6-(5-bromo-3-fluoropyridin-2-yl)-8-methyl-7-(2,2,2-trifluoroethyl)-6,7,8,9tetrahydro-3 $\mathrm{H}$-pyrazolo[4,3-f] isoquinoline $(42.0 \mathrm{mg}, 64 \%)$ as a cream solid. ${ }^{1} \mathrm{H} \mathrm{NMR}\left(500 \mathrm{MHz}, \mathrm{CDCl}_{3}\right.$, $\left.27^{\circ} \mathrm{C}\right) 1.16(3 \mathrm{H}, \mathrm{d}), 2.87(1 \mathrm{H}, \mathrm{dd}), 3.01(1 \mathrm{H}, \mathrm{dq}), 3.21-3.35(2 \mathrm{H}, \mathrm{m}), 3.68-3.77(1 \mathrm{H}, \mathrm{m}), 5.42(1 \mathrm{H}, \mathrm{s})$, $6.81(1 \mathrm{H}, \mathrm{d}), 7.22(1 \mathrm{H}, \mathrm{dd}), 7.58(1 \mathrm{H}, \mathrm{dd}), 8.07(1 \mathrm{H}, \mathrm{d}), 8.36(1 \mathrm{H}, \mathrm{dd}), 10.16(1 \mathrm{H}, \mathrm{s}) ;{ }^{19} \mathrm{~F} \mathrm{NMR}(471 \mathrm{MHz}$, $\left.\mathrm{CDCl}_{3}, 27^{\circ} \mathrm{C}\right)-118.71(J=8.5),-71.34(J=8.5) ; \mathrm{m} / \mathrm{z}$ : $\mathrm{ESI}+$ calcd $\mathrm{C}_{18} \mathrm{H}_{15} \mathrm{BrF}_{4} \mathrm{~N}_{4}[\mathrm{M}+\mathrm{H}]+:$ : 443 ; observed 443. 
<smiles></smiles>

Sodium tert-butoxide $(1.08 \mathrm{~g}, 11.3 \mathrm{mmol})$ and BrettPhos 3rd Generation precatalyst $(0.164 \mathrm{~g}, 0.18$ $\mathrm{mmol})$ were added to a degassed solution of (6S,8R)-6-(5-bromo-6-fluoropyridin-2-yl)-8-methyl-7(2,2,2-trifluoroethyl)-6,7,8,9-tetrahydro-3H-pyrazolo[4,3-f]isoquinoline 17 (2.00 g, $4.51 \mathrm{mmol}$ ) and 1(3-fluoropropyl)azetidin-3-amine $(0.900 \mathrm{~g}, 5.41 \mathrm{mmol})$ in 1,4-dioxane $(22.6 \mathrm{~mL})$. The resulting solution was stirred at $45{ }^{\circ} \mathrm{C}$ for 30 minutes. The reaction mixture was poured into EtOAc $(100 \mathrm{~mL})$ and saturated brine $(100 \mathrm{~mL})$. The layers were separated, then the aqueous layer was extracted with EtOAc $(3 \times 100 \mathrm{~mL})$. The combined organic layers were washed with saturated brine, dried over $\mathrm{Na}_{2} \mathrm{SO}_{4}$, filtered and evaporated. The residue was purified by flash silica chromatography, elution gradient 0 to $30 \% \mathrm{MeOH}$ in EtOAc to afford 2-fluoro- $N$-(1-(3-fluoropropyl)azetidin-3-yl)-6-((6S,8R)-8-methyl-7(2,2,2-trifluoroethyl)-6,7,8,9-tetrahydro-3H-pyrazolo[4,3-f]isoquinolin-6-yl)pyridin-3-amine 2 (1.580 $\mathrm{g}, 71 \%)$ as a light yellow foam solid. ${ }^{1} \mathrm{H}$ NMR $\left(300 \mathrm{MHz}, \mathrm{DMSO}-d_{6}\right) 1.11(3 \mathrm{H}, \mathrm{d}), 1.53-1.76(2 \mathrm{H}, \mathrm{m}), 2.43$ - $2.49(2 \mathrm{H}, \mathrm{m}), 2.78-3.08(5 \mathrm{H}, \mathrm{m}), 3.39-3.60(2 \mathrm{H}, \mathrm{m}), 3.64(2 \mathrm{H}, \mathrm{brt}), 3.91-4.02(1 \mathrm{H}, \mathrm{m}), 4.45(2 \mathrm{H}, \mathrm{dt})$, $4.92(1 \mathrm{H}, \mathrm{s}), 6.12(1 \mathrm{H}, \mathrm{d}), 6.88(1 \mathrm{H}, \mathrm{d}), 6.92-7.01(2 \mathrm{H}, \mathrm{m}), 7.26(1 \mathrm{H}, \mathrm{d}), 8.06(1 \mathrm{H}, \mathrm{s}), 12.99(1 \mathrm{H}, \mathrm{s}) ;{ }^{13} \mathrm{C}$ $\operatorname{NMR}\left(126 \mathrm{MHz}, \mathrm{DMSO}-d_{6}, 27^{\circ} \mathrm{C}\right) 16.8,27.9,29.3,42.7,46.7,48.3,54.3,60.4,66.2,81.9(\mathrm{~J}=167.7 \mathrm{~Hz})$, $107.4,119.8,121.4,122.3,125.3,126.1,126.5,127.4,129.1,131.4,138.4,144.8,150.8(J=228.1 \mathrm{~Hz})$. ${ }^{19} \mathrm{~F}$ NMR $\left(471 \mathrm{MHz}\right.$, DMSO- $\left.d_{6}, 27^{\circ} \mathrm{C}\right)-218.14(J=47.3,25.3),-83.94--83.86,-69.87(J=9.9) ; \mathrm{m} / \mathrm{z}$ : ESI+ calcd $\mathrm{C}_{24} \mathrm{H}_{27} \mathrm{~N}_{6} \mathrm{~F}_{5}[\mathrm{M}+\mathrm{H}]+$ : 495 ; observed 495; HRMS $\left(\mathrm{ESI}^{+}\right)$: Anal. calcd. For $\mathrm{C}_{24} \mathrm{H}_{27} \mathrm{~N}_{6} \mathrm{~F}_{5}[\mathrm{M}+\mathrm{H}]+$ : 495.2296; observed 495.2293

Preparation of 5-fluoro- $N$-(1-(3-fluoropropyl)azetidin-3-yl)-6-((6S,8R)-8-methyl-7-(2,2,2trifluoroethyl)-6,7,8,9-tetrahydro-3H-pyrazolo[4,3-f] isoquinolin-6-yl)pyridin-3-amine (3)<smiles>C[C@H]1Cc2c(ccc3[nH]ncc23)C(c2ncc(NC3CN(CCCF)C3)cc2F)N1CC(F)(F)F</smiles>

1-(3-Fluoropropyl)azetidin-3-amine (435 mg, $3.29 \mathrm{mmol}),(65,8 R)$-6-(5-bromo-3-fluoropyridin-2-yl)-8methyl-7-(2,2,2-trifluoroethyl)-6,7,8,9-tetrahydro-3H-pyrazolo[4,3-f]isoquinoline $(730 \mathrm{mg}, \quad 1.65$ $\mathrm{mmol}$ ) and sodium tert-butoxide (950 $\mathrm{mg}, 9.88 \mathrm{mmol}$ ) were suspended in 1,4-dioxane $(18.3 \mathrm{~mL})$. The mixture was degassed and Brettphos $3^{\text {rd }}$ generation precatalyst $(149 \mathrm{mg}, 0.16 \mathrm{mmol}$ ) added and the reaction was stirred at $80^{\circ} \mathrm{C}$ for 1 hour. The reaction mixture was cooled to room temperature and diluted with EtOAc $(10 \mathrm{~mL})$ and washed with water $(10 \mathrm{~mL})$. The organic layer was dried over $\mathrm{MgSO}_{4}$, filtered and evaporated. The crude product was purified by preparative HPLC (Waters XSelect CSH C18 column, $5 \mu$ silica, $50 \mathrm{~mm}$ diameter, $100 \mathrm{~mm}$ length), using decreasingly polar mixtures of water (containing $1 \% \mathrm{NH}_{3}$ ) and $\mathrm{MeCN}$ as eluents to afford the product which contained $\sim 12 \%$ cis isomer. The sample was dissolved in $\mathrm{MeOH}$ and separated by SFC using the following chromatographc conditions: Column: Phenomonex Lux C1, $30 \times 250 \mathrm{~mm}, 5$ micron, Mobile phase: $30 \% \mathrm{MeOH}+0.1 \% \mathrm{NH}_{3} / 70 \%$ 
$\mathrm{SCCO}_{2}$ to afford 5-fluoro- $N$-(1-(3-fluoropropyl)azetidin-3-yl)-6-((6S,8R)-8-methyl-7-(2,2,2trifluoroethyl)-6,7,8,9-tetrahydro-3H-pyrazolo[4,3-f] isoquinolin-6-yl)pyridin-3-amine 3 (396 mg, 49\%) as a yellow solid. ${ }^{1} \mathrm{H}$ NMR $\left(500 \mathrm{MHz}, \mathrm{CDCl}_{3}, 27^{\circ} \mathrm{C}\right) 1.15(3 \mathrm{H}, \mathrm{d}), 1.69-1.81(2 \mathrm{H}, \mathrm{m}), 2.60(2 \mathrm{H}, \mathrm{t}), 2.77$ $(1 \mathrm{H}, \mathrm{dd}), 2.92-3.03(3 \mathrm{H}, \mathrm{m}), 3.14-3.31(2 \mathrm{H}, \mathrm{m}), 3.65-3.79(3 \mathrm{H}, \mathrm{m}), 4.04(1 \mathrm{H}, \mathrm{q}), 4.43(2 \mathrm{H}, \mathrm{t}), 4.53$ $(1 \mathrm{H}, \mathrm{t}), 5.35(1 \mathrm{H}, \mathrm{s}), 6.54(1 \mathrm{H}, \mathrm{dd}), 6.76(1 \mathrm{H}, \mathrm{d}), 7.00(1 \mathrm{H}, \mathrm{d}), 7.66(1 \mathrm{H}, \mathrm{d}), 7.93(1 \mathrm{H}, \mathrm{d}), 11.06(1 \mathrm{H}, \mathrm{s}) ;{ }^{13} \mathrm{C}$ NMR $\left(126 \mathrm{MHz}\right.$, DMSO- $\left.d_{6}, 27^{\circ} \mathrm{C}\right) 17.8,28.7,29.6,43.4,47.4,49.1,55.4,61.4,62.4,82.6(\mathrm{~J}=165.6 \mathrm{~Hz})$, $105.3,108.1,122.9,125.7,126.7,127.1,127.8,130.3,132.0,136.7,139.1,145.4,158.7(J=252.9 \mathrm{~Hz})$; ${ }^{19} \mathrm{~F}$ NMR $\left(471 \mathrm{MHz}\right.$, DMSO- $\left.d_{6}, 27^{\circ} \mathrm{C}\right)-218.16(J=47.7,25.2),-124.72(J=13.2,7.3),-69.99(J=9.5)$; $\mathrm{m} / \mathrm{z}$ : ESI+ calcd $\mathrm{C}_{24} \mathrm{H}_{27} \mathrm{~N}_{6} \mathrm{~F}_{5}[\mathrm{M}+\mathrm{H}]+:$ 495; observed 495; HRMS (ESI+): Anal. calcd. For $\mathrm{C}_{24} \mathrm{H}_{27} \mathrm{~N}_{6} \mathrm{~F}_{5}$ $[\mathrm{M}+\mathrm{H}]+:$ : 495.2296; observed 495.2293.

\section{Scheme 2}

Preparation of tert-butyl (R)-(1-(7-fluoro-1H-indazol-4-yl)propan-2-yl)carbamate<smiles>C[C@H](Cc1ccc(F)c2[nH]ncc12)NC(=O)OC(C)(C)C</smiles>

4-Bromo-7-fluoro- $1 \mathrm{H}$-indazole $(1.50 \mathrm{~g}, 6.98 \mathrm{mmol})$ was dissolved in THF $(23 \mathrm{~mL})$ in an oven dried flask and cooled to $-78^{\circ} \mathrm{C}$ under nitrogen. The solution was then treated with n-butyllithium $(1.6 \mathrm{M}, 6.98$ $\mathrm{mL}, 17.4 \mathrm{mmol}$ ). After stirring for $20 \mathrm{~min}$, the reaction was warmed to $-45^{\circ} \mathrm{C}$ for $30 \mathrm{~min}$, then cooled to $-78^{\circ} \mathrm{C}$. tert-Butyl $(R)$-4-methyl-1,2,3-oxathiazolidine-3-carboxylate 2,2-dioxide ( $2.32 \mathrm{~g}, 9.77 \mathrm{mmol}$ ) was added and the resulting solution was stirred for 1 hour before being allowed to warm up to $0{ }^{\circ} \mathrm{C}$ over a further 1 hour. The reaction was quenched with water and $1 \mathrm{~N}$ citric acid $(20 \mathrm{~mL})$ and the biphasic mixture was stirred at room temperature for 1 hour. The crude product was extracted with EtOAc, dried over $\mathrm{Na}_{2} \mathrm{SO}_{4}$, filtered and evaporated. The residue was purified by flash silica chromatography, elution gradient 0 to $60 \%$ EtOAc in hexanes to afford tert-butyl $(R)$-(1-(7-fluoro- $1 \mathrm{H}$ indazol-4-yl)propan-2-yl)carbamate $(1.31 \mathrm{~g}, 64 \%)$ as a colourless solid. ${ }^{1} \mathrm{H}$ NMR $\left(300 \mathrm{MHz}\right.$, DMSO- $d_{6}$, $\left.27^{\circ} \mathrm{C}\right) 1.03(3 \mathrm{H}, \mathrm{br} \mathrm{d}), 1.31(9 \mathrm{H}, \mathrm{s}), 2.75-3.13(2 \mathrm{H}, \mathrm{m}), 3.69-3.88(1 \mathrm{H}, \mathrm{m}), 6.75-6.88(2 \mathrm{H}, \mathrm{m}), 7.07(1 \mathrm{H}$, dd), $8.27(1 \mathrm{H}, \mathrm{br} d), 13.52(1 \mathrm{H}, \mathrm{s}) ; \mathrm{m} / \mathrm{z}$ : $\mathrm{ESI}+$ calcd $\mathrm{C}_{15} \mathrm{H}_{20} \mathrm{FN}_{3} \mathrm{O}_{2}[\mathrm{M}+\mathrm{H}]+:$ 294; observed 294.

\section{Preparation of $(R)$-1-(7-fluoro-1H-indazol-4-yl)propan-2-amine dihydrochloride (19)}<smiles>C[C@H](N)Cc1ccc(F)c2[nH]ncc12</smiles>

$\mathrm{HCl}$ in dioxane $(4 \mathrm{M}, 6.70 \mathrm{~mL}, 26.8 \mathrm{mmol})$ was added to a suspension of tert-butyl ( $R$ )-(1-(7-fluoro- $1 \mathrm{H}$ indazol-4-yl)propan-2-yl)carbamate (1.31 g, $4.47 \mathrm{mmol})$ in DCM (23 mL) at room temperature over 10 minutes. The resulting solution was stirred at room temperature for 1 hour and then concentrated under reduced pressure to afford the dihydrochloride of $(R)$-1-(7-fluoro-1H-indazol-4-yl)propan-2amine dihydrochloride $(1.180 \mathrm{~g}, 99 \%) 19$ as a colourless solid. ${ }^{1} \mathrm{H}$ NMR $\left(300 \mathrm{MHz}\right.$, DMSO- $\left.d_{6}, 27^{\circ} \mathrm{C}\right) 1.15$ $(3 \mathrm{H}, \mathrm{d}), 2.98(1 \mathrm{H}, \mathrm{dd}), 3.33(1 \mathrm{H}, \mathrm{dd}), 3.41-3.56(1 \mathrm{H}, \mathrm{m}), 6.93(1 \mathrm{H}, \mathrm{dd}), 7.13(1 \mathrm{H}, \mathrm{dd}), 8.03-8.37(3 \mathrm{H}$, m), $8.40(1 \mathrm{H}, \mathrm{d}) ; \mathrm{m} / \mathrm{z}$ : $\mathrm{ESI}+$ calcd $\mathrm{C}_{10} \mathrm{H}_{12} \mathrm{FN}_{3}[\mathrm{M}+\mathrm{H}]+$ : 194; observed 194.

\section{Preparation of $(R)$-2,2,2-trifluoro- $N$-(1-(7-fluoro-1H-indazol-4-yl)propan-2-yl)acetamide}<smiles>C[C@H](Cc1ccc(F)c2[nH]ncc12)NC(=O)C(F)(F)F</smiles> 
(R)-1-(7-fluoro-1H-indazol-4-yl)propan-2-amine, $2 \mathrm{HCl} 19$ (1.18 g, $4.43 \mathrm{mmol})$ was dissolved in $\mathrm{MeOH}$ $(14.0 \mathrm{~mL})$ and treated with ethyl 2,2,2-trifluoroacetate $(0.582 \mathrm{~mL}, 4.88 \mathrm{mmol})$, followed by triethylamine $(1.85 \mathrm{~mL}, 13.30 \mathrm{mmol})$. The resulting mixture was stirred at room temperature overnight. The reaction mixture was concentrated under reduced pressure and the residue was dissolved in EtOAc $(100 \mathrm{~mL})$ and washed with water and brine. The organic phase was dried over $\mathrm{Na}_{2} \mathrm{SO}_{4}$, filtered and evaporated to afford $(R)$-2,2,2-trifluoro- $N$-(1-(7-fluoro-1H-indazol-4-yl)propan-2yl)acetamide $(1.26 \mathrm{~g}, 98 \%)$ as a beige solid. ${ }^{1} \mathrm{H}$ NMR $\left(300 \mathrm{MHz}, \mathrm{DMSO}-d_{6}, 27^{\circ} \mathrm{C}\right) 1.20(3 \mathrm{H}, \mathrm{d}), 2.94-3.16$ $(2 \mathrm{H}, \mathrm{m}), 4.09-4.27(1 \mathrm{H}, \mathrm{m}), 6.84(1 \mathrm{H}, \mathrm{dd}), 7.09(1 \mathrm{H}, \mathrm{dd}), 8.21-8.33(1 \mathrm{H}, \mathrm{m}), 9.32(1 \mathrm{H}, \mathrm{br} \mathrm{d}), 13.57(1 \mathrm{H}$, br s); $m / z$ : ESI+ calcd $\mathrm{C}_{12} \mathrm{H}_{11} \mathrm{~F}_{4} \mathrm{~N}_{3} \mathrm{O}[\mathrm{M}+\mathrm{H}]+$ : 290; observed 290.

\section{Preparation of $(R)$-1-(7-fluoro-1H-indazol-4-yl)-N-(2,2,2-trifluoroethyl)propan-2-amine (20)}<smiles>C[C@H](Cc1ccc(F)c2[nH]ncc12)NCC(F)(F)F</smiles>

Borane tetrahydrofuran complex (1.0M in THF, $26.1 \mathrm{~mL}, 26.14 \mathrm{mmol}$ ) was added dropwise to a stirred solution of $(R)$-2,2,2-trifluoro- $N$-(1-(7-fluoro-1H-indazol-4-yl)propan-2-yl)acetamide $(1.26 \mathrm{~g}, 4.36$ $\mathrm{mmol})$ in THF $(8 \mathrm{~mL})$. The resulting mixture was stirred at $60{ }^{\circ} \mathrm{C}$ overnight. After cooling to room temperature, the reaction mixture was quenched by dropwise addition of $\mathrm{MeOH}(20 \mathrm{~mL})$ and concentrated under reduced pressure. The resulting residue was dissolved in $\mathrm{MeOH}(35 \mathrm{~mL})$ treated with $10 \%$ palladium on carbon $(0.464 \mathrm{~g}, 0.44 \mathrm{mmol})$. The reaction mixture was heated at $60^{\circ} \mathrm{C}$ for 1 hour. The reaction was allowed to cool to room temperature and was filtered through celite. The solids were washed with $\mathrm{MeOH}$ and the filtrate was concentrated under reduced pressure. The residue was purified by flash silica chromatography, elution gradient 0 to $70 \%$ EtOAc in hexanes to afford $(R)$-1-(7fluoro- $1 \mathrm{H}$-indazol-4-yl)- $\mathrm{N}$-(2,2,2-trifluoroethyl)propan-2-amine $\mathbf{2 0}(0.856 \mathrm{~g}, 71 \%)$ as a colorless oil. ${ }^{1} \mathrm{H}$ $\operatorname{NMR}\left(300 \mathrm{MHz}, \mathrm{DMSO}-d_{6}, 27^{\circ} \mathrm{C}\right) 0.90(3 \mathrm{H}, \mathrm{d}), 2.16-2.30(1 \mathrm{H}, \mathrm{m}), 2.70(1 \mathrm{H}, \mathrm{dd}), 2.93-3.13(2 \mathrm{H}, \mathrm{m})$, $3.20-3.38(2 \mathrm{H}, \mathrm{m}), 6.84(1 \mathrm{H}, \mathrm{dd}), 7.07(1 \mathrm{H}, \mathrm{dd}), 8.22(1 \mathrm{H}, \mathrm{dd}), 13.53(1 \mathrm{H}, \mathrm{br} \mathrm{s}) ; \mathrm{m} / \mathrm{z}$ : ESI+ calcd $\mathrm{C}_{12} \mathrm{H}_{13} \mathrm{~F}_{4} \mathrm{~N}_{3}[\mathrm{M}+\mathrm{H}]+$ : 276; observed 276.

Preparation of (6S,8R)-6-(5-bromopyridin-2-yl)-4-fluoro-8-methyl-7-(2,2,2-trifluoroethyl)-6,7,8,9tetrahydro-3H-pyrazolo[4,3-f]isoquinoline<smiles>C[C@H]1Cc2c(ccc3[nH]ncc23)[C@@H](c2ccc(Br)cn2)N1CC(F)(F)F</smiles>

5-Bromopicolinaldehyde $(81.0 \mathrm{mg}, 0.43 \mathrm{mmol})$ was added to a stirred solution of $(\mathrm{R})$-1-(7-fluoro- $1 \mathrm{H}$ indazol-4-yl)- $N$-(2,2,2-trifluoroethyl)propan-2-amine $20(117 \mathrm{mg}, 0.43 \mathrm{mmol})$ in toluene $(2.0 \mathrm{~mL})$ under nitrogen. Trifluoroacetic acid $(0.10 \mathrm{~mL})$ was then added and the resulting mixture was stirred at $90^{\circ} \mathrm{C}$ for 21 hours. The reaction was cooled to room temperature, diluted with EtOAc $(50 \mathrm{~mL})$ and neutralized by addition of saturated aqueous $\mathrm{NaHCO}_{3}$ solution. The layers were separated and the organic phase was dried over $\mathrm{Na}_{2} \mathrm{SO}_{4}$, filtered and concentrated under reduced pressure. The residue was purified by flash silica chromatography, elution gradient 0 to $70 \%$ EtOAc in hexanes to afford (6S,8R)-6-(5-bromopyridin-2-yl)-4-fluoro-8-methyl-7-(2,2,2-trifluoroethyl)-6,7,8,9-tetrahydro-3Hpyrazolo[4,3-f] isoquinoline $(150 \mathrm{mg}, 80 \%)$ as a yellow solid, which contained $\sim 18 \%$ cis isomer by ${ }^{1} \mathrm{H}$ NMR analysis. ${ }^{1} \mathrm{H}$ NMR $\left(300 \mathrm{MHz}, \mathrm{DMSO}_{-} \mathrm{d}_{6}\right) 1.10(3 \mathrm{H}, \mathrm{d}), 2.74-2.89(1 \mathrm{H}, \mathrm{m}), 2.89-3.08(2 \mathrm{H}, \mathrm{m}), 3.30$ 
- $3.38(1 \mathrm{H}, \mathrm{m}), 3.45-3.74(1 \mathrm{H}, \mathrm{m}), 5.12(1 \mathrm{H}, \mathrm{s}), 6.80(1 \mathrm{H}, \mathrm{d}), 7.42(1 \mathrm{H}, \mathrm{d}), 8.02(1 \mathrm{H}, \mathrm{dd}), 8.17(1 \mathrm{H}, \mathrm{dd})$, $8.55(1 \mathrm{H}, \mathrm{d}), 13.57(1 \mathrm{H}, \mathrm{s}) ; \mathrm{m} / \mathrm{z}$ : $\mathrm{ESI}+$ calcd $_{18} \mathrm{H}_{15} \mathrm{BrF}_{4} \mathrm{~N}_{4}[\mathrm{M}+\mathrm{H}]+:$ 443; observed 443.

Preparation of 6-((6S,8R)-4-fluoro-8-methyl-7-(2,2,2-trifluoroethyl)-6,7,8,9-tetrahydro-3Hpyrazolo[4,3-f] isoquinolin-6-yl)-N-(1-(3-fluoropropyl)azetidin-3-yl)pyridin-3-amine (4)<smiles>C[C@H]1Cc2c(cc(F)c3[nH]ncc23)[C@@H](c2ccc(NC3CN(CCCF)C3)cn2)N1CC(F)(F)F</smiles>

(6S,8R)-6-(5-bromopyridin-2-yl)-4-fluoro-8-methyl-7-(2,2,2-trifluoroethyl)-6,7,8,9-tetrahydro-3Hpyrazolo[4,3-f] isoquinoline (150 mg, $0.34 \mathrm{mmol}$ ), 1-(3-fluoropropyl)azetidin-3-amine (67.1 $\mathrm{mg}, 0.51$ $\mathrm{mmol})$, and sodium tert-butoxide $(98.0 \mathrm{mg}, 1.02 \mathrm{mmol})$ were suspended in 1,4-dioxane $(2.0 \mathrm{~mL})$. The reaction was evacuated and backfilled with nitrogen 3 times. BrettPhos 3rd generation precatalyst (15.34 $\mathrm{mg}, 0.02 \mathrm{mmol})$ was added and the reaction was evacuated and backfilled with nitrogen again. The resulting mixture was stirred at $50{ }^{\circ} \mathrm{C}$ for $30 \mathrm{~min}$. The reaction was diluted with EtOAc $(20 \mathrm{~mL})$ and washed with brine $(20 \mathrm{~mL})$. The organic phase was dried over $\mathrm{Na}_{2} \mathrm{SO}_{4}$, filtered, and concentrated under reduced pressure. The resulting residue was purified by flash silica chromatography, elution gradient 0 to $50 \% \mathrm{MeOH}$ in EtOAc to afford a yellow solid which contained cis isomer. The resulting residue was purified by preparative SFC (Whelk-O 1 (S,S) column, $5 \mu \mathrm{m}, 21 \mathrm{~mm}$ diameter, $250 \mathrm{~mm}$ length), 20 ${ }^{\circ} \mathrm{C}$ column temperature, $70 \mathrm{~mL} / \mathrm{min}$ flow rate), eluting with $20 \% \mathrm{MeOH}$ containing $0.2 \% \mathrm{NH}_{4} \mathrm{OH}$ in $\mathrm{CO}_{2}$, to afford 6-((6S,8R)-4-fluoro-8-methyl-7-(2,2,2-trifluoroethyl)-6,7,8,9-tetrahydro-3H-pyrazolo[4,3flisoquinolin-6-yl)- $N$-(1-(3-fluoropropyl)azetidin-3-yl)pyridin-3-amine 4 (91 $\mathrm{mg}, 54 \%)$ as a yellow dry film. ${ }^{1} \mathrm{H}$ NMR $\left(300 \mathrm{MHz}\right.$, DMSO- $\left.d_{6}, 27^{\circ} \mathrm{C}\right) 1.09(3 \mathrm{H}, \mathrm{d}), 1.52-1.80(2 \mathrm{H}, \mathrm{m}), 2.45-2.54(2 \mathrm{H}, \mathrm{m}), 2.70-$ $2.88(3 \mathrm{H}, \mathrm{m}), 2.89-3.08(2 \mathrm{H}, \mathrm{m}), 3.34-3.61(2 \mathrm{H}, \mathrm{m}), 3.60-3.72(2 \mathrm{H}, \mathrm{m}), 3.95(1 \mathrm{H}, \mathrm{sxt}), 4.30-4.60(2 \mathrm{H}$, m), $4.94(1 \mathrm{H}, \mathrm{s}), 6.25(1 \mathrm{H}, \mathrm{d}), 6.66(1 \mathrm{H}, \mathrm{br} \mathrm{d}), 6.87(1 \mathrm{H}, \mathrm{dd}), 7.06(1 \mathrm{H}, \mathrm{d}), 7.73(1 \mathrm{H}, \mathrm{d}), 8.16(1 \mathrm{H}, \mathrm{br} \mathrm{s})$, $13.54(1 \mathrm{H}, \mathrm{br} \mathrm{s}) ;{ }^{13} \mathrm{C}$ NMR $\left(126 \mathrm{MHz}\right.$, DMSO- $\left.d_{6}, 27^{\circ} \mathrm{C}\right) 17.0,28.8,29.7,43.4,47.3,48.7,55.0,61.7,67.7$, $82.6(J=165.9 \mathrm{~Hz}), 111.6,119.7,123.1,124.0,126.5,126.6,127.6,128.5,133.1,133.4,142.8,146.1(\mathrm{~J}$ $=252.9 \mathrm{~Hz}), 150.07 .{ }^{19} \mathrm{~F}$ NMR $\left(471 \mathrm{MHz}, \mathrm{DMSO}-d_{6}, 27^{\circ} \mathrm{C}\right)-218.17(\mathrm{~J}=47.9,25.3),-134.92,-69.82(\mathrm{~J}=$ 9.9); $m / z$ : ESI+ calcd $\mathrm{C}_{24} \mathrm{H}_{27} \mathrm{~N}_{6} \mathrm{~F}_{5}[\mathrm{M}+\mathrm{H}]+:$ 495; observed 495; HRMS (ESI ${ }^{+}$: Anal. calcd. For $\mathrm{C}_{24} \mathrm{H}_{27} \mathrm{~N}_{6} \mathrm{~F}_{5}$ $[\mathrm{M}+\mathrm{H}]+:$ : 495.2296; observed 495.2293.

\section{Scheme 3}

Preparation of $(6 S, 8 R)-6-(5$-bromopyridin-2-yl)-8-methyl-2-(tetrahydro-2H-pyran-2-yl)-7-(2,2,2trifluoroethyl)-6,7,8,9-tetrahydro-2H-pyrazolo[4,3-flisoquinoline (21)<smiles>C[C@H]1Cc2c(ccc3nn(C4CCCCO4)cc23)[C@@H](c2ccc(Br)cn2)N1CC(F)(F)F</smiles>

PTSA hydrate $(0.22 \mathrm{~g}, 1.18 \mathrm{mmol})$ was added to (6S,8R)-6-(5-bromopyridin-2-yl)-8-methyl-7-(2,2,2trifluoroethyl)-6,7,8,9-tetrahydro-3H-pyrazolo[4,3-f] isoquinoline $(5.00 \mathrm{~g}, 11.8 \mathrm{mmol}$ ) and 3,4-dihydro- 
$2 \mathrm{H}$-pyran $(2.68 \mathrm{~mL}, 29.4 \mathrm{mmol})$ in $\mathrm{DCM}(232 \mathrm{~mL})$. The resulting solution was stirred at room tempeature for 66 hours. The reaction mixture was diluted with DCM $(100 \mathrm{~mL})$ and washed with saturated $\mathrm{NaHCO}_{3}(200 \mathrm{~mL})$. The organic layer was dried with $\mathrm{MgSO}_{4}$, filtered and concentrated under reduced pressure. The residue was purified by flash silica chromatography, elution gradient 0 to $20 \%$ EtOAc in heptane to afford (6S,8R)-6-(5-bromopyridin-2-yl)-8-methyl-2-(tetrahydro-2H-pyran-2-yl)-7(2,2,2-trifluoroethyl)-6,7,8,9-tetrahydro-2H-pyrazolo[4,3-f]isoquinoline 21 (5.78 g, 96\%) as a white solid. ${ }^{1} \mathrm{H}$ NMR $\left(500 \mathrm{MHz}, \mathrm{CDCl}_{3}, 27^{\circ} \mathrm{C}\right) 1.06(3 \mathrm{H}, \mathrm{d}), 1.52-1.62(1 \mathrm{H}, \mathrm{m}), 1.63-1.73(2 \mathrm{H}, \mathrm{m}), 1.98(1 \mathrm{H}$, $\mathrm{dt}), 2.03-2.11(1 \mathrm{H}, \mathrm{m}), 2.44-2.55(1 \mathrm{H}, \mathrm{m}), 2.81(1 \mathrm{H}, \mathrm{dd}), 2.86-2.96(1 \mathrm{H}, \mathrm{m}), 3.17-3.28(2 \mathrm{H}, \mathrm{m})$, $3.48(1 \mathrm{H}, \mathrm{dq}), 3.60-3.69(1 \mathrm{H}, \mathrm{m}), 3.91-3.99(1 \mathrm{H}, \mathrm{m}), 5.01(1 \mathrm{H}, \mathrm{s}), 5.60(1 \mathrm{H}, \mathrm{dt}), 6.85(1 \mathrm{H}, \mathrm{t}), 7.24(1 \mathrm{H}$, d), $7.26-7.30(1 \mathrm{H}, \mathrm{m}), 7.65(1 \mathrm{H}, \mathrm{ddd}), 7.94(1 \mathrm{H}, \mathrm{s}), 8.47-8.50(1 \mathrm{H}, \mathrm{m}) ; \mathrm{m} / \mathrm{z}$ : ESI+ calcd $\mathrm{C}_{23} \mathrm{H}_{24} \mathrm{BrF}_{3} \mathrm{~N}_{4} \mathrm{O}$ $[\mathrm{M}+\mathrm{H}]+$ : 509; observed 509 .

Preparation of (6S,8R)-6-(5-bromopyridin-2-yl)-8-methyl-2-(tetrahydro-2H-pyran-2-yl)-5-(4,4,5,5tetramethyl-1,3,2-dioxaborolan-2-yl)-7-(2,2,2-trifluoroethyl)-6,7,8,9-tetrahydro-2H-pyrazolo[4,3f]isoquinoline (22)

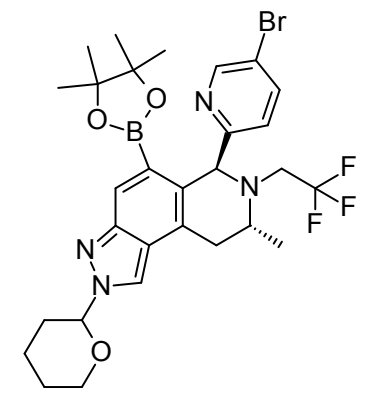

(1,5- Cyclooctadiene)(methoxy)Iridium(I) dimer $(677 \mathrm{mg}, 1.02 \mathrm{mmol})$ was added to a degassed solution of $(6 S, 8 R)-6$-(5-bromopyridin-2-yl)-8-methyl-2-(tetrahydro-2H-pyran-2-yl)-7-(2,2,2trifluoroethyl)-6,7,8,9-tetrahydro-2H-pyrazolo[4,3-f]isoquinoline $(5.20 \mathrm{~g}, 10.2 \mathrm{mmol})$ and

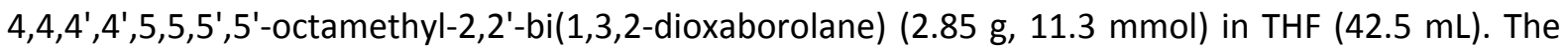
resulting solution was stirred at room temperature for 15 minutes under vacuum. The reaction mixture was then heated to $75^{\circ} \mathrm{C}$ for 18 hours, cooled to room temperature and concentrated under reduced pressure. The residue was purified by flash silica chromatography, elution gradient 0 to $20 \%$ EtOAc in heptane to afford (6S,8R)-6-(5-bromopyridin-2-yl)-8-methyl-2-(tetrahydro-2H-pyran-2-yl)-5(4,4,5,5-tetramethyl-1,3,2-dioxaborolan-2-yl)-7-(2,2,2-trifluoroethyl)-6,7,8,9-tetrahydro- $2 \mathrm{H}$ -

pyrazolo[4,3-f] isoquinoline $22(4.12 \mathrm{~g}, 64 \%)$ as a beige foam. ${ }^{1} \mathrm{H}$ NMR $\left(500 \mathrm{MHz}, \mathrm{CDCl}_{3}, 27^{\circ} \mathrm{C}\right) 1.15(3 \mathrm{H}$, d), $1.26(12 \mathrm{H}, \mathrm{dd}), 1.36(3 \mathrm{H}, \mathrm{dd}), 1.70-1.81(2 \mathrm{H}, \mathrm{m}), 2.47-2.68(1 \mathrm{H}, \mathrm{m}), 2.81(2 \mathrm{H}, \mathrm{d}), 3.03-3.14(1 \mathrm{H}$, m), $3.17-3.33(1 \mathrm{H}, \mathrm{m}), 3.46-3.58(1 \mathrm{H}, \mathrm{m}), 3.73(1 \mathrm{H}, \mathrm{dtd}), 3.98-4.09(1 \mathrm{H}, \mathrm{m}), 5.73(1 \mathrm{H}, \mathrm{ddd}), 5.84(1 \mathrm{H}$, d), $7.78(1 \mathrm{H}, \mathrm{d}), 7.91(1 \mathrm{H}, \mathrm{d}), 7.92(1 \mathrm{H}, \mathrm{s}), 7.97(1 \mathrm{H}, \mathrm{ddd}), 8.93(1 \mathrm{H}, \mathrm{dd}) ; \mathrm{m} / \mathrm{z}$ : $\mathrm{ESI}+$ calcd C $_{29} \mathrm{H}_{35} \mathrm{BBrF}_{3} \mathrm{~N}_{4} \mathrm{O}_{3}$ $[\mathrm{M}+\mathrm{H}]+:$ 635; observed 635.

Preparation of (6S,8R)-6-(5-bromopyridin-2-yl)-8-methyl-2-(tetrahydro-2H-pyran-2-yl)-7-(2,2,2trifluoroethyl)-6,7,8,9-tetrahydro-2H-pyrazolo[4,3-flisoquinolin-5-amine (23) 


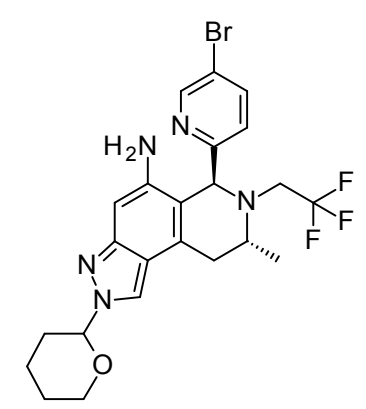

Copper(II) sulfate (20.10 mg, $0.13 \mathrm{mmol}$ ) was added to (6S,8R)-6-(5-bromopyridin-2-yl)-8-methyl-2(tetrahydro-2H-pyran-2-yl)-5-(4,4,5,5-tetramethyl-1,3,2-dioxaborolan-2-yl)-7-(2,2,2-trifluoroethyl)6,7,8,9-tetrahydro-2H-pyrazolo[4,3-f]isoquinoline $(800 \mathrm{mg}, 1.26 \mathrm{mmol})$ and sodium azide $(98 \mathrm{mg}, 1.51$ $\mathrm{mmol})$ in $\mathrm{MeOH}(8 \mathrm{~mL})$ under nitrogen. The resulting solution was stirred at room temperature for 18 hours. Sodium tetrahydroborate $(95 \mathrm{mg}, 2.52 \mathrm{mmol}$ ) was then added portionwise over 5 minutes to the reaction and allowed to stir for 30 minutes at room temperature. The reaction mixture was diluted with EtOAc $(25 \mathrm{~mL})$ and water $(25 \mathrm{~mL})$, the layers were separated, and the aqueous layer was extracted with EtOAc $(25 \mathrm{~mL})$. The combined organic layers were washed with saturated brine $(25 \mathrm{~mL})$. The organic layer was dried with $\mathrm{MgSO}_{4}$, filtered and concentrated under reduced pressure. The residue was purified by flash silica chromatography, elution gradient 0 to $40 \%$ EtOAc in heptane to afford (6S,8R)-6-(5-bromopyridin-2-yl)-8-methyl-2-(tetrahydro-2H-pyran-2-yl)-7-(2,2,2-trifluoroethyl)-

6,7,8,9-tetrahydro-2H-pyrazolo[4,3-f]isoquinolin-5-amine 23 (434 mg, 66\%) as a cream gum. ${ }^{1} \mathrm{H}$ NMR $\left(500 \mathrm{MHz}, \mathrm{CDCl}_{3}, 27^{\circ} \mathrm{C}\right) 1.16(3 \mathrm{H}, \mathrm{d}), 1.64(1 \mathrm{H}, \mathrm{s}), 1.75(2 \mathrm{H}, \mathrm{t}), 1.99-2.07(1 \mathrm{H}, \mathrm{m}), 2.15(1 \mathrm{H}, \mathrm{dd}), 2.55$ $(1 \mathrm{H}, \mathrm{q}), 2.79(1 \mathrm{H}, \mathrm{ddd}), 2.9-3.06(2 \mathrm{H}, \mathrm{m}), 3.25-3.34(2 \mathrm{H}, \mathrm{m}), 3.68-3.76(1 \mathrm{H}, \mathrm{m}), 3.94(2 \mathrm{H}, \mathrm{d}), 4.03$ $(1 \mathrm{H}, \mathrm{d}), 5.03(1 \mathrm{H}, \mathrm{s}), 5.57(1 \mathrm{H}, \mathrm{dt}), 6.69-6.74(1 \mathrm{H}, \mathrm{m}), 7.67(1 \mathrm{H}, \mathrm{dd}), 7.82(1 \mathrm{H}, \mathrm{ddd}), 7.87(1 \mathrm{H}, \mathrm{s}), 8.50$ $(1 \mathrm{H}, \mathrm{d}) ; \mathrm{m} / \mathrm{z}$ : $\mathrm{ESI}+$ calcd $\mathrm{C}_{23} \mathrm{H}_{25} \mathrm{BrF}_{3} \mathrm{~N}_{5} \mathrm{O}[\mathrm{M}+\mathrm{H}]+: 524$; observed 524 .

\section{Preparation of (6S,8R)-6-(5-bromopyridin-2-yl)-5-fluoro-8-methyl-7-(2,2,2-trifluoroethyl)-6,7,8,9-} tetrahydro-3H-pyrazolo[4,3-f]isoquinoline<smiles>C[C@H]1Cc2c(c(F)cc3[nH]ncc23)[C@@H](c2ccc(Br)cn2)N1CC(F)(F)F</smiles>

Sodium nitrite $(39.8 \mathrm{mg}, 0.58 \mathrm{mmol})$ dissolved in water $(0.5 \mathrm{~mL})$ was added dropwise to $(6 \mathrm{~S}, 8 \mathrm{R})-6-(5-$ bromopyridin-2-yl)-8-methyl-2-(tetrahydro-2H-pyran-2-yl)-7-(2,2,2-trifluoroethyl)-6,7,8,9-

tetrahydro-2H-pyrazolo[4,3-f]isoquinolin-5-amine $(275 \mathrm{mg}, 0.52 \mathrm{mmol})$ and trifluoroborane hydrofluoride $\left(50 \%\right.$ in water) $(0.261 \mathrm{~mL}, 2.10 \mathrm{mmol})$ in THF $(2.00 \mathrm{~mL})$ at $0^{\circ} \mathrm{C}$ over a period of 1 minute under nitrogen. The resulting solution was stirred at room temperature for 10 minutes. The reaction mixture was concentrated under reduced pressure, then heated neat, under nitrogen, to $150{ }^{\circ} \mathrm{C}$ for 10 minutes until the gas had stopped evolving. The reaction mixture was diluted with EtOAc $(25 \mathrm{~mL})$ and water $(25 \mathrm{~mL}$ ), the layers were separated, and the aqueous layer was extracted with EtOAc ( 25 $\mathrm{mL})$. The combined organic layers were washed sequentially with saturated brine $(50 \mathrm{~mL})$ and dried over $\mathrm{MgSO}_{4}$, filtered and concentrated under reduced pressure. The crude product was purified by flash silica chromatography, elution gradient 0 to $50 \%$ EtOAc in heptane to afford $(65,8 R)-6-(5-$ bromopyridin-2-yl)-5-fluoro-8-methyl-7-(2,2,2-trifluoroethyl)-6,7,8,9-tetrahydro-3H-pyrazolo[4,3-

f]isoquinoline (19.0 mg, 8\%) as a white solid. $\mathrm{m} / \mathrm{z}$ : $\mathrm{ESI}+$ calcd $\mathrm{C}_{16} \mathrm{H}_{15} \mathrm{BrF}_{4} \mathrm{~N}_{4}[\mathrm{M}+\mathrm{H}]+:$ : 443; observed 443. 
Preparation of 6-((6S,8R)-5-fluoro-8-methyl-7-(2,2,2-trifluoroethyl)-6,7,8,9-tetrahydro-3Hpyrazolo[4,3-flisoquinolin-6-yl)-N-(1-(3-fluoropropyl)azetidin-3-yl)pyridin-3-amine (5)<smiles>FCCCN1CCC(Nc2ccc(C3CN(CC(F)(F)F)[C@@H](F)Cc4c5cc(F)c3c4C=NN5)cn2)C1</smiles>

BrettPhos Pd G3 (1.94 mg, $2.14 \mu \mathrm{mol})$ was added to a degassed solution of $(65,8 R)$-6-(5-bromopyridin2-yl)-5-fluoro-8-methyl-7-(2,2,2-trifluoroethyl)-6,7,8,9-tetrahydro-3H-pyrazolo[4,3-f]isoquinoline $(19.0 \mathrm{mg}, 0.04 \mathrm{mmol}), 1$-(3-fluoropropyl)azetidin-3-amine $(9.92 \mathrm{mg}, 0.08 \mathrm{mmol}$ ) and sodium 2methylpropan-2-olate $(20.6 \mathrm{mg}, 0.21 \mathrm{mmol})$ in 1,4-dioxane $(857 \mu \mathrm{l})$ under nitrogen. The resulting solution was stirred at $70{ }^{\circ} \mathrm{C}$ for 4 hours. The reaction mixture was cooled to room temperature, diluted with EtOAc $(10 \mathrm{~mL})$ and water $(10 \mathrm{~mL})$. The layers were separated, and the aqueous layer was extracted with EtOAc) $(10 \mathrm{~mL})$. The combined organic layers were dried over $\mathrm{MgSO}_{4}$, filtered and concentrated under reduced pressure. The crude product was purified by preparative HPLC (Waters XSelect CSH C18 column, $5 \mu$ silica, $50 \mathrm{~mm}$ diameter, $150 \mathrm{~mm}$ length), using decreasingly polar mixtures of water (containing $1 \% \mathrm{NH}_{3}$ ) and $\mathrm{MeCN}$ as eluents. Fractions containing the desired compound were concentrated under reduced pressure to afford 6-((6S,8R)-5-fluoro-8-methyl-7-(2,2,2-trifluoroethyl)6,7,8,9-tetrahydro-3H-pyrazolo[4,3-f]isoquinolin-6-yl)-N-(1-(3-fluoropropyl)azetidin-3-yl)pyridin-3amine $5(5.30 \mathrm{mg}, 25 \%)$ as a white solid. ${ }^{1} \mathrm{H} \mathrm{NMR}\left(500 \mathrm{MHz}, \mathrm{CDCl}_{3}, 27^{\circ} \mathrm{C}\right) 1.10(3 \mathrm{H}, \mathrm{d}), 1.62-1.72(2 \mathrm{H}$, $\mathrm{m}), 2.52(2 \mathrm{H}, \mathrm{t}), 2.55-2.63(1 \mathrm{H}, \mathrm{m}), 2.80-2.93(4 \mathrm{H}, \mathrm{m}), 3.11-3.25(1 \mathrm{H}, \mathrm{m}), 3.36(1 \mathrm{H}, \mathrm{ddd}), 3.61-$ $3.68(2 \mathrm{H}, \mathrm{m}), 4.01(2 \mathrm{H}, \mathrm{d}), 4.40(2 \mathrm{H}, \mathrm{dt}), 5.15(1 \mathrm{H}, \mathrm{s}), 6.68(1 \mathrm{H}, \mathrm{d}), 6.86(1 \mathrm{H}, \mathrm{dd}), 7.44(1 \mathrm{H}, \mathrm{d}), 7.72(1 \mathrm{H}$, d), $7.75(1 \mathrm{H}, \mathrm{s})$, exchangeable $\mathrm{NH}$ not observed; ${ }^{13} \mathrm{C}$ NMR $\left(126 \mathrm{MHz}\right.$, DMSO- $\left.d_{6}, 27^{\circ} \mathrm{C}\right) 18.6,27.7,28.1$, $42.8,45.3,47.3,54.8,61.3,63.9,82.0(\mathrm{~J}=161.9 \mathrm{~Hz}), 92.8,115.8,119.0,119.2,123.0,126.4,130.0$, $131.8,132.6,138.3,142.2,148.7,160.1(\mathrm{~J}=234.8 \mathrm{~Hz}) ;{ }^{19} \mathrm{~F} \mathrm{NMR}\left(471 \mathrm{MHz}, \mathrm{CDCl}_{3}, 27^{\circ} \mathrm{C}\right)-219.26,-118.72$ $(J=9.1),-71.25(J=9.2) ; \mathrm{m} / \mathrm{z}$ : $\mathrm{ESI}+$ calcd $\mathrm{C}_{24} \mathrm{H}_{27} \mathrm{~N}_{6} \mathrm{~F}_{5}[\mathrm{M}+\mathrm{H}]+:$ 495; observed 495; HRMS (ESI $\left.{ }^{+}\right)$: Anal. calcd. For $\mathrm{C}_{24} \mathrm{H}_{27} \mathrm{~N}_{6} \mathrm{~F}_{5}[\mathrm{M}+\mathrm{H}]+:$ : 495.2296; observed 495.2293.

Preparation of $(6 S, 8 R)-6$-(5-bromopyridin-2-yl)-5-methoxy-8-methyl-2-(tetrahydro-2H-pyran-2-yl)7-(2,2,2-trifluoroethyl)-6,7,8,9-tetrahydro-2H-pyrazolo[4,3-flisoquinoline (24)

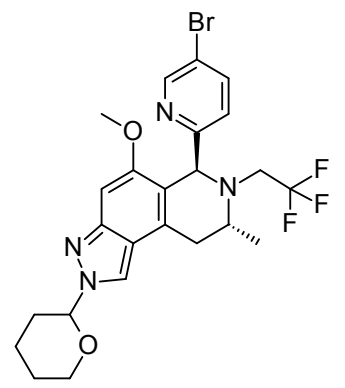

Bis(((trifluoromethyl)sulfonyl)oxy)copper (455 mg, $1.26 \mathrm{mmol}$ ) was added to (6S,8R)-6-(5bromopyridin-2-yl)-8-methyl-2-(tetrahydro-2H-pyran-2-yl)-5-(4,4,5,5-tetramethyl-1,3,2-

dioxaborolan-2-yl)-7-(2,2,2-trifluoroethyl)-6,7,8,9-tetrahydro-2H-pyrazolo[4,3-f]isoquinoline (200 $\mathrm{mg}, 0.31 \mathrm{mmol})$, and cesium fluoride $(287 \mathrm{mg}, 1.89 \mathrm{mmol})$ in $\mathrm{MeOH}(2.50 \mathrm{~mL})$. The resulting solution was stirred at room temperature for 18 hours. The reaction mixture was concentrated under reduced 
pressure and diluted with EtOAc $(25 \mathrm{~mL})$, and washed sequentially with water $(25 \mathrm{~mL})$ and saturated brine $(25 \mathrm{~mL})$. The organic layer was dried over $\mathrm{MgSO}_{4}$, filtered and concentrated under reduced pressure. The residue was purified by flash silica chromatography, elution gradient 0 to $30 \%$ EtOAc in heptane to afford $(6 S, 8 R)$-6-(5-bromopyridin-2-yl)-5-methoxy-8-methyl-2-(tetrahydro-2H-pyran-2-yl)7-(2,2,2-trifluoroethyl)-6,7,8,9-tetrahydro-2H-pyrazolo[4,3-f]isoquinoline $24(95.0 \mathrm{mg}, 56 \%)$ as a colourless gum. ${ }^{1} \mathrm{H}$ NMR $\left(500 \mathrm{MHz}, \mathrm{CDCl}_{3}, 27^{\circ} \mathrm{C}\right) 1.13(3 \mathrm{H}, \mathrm{d}), 1.61-1.72(1 \mathrm{H}, \mathrm{m}), 1.72-1.83(2 \mathrm{H}, \mathrm{m})$, $2.00-2.10(1 \mathrm{H}, \mathrm{m}), 2.12-2.24(1 \mathrm{H}, \mathrm{m}), 2.53-2.67(1 \mathrm{H}, \mathrm{m}), 2.71-2.78(1 \mathrm{H}, \mathrm{m}), 2.93-3.00(2 \mathrm{H}, \mathrm{m})$, $3.27-3.36(2 \mathrm{H}, \mathrm{m}), 3.68(3 \mathrm{H}, \mathrm{d}), 3.75(1 \mathrm{H}, \mathrm{s}), 4.02(1 \mathrm{H}, \mathrm{dd}), 5.21(1 \mathrm{H}, \mathrm{s}), 5.65(1 \mathrm{H}, \mathrm{dt}), 6.75(1 \mathrm{H}, \mathrm{d})$, $7.41(1 \mathrm{H}, \mathrm{dd}), 7.74(1 \mathrm{H}, \mathrm{td}), 7.93(1 \mathrm{H}, \mathrm{s}), 8.42-8.50(1 \mathrm{H}, \mathrm{m}) ; \mathrm{m} / \mathrm{z}$ : $\mathrm{ESI}+$ calcd $\mathrm{C}_{24} \mathrm{H}_{26} \mathrm{BrF}_{3} \mathrm{~N}_{4} \mathrm{O}_{2}[\mathrm{M}+\mathrm{H}]+$ : 539; observed 539.

Preparation of (6S,8R)-6-(5-bromopyridin-2-yl)-5-methoxy-8-methyl-7-(2,2,2-trifluoroethyl)6,7,8,9-tetrahydro-3H-pyrazolo[4,3-flisoquinoline<smiles>COc1cc2[nH]ncc2c2c1C(c1ccc(Br)cn1)N(CC(F)(F)F)C(C)C2</smiles>

$\mathrm{HCl}$ in dioxane (4M, $496 \mu \mathrm{L}, 1.98 \mathrm{mmol})$ was added to (6S,8R)-6-(5-bromopyridin-2-yl)-5-methoxy-8methyl-2-(tetrahydro-2H-pyran-2-yl)-7-(2,2,2-trifluoroethyl)-6,7,8,9-tetrahydro-2H-pyrazolo[4,3f]isoquinoline $(107 \mathrm{mg}, 0.20 \mathrm{mmol})$ in $\mathrm{MeOH}(2.00 \mathrm{~mL})$. The resulting solution was stirred at room temperature for 18 hours. The reaction was then evaporated to dryness and purified by ion exchange chromatography, using an SCX column. The desired product was eluted from the column using $7 \mathrm{M}$ $\mathrm{NH}_{3} / \mathrm{MeOH}$ and concentrated under reduced pressure to afford $(65,8 R)-6$-(5-bromopyridin-2-yl)-5methoxy-8-methyl-7-(2,2,2-trifluoroethyl)-6,7,8,9-tetrahydro-3H-pyrazolo[4,3-f]isoquinoline $\quad$ (74.0 $\mathrm{mg}, 82 \%)$ as a colourless gum. ${ }^{1} \mathrm{H}$ NMR $\left(500 \mathrm{MHz}, \mathrm{CDCl}_{3}, 27^{\circ} \mathrm{C}\right) 1.15(3 \mathrm{H}, \mathrm{d}), 2.74(1 \mathrm{H}, \mathrm{dd}), 2.93-3.04$ $(2 \mathrm{H}, \mathrm{m}), 3.22-3.40(2 \mathrm{H}, \mathrm{m}), 3.66(3 \mathrm{H}, \mathrm{s}), 5.23(1 \mathrm{H}, \mathrm{s}), 6.69(1 \mathrm{H}, \mathrm{s}), 7.47(1 \mathrm{H}, \mathrm{d}), 7.77(1 \mathrm{H}, \mathrm{dd}), 7.95(1 \mathrm{H}$, d), $8.44-8.49(1 \mathrm{H}, \mathrm{m}), 10.00(1 \mathrm{H}, \mathrm{s}) ; \mathrm{m} / \mathrm{z}$ : $\mathrm{ESI}+$ calcd $\mathrm{C}_{19} \mathrm{H}_{18} \mathrm{BrF}_{3} \mathrm{~N}_{4} \mathrm{O}[\mathrm{M}+\mathrm{H}]+:$ 455; observed 455.

Preparation of N-(1-(3-fluoropropyl)azetidin-3-yl)-6-((6S,8R)-5-methoxy-8-methyl-7-(2,2,2trifluoroethyl)-6,7,8,9-tetrahydro-3H-pyrazolo[4,3-f] isoquinolin-6-yl)pyridin-3-amine (6)<smiles>COc1cc2[nH]ncc2c2c1C(c1ccc(NC3CN(CCCF)C3)cn1)N(CC(F)(F)F)C[C@@H]2C</smiles>

1-(3-Fluoropropyl)azetidin-3-amine $\quad(24.7 \mathrm{mg}, \quad 0.19 \mathrm{mmol}), \quad(6 \mathrm{~S}, 8 R)-6$-(5-bromopyridin-2-yl)-5methoxy-8-methyl-7-(2,2,2-trifluoroethyl)-6,7,8,9-tetrahydro-3H-pyrazolo[4,3-f]isoquinoline $(74 \mathrm{mg}$, $0.16 \mathrm{mmol})$, BrettPhos $\mathrm{G} 3(7.37 \mathrm{mg}, 8.13 \mu \mathrm{mol})$ and sodium 2-methylpropan-2-olate $(62.5 \mathrm{mg}, 0.65$ $\mathrm{mmol})$ were suspended in 1,4-dioxane $(163 \mu \mathrm{l})$ and sealed into a microwave tube. The resulting solution was stirred at $70{ }^{\circ} \mathrm{C}$ for 9 hours. The reaction mixture was diluted with EtOAc $(10 \mathrm{~mL})$ and water $(10 \mathrm{~mL})$, the layers were separated, and the aqueous layer was extracted with EtOAc) $(10 \mathrm{~mL})$. 
The combined organic layers were dried over $\mathrm{MgSO}_{4}$, filtered and concentrated under reduced pressure. The crude product was purified by preparative HPLC (Waters CSH C18 OBD column, $5 \mu$ silica, $30 \mathrm{~mm}$ diameter, $100 \mathrm{~mm}$ length), using decreasingly polar mixtures of water (containing $1 \% \mathrm{NH}_{3}$ ) and $\mathrm{MeCN}$ as eluents. Fractions containing the desired compound were evaporated to dryness to afford N-(1-(3-fluoropropyl)azetidin-3-yl)-6-((6S,8R)-5-methoxy-8-methyl-7-(2,2,2-trifluoroethyl)-6,7,8,9tetrahydro-3H-pyrazolo[4,3-f]isoquinolin-6-yl)pyridin-3-amine $6(23.6 \mathrm{mg}, 29 \%)$ as a white solid. ${ }^{1} \mathrm{H}$ $\operatorname{NMR}\left(500 \mathrm{MHz}, \mathrm{CDCl}_{3}, 27^{\circ} \mathrm{C}\right) 1.14(3 \mathrm{H}, \mathrm{d}), 1.70-1.81(2 \mathrm{H}, \mathrm{m}), 2.57-2.63(2 \mathrm{H}, \mathrm{m}), 2.70(1 \mathrm{H}, \mathrm{dd}), 2.88-$ $3.00(4 \mathrm{H}, \mathrm{m}), 3.21-3.31(1 \mathrm{H}, \mathrm{m}), 3.37-3.45(1 \mathrm{H}, \mathrm{m}), 3.65(3 \mathrm{H}, \mathrm{s}), 3.72(2 \mathrm{H}, \mathrm{t}), 3.99(1 \mathrm{H}, \mathrm{s}), 4.09(1 \mathrm{H}$, s), $4.43(1 \mathrm{H}, \mathrm{t}), 4.53(1 \mathrm{H}, \mathrm{t}), 5.20(1 \mathrm{H}, \mathrm{s}), 6.63(1 \mathrm{H}, \mathrm{s}), 6.83(1 \mathrm{H}, \mathrm{dd}), 7.30(1 \mathrm{H}, \mathrm{d}), 7.78(1 \mathrm{H}, \mathrm{d}), 7.91(1 \mathrm{H}$, d) Indazole NH missing; ${ }^{13} \mathrm{C}$ NMR $\left(126 \mathrm{MHz}\right.$, DMSO- $\left.d_{6}, 27^{\circ} \mathrm{C}\right) 19.5,28.7,29.0,43.4,45.6,48.0,55.4$, $55.7,61.7,64.9,82.6(J=167.1 \mathrm{~Hz}), 88.4,117.4,118.2,119.4,124.0,127.2,129.0,131.7,133.4,140.0$, 142.5, 150.0, 157.6. ${ }^{19} \mathrm{~F} \mathrm{NMR}\left(471 \mathrm{MHz}\right.$, DMSO- $\left.d_{6}, 27^{\circ} \mathrm{C}\right)-218.14(\mathrm{~J}=47.6,25.1),-69.94(\mathrm{~J}=10.0) ; \mathrm{m} / \mathrm{z}$ : $\mathrm{ESI}+$ calcd $\mathrm{C}_{25} \mathrm{H}_{30} \mathrm{~N}_{6} \mathrm{OF}_{4}[\mathrm{M}+\mathrm{H}]+: 507$; observed 507; HRMS (ESI+): Anal. calcd. For $\mathrm{C}_{25} \mathrm{H}_{30} \mathrm{~N}_{6} \mathrm{OF}_{4}[\mathrm{M}+\mathrm{H}]+$ : 507.2495; observed 507.2483.

Preparation of (6S,8R)-6-(5-bromo-2-pyridyl)-8-methyl-2-tetrahydropyran-2-yl-7-(2,2,2trifluoroethyl)-8,9-dihydro-6H-pyrazolo[4,3-f] isoquinolin-5-ol (25)<smiles></smiles>

Sodium 1,2,3-dioxaboriran-3-olate tetrahydrate $(363 \mathrm{mg}, 2.36 \mathrm{mmol})$ was added to $(6 \mathrm{~S}, 8 R)$-6-(5bromopyridin-2-yl)-8-methyl-2-(tetrahydro-2H-pyran-2-yl)-5-(4,4,5,5-tetramethyl-1,3,2-

dioxaborolan-2-yl)-7-(2,2,2-trifluoroethyl)-6,7,8,9-tetrahydro-2H-pyrazolo[4,3-f]isoquinoline $\quad$ (500 $\mathrm{mg}, 0.79 \mathrm{mmol})$ in THF $(2.62 \mathrm{~mL}) /$ water $(2.62 \mathrm{~mL})$. The resulting solution was stirred at $66^{\circ} \mathrm{C}$ for 1 hour. The reaction mixture was cooled to room temperature, concentrated under reduced pressure and diluted with EtOAc $(25 \mathrm{~mL})$ and water $(25 \mathrm{~mL})$. The layers were separated, and the aqueous layer was extracted with EtOAc $(25 \mathrm{~mL})$. The combined organic layers were dried over $\mathrm{MgSO}_{4}$, filtered and concentrated under reduced pressure to afford crude (6S,8R)-6-(5-bromo-2-pyridyl)-8-methyl-2tetrahydropyran-2-yl-7-(2,2,2-trifluoroethyl)-8,9-dihydro-6H-pyrazolo[4,3-f]isoquinolin-5-ol 25. Product was reacted onwards in the next step. ${ }^{1} \mathrm{H}$ NMR $\left(500 \mathrm{MHz}, \mathrm{CDCl}_{3}, 27^{\circ} \mathrm{C}\right) 1.37(3 \mathrm{H}, \mathrm{d}), 1.62(2 \mathrm{H}$, d), $1.71-1.80(2 \mathrm{H}, \mathrm{m}), 2.13(1 \mathrm{H}, \mathrm{d}), 2.49-2.60(1 \mathrm{H}, \mathrm{m}), 2.79(1 \mathrm{H}, \mathrm{td}), 2.83-2.94(2 \mathrm{H}, \mathrm{m}), 3.25-3.33$ $(1 \mathrm{H}, \mathrm{m}), 3.38(1 \mathrm{H}, \mathrm{dt}), 3.70-3.78(1 \mathrm{H}, \mathrm{m}), 4.00-4.09(1 \mathrm{H}, \mathrm{m}), 5.30(1 \mathrm{H}, \mathrm{d}), 5.61(1 \mathrm{H}, \mathrm{dt}), 7.09-7.12$ $(1 \mathrm{H}, \mathrm{m}), 7.84(1 \mathrm{H}, \mathrm{dd}), 7.88(1 \mathrm{H}, \mathrm{s}), 7.97(1 \mathrm{H}, \mathrm{dd}), 8.53(1 \mathrm{H}, \mathrm{dd}), 11.15(1 \mathrm{H}, \mathrm{s}) ; \mathrm{m} / \mathrm{z}$ : ESI+ calcd $\mathrm{C}_{23} \mathrm{H}_{24} \mathrm{BrF}_{3} \mathrm{~N}_{4} \mathrm{O}_{2}[\mathrm{M}+\mathrm{H}]+$ : 525 ; observed 525 .

Preparation of (6S,8R)-6-(5-bromopyridin-2-yl)-8-methyl-7-(2,2,2-trifluoroethyl)-6,7,8,9tetrahydro-3H-pyrazolo[4,3-flisoquinolin-5-ol 
<smiles>C[C@H]1Cc2c(c(O)cc3[nH]ncc23)[C@@H](c2ccc(Br)cn2)N1CC(F)(F)F</smiles>

$\mathrm{HCl}$ in dioxane (4M, $1.856 \mathrm{~mL}, 7.42 \mathrm{mmol})$ was added to (6S,8R)-6-(5-bromopyridin-2-yl)-8-methyl-2(tetrahydro-2H-pyran-2-yl)-7-(2,2,2-trifluoroethyl)-6,7,8,9-tetrahydro-2H-pyrazolo[4,3-f]isoquinolin5 -ol $(390 \mathrm{mg}, 0.74 \mathrm{mmol})$ in $\mathrm{MeOH}(5.00 \mathrm{~mL})$. The resulting solution was stirred at room temperature for 18 hours. The reaction was concentrated under reduced pressure. The residue was purified by ion exchange chromatography, using an SCX column. The desired product was eluted from the column using $1 \mathrm{M} \mathrm{NH}_{3} / \mathrm{MeOH}$ and to afford a crude product. The crude product was purified by flash silica chromatography, elution gradient 0 to $70 \%$ EtOAc in heptane to afford $(6 S, 8 R)$-6-(5-bromopyridin-2yl)-8-methyl-7-(2,2,2-trifluoroethyl)-6,7,8,9-tetrahydro-3H-pyrazolo[4,3-f]isoquinolin-5-ol (161 mg, $49 \%)$ as a white solid. ${ }^{1} \mathrm{H}$ NMR $\left(500 \mathrm{MHz}, \mathrm{CDCl}_{3}, 27^{\circ} \mathrm{C}\right) 1.39(3 \mathrm{H}, \mathrm{d}), 2.82(1 \mathrm{H}, \mathrm{dd}), 2.87-2.97(2 \mathrm{H}, \mathrm{m})$, $3.22-3.47(2 \mathrm{H}, \mathrm{m}), 5.32(1 \mathrm{H}, \mathrm{s}), 6.99-7.03(1 \mathrm{H}, \mathrm{m}), 7.85(1 \mathrm{H}, \mathrm{d}), 7.93(1 \mathrm{H}, \mathrm{d}), 7.98(1 \mathrm{H}, \mathrm{dd}), 8.54(1 \mathrm{H}$, d), $9.98(1 \mathrm{H}, \mathrm{s}), 11.23(1 \mathrm{H}, \mathrm{s}) ; \mathrm{m} / \mathrm{z}$ : $\mathrm{ESI}+$ calcd $\mathrm{C}_{18} \mathrm{H}_{16} \mathrm{BrF}_{3} \mathrm{~N}_{4} \mathrm{O}[\mathrm{M}+\mathrm{H}]+:$ : 441 ; observed 441.

Preparation of (6S,8R)-6-(5-((1-(3-fluoropropyl)azetidin-3-yl)amino)pyridin-2-yl)-8-methyl-7-(2,2,2trifluoroethyl)-6,7,8,9-tetrahydro-3H-pyrazolo[4,3-f]isoquinolin-5-ol (7)<smiles></smiles>

BrettPhos G3 (19.0 mg, $0.02 \mathrm{mmol}$ ) was added to a degassed solution of $(6 \mathrm{~S}, 8 R)$-6-(5-bromopyridin-2yl)-8-methyl-7-(2,2,2-trifluoroethyl)-6,7,8,9-tetrahydro-3H-pyrazolo[4,3-f]isoquinolin-5-ol (181 mg, $0.41 \mathrm{mmol})$, sodium 2-methylpropan-2-olate $(0.158 \mathrm{~g}, 1.64 \mathrm{mmol}$ ) and 1-(3-fluoropropyl)azetidin-3amine $(0.062 \mathrm{~g}, 0.47 \mathrm{mmol})$ in 1,4-dioxane $(4.10 \mathrm{~mL})$ under nitrogen. The resulting solution was stirred at $65{ }^{\circ} \mathrm{C}$ for 4 hours. The reaction mixture was cooled to room temperature and diluted with EtOAc $(10 \mathrm{~mL})$ and water $(10 \mathrm{~mL})$. The layers were separated, and the aqueous layer was extracted with EtOAc $(2 \times 10 \mathrm{~mL})$. The combined organic layers were washed with saturated brine $(20 \mathrm{~mL})$. The organic layer was dried over $\mathrm{MgSO}_{4}$, filtered and concentrated under reduced pressure. The residue was purified by preparative HPLC (Waters XSelect CSH C18 column, $5 \mu$ silica, $50 \mathrm{~mm}$ diameter, $150 \mathrm{~mm}$ length), using decreasingly polar mixtures of water (containing $1 \% \mathrm{NH} 3$ ) and $\mathrm{MeCN}$ as eluents. Fractions containing the desired compound were concentrated under reduced pressure to afford crude material. The crude material was purified by flash silica chromatography, elution gradient 0 to $10 \% \mathrm{MeOH}$ in DCM to afford (6S,8R)-6-(5-((1-(3-fluoropropyl)azetidin-3-yl)amino)pyridin-2-yl)-8methyl-7-(2,2,2-trifluoroethyl)-6,7,8,9-tetrahydro-3H-pyrazolo[4,3-f]isoquinolin-5-ol 7 (8.00 mg, 4\%) as a white solid. ${ }^{1} \mathrm{H} \mathrm{NMR}\left(400 \mathrm{MHz}, \mathrm{CDCl}_{3}, 30^{\circ} \mathrm{C}\right) 1.31(3 \mathrm{H}, \mathrm{d}), 1.62-1.67(1 \mathrm{H}, \mathrm{m}), 1.69-1.75(1 \mathrm{H}, \mathrm{m})$, 2.50 - $2.57(2 \mathrm{H}, \mathrm{m}), 2.70-2.81(2 \mathrm{H}, \mathrm{m}), 2.85(2 \mathrm{H}, \mathrm{dd}), 3.22(1 \mathrm{H}, \mathrm{dd}), 3.36(1 \mathrm{H}, \mathrm{dq}), 3.64(2 \mathrm{H}, \mathrm{q}), 3.97-$ $4.09(2 \mathrm{H}, \mathrm{m}), 4.35(1 \mathrm{H}, \mathrm{t}), 4.47(1 \mathrm{H}, \mathrm{t}), 5.20(1 \mathrm{H}, \mathrm{s}), 6.89-6.94(2 \mathrm{H}, \mathrm{m}), 7.61(1 \mathrm{H}, \mathrm{d}), 7.70(1 \mathrm{H}, \mathrm{d}), 7.84$ 
$(1 \mathrm{H}, \mathrm{s}) 3$ exchangeable protons are missing; $\mathrm{m} / \mathrm{z}$ : $\mathrm{ESI}+$ calcd $\mathrm{C}_{24} \mathrm{H}_{28} \mathrm{~N}_{6} \mathrm{OF}_{4}[\mathrm{M}+\mathrm{H}]+:$ 493; observed 493; HRMS (ESI+): Anal. calcd. For $\mathrm{C}_{24} \mathrm{H}_{28} \mathrm{~N}_{6} \mathrm{OF}_{4}[\mathrm{M}+\mathrm{H}]+$ : 493.2339; observed 493.2331.

\section{Scheme 4}

\section{Preparation of 4-bromo-3-fluoro-1H-indazole (26)}<smiles>Fc1n[nH]c2cccc(Br)c12</smiles>

1-(Chloromethyl)-4-fluoro-1,4-diazabicyclo[2.2.2] octane-1,4-diium tetrafluoroborate (19.8 g, 55.8 $\mathrm{mmol})$ was added to 4-bromo- $1 \mathrm{H}$-indazole $(10.0 \mathrm{~g}, 50.7 \mathrm{mmol})$ in DMA $(254 \mathrm{~mL})$ under nitrogen. The resulting solution was stirred at $60{ }^{\circ} \mathrm{C}$ for 16 hours. The reaction mixture was concentrated under reduced pressure and diluted with EtOAc $(200 \mathrm{~mL})$, and washed sequentially with water $(200 \mathrm{~mL})$ and saturated brine $(200 \mathrm{~mL})$. The organic layer was dried over $\mathrm{MgSO}_{4}$, filtered and concentrated under reduced pressure. The residue was purified by flash silica chromatography, elution gradient 0 to $20 \%$ EtOAc in heptane to afford 4-bromo-3-fluoro- $1 \mathrm{H}$-indazole $(2.87 \mathrm{~g}, 26 \%)$ as a cream solid. ${ }^{1} \mathrm{H}$ NMR (500 $\left.\mathrm{MHz}, \mathrm{CDCl}_{3}, 27^{\circ} \mathrm{C}\right) 7.24-7.27(1 \mathrm{H}, \mathrm{m}), 7.32-7.38(2 \mathrm{H}, \mathrm{m}), 9.45(1 \mathrm{H}, \mathrm{s}) ; \mathrm{m} / \mathrm{z}$ : ESI- calcd $\mathrm{C}_{7} \mathrm{H}_{4} \mathrm{BrFN}_{2}[\mathrm{M}-$ H]-: 213; observed 213.

\section{Preparation of $(R)$-tert-butyl (1-(3-fluoro-1H-indazol-4-yl)propan-2-yl)carbamate}<smiles>C[C@H](Cc1cccc2[nH]nc(F)c12)NC(=O)OC(C)(C)C</smiles>

n-Butyllithium (2.89 mL, $4.63 \mathrm{mmol}$ ) was added to a solution of 4-bromo-3-fluoro-1H-indazole (398 $\mathrm{mg}, 1.85 \mathrm{mmol})$ in THF $(10 \mathrm{~mL})$ at $-78^{\circ} \mathrm{C}$. The resulting solution was stirred at $-78^{\circ} \mathrm{C}$ for 10 minutes. The reaction was warmed to $-50{ }^{\circ} \mathrm{C}$ for $30 \mathrm{~min}$, then cooled back to $-78{ }^{\circ} \mathrm{C}$. $(R)$-tert-butyl 4-methyl1,2,3-oxathiazolidine-3-carboxylate 2,2-dioxide $(615 \mathrm{mg}, 2.59 \mathrm{mmol})$ was added in portions and the reaction mixture was stirred for 1 hour before being allowed to warm to $0{ }^{\circ} \mathrm{C}$ and diluted with water $(20 \mathrm{~mL})$ and diethyl ether $(20 \mathrm{~mL})$. The layers were seperated and the organic layer was extracted with another portion of water $(10 \mathrm{~mL})$. The aqueous layers were combined and acidified with aqueous $\mathrm{HCl}(2 \mathrm{M}, 5 \mathrm{~mL})$ and stirred for 15 minutes. The resulting mixture was extracted with DCM $(2 \times 25 \mathrm{~mL})$ and the combined organics were dried over $\mathrm{MgSO}_{4}$ and concentrated under reduced presure to afford (R)-tert-butyl (1-(3-fluoro-1H-indazol-4-yl)propan-2-yl)carbamate $(490 \mathrm{mg}, 90 \%)$ as a brown solid. ${ }^{1} \mathrm{H}$ $\operatorname{NMR}\left(500 \mathrm{MHz}, \mathrm{CDCl}_{3}, 27^{\circ} \mathrm{C}\right) 1.17(3 \mathrm{H}, \mathrm{d}), 1.35(9 \mathrm{H}, \mathrm{s}), 3.09(2 \mathrm{H}, \mathrm{s}), 4.05(1 \mathrm{H}, \mathrm{s}), 6.97(1 \mathrm{H}, \mathrm{s}), 7.23(1 \mathrm{H}$, dd), $7.34(1 \mathrm{H}, \mathrm{dd}), 9.32(1 \mathrm{H}, \mathrm{s}) ; \mathrm{m} / \mathrm{z}$ : $\mathrm{ESI}+$ calcd $\mathrm{C}_{15} \mathrm{H}_{20} \mathrm{FN}_{3} \mathrm{O}_{2}[\mathrm{M}+\mathrm{H}]+:$ 294; observed 294.

\section{Preparation of $(R)$-1-(3-fluoro-1H-indazol-4-yl)propan-2-amine}<smiles>CC(N)Cc1cccc2[nH]nc(F)c12</smiles>

$\mathrm{HCl}$ in dioxane $(4 \mathrm{M}, 9.54 \mathrm{~mL}, 38.15 \mathrm{mmol})$ was added to tert-butyl $(R)$-(1-(3-fluoro-1H-indazol-4yl)propan-2-yl)carbamate $(2.24 \mathrm{~g}, 7.63 \mathrm{mmol})$. The resulting solution was stirred at room temperature for 5 hours. The reaction mixture was concentated under reduced pressure. The residue was purified by ion exchange chromatography, using an SCX column. The desired product was eluted from the column using $7 \mathrm{M} \mathrm{NH}_{3} / \mathrm{MeOH}$ to afford ( $R$ )-1-(3-fluoro-1H-indazol-4-yl)propan-2-amine (1.390 g, 94\%) as a light brown oil. ${ }^{1} \mathrm{H}$ NMR $\left(500 \mathrm{MHz}\right.$, DMSO $\left.-d_{6}, 27^{\circ} \mathrm{C}\right) 0.96(3 \mathrm{H}, \mathrm{d}), 2.82(2 \mathrm{H}, \mathrm{d}), 3.09(1 \mathrm{H}, \mathrm{qd}), 3.30$ 
$(2 \mathrm{H}, \mathrm{s}), 6.90(1 \mathrm{H}, \mathrm{d}), 7.21-7.39(2 \mathrm{H}, \mathrm{m}), 12.47(1 \mathrm{H}, \mathrm{s}) ; \mathrm{m} / \mathrm{z}$ : $\mathrm{ESI}+$ calcd $\mathrm{C}_{10} \mathrm{H}_{12} \mathrm{FN}_{3}[\mathrm{M}+\mathrm{H}]+:$ 194; observed 194.

Preparation of $(R)$-1-(3-fluoro-1H-indazol-4-yl)-N-(2,2,2-trifluoroethyl)propan-2-amine (27)<smiles>C[C@H](Cc1cccc2[nH]nc(F)c12)NCC(F)(F)F</smiles>

2,2,2-Trifluoroethyl trifluoromethanesulfonate in DCM $(0.1 \mathrm{M}, 105 \mathrm{~mL}, 21.0 \mathrm{mmol})$ was added to $(R)$ 1-(3-fluoro-1H-indazol-4-yl)propan-2-amine $(2.90 \mathrm{~g}, 15.0 \mathrm{mmol})$ and $\mathrm{N}$-ethyl- $\mathrm{N}$-isopropylpropan-2amine $(3.92 \mathrm{~mL}, 22.5 \mathrm{mmol})$ in 1,4-dioxane $(20.0 \mathrm{~mL})$. The resulting mixture stirred at $50{ }^{\circ} \mathrm{C}$ for 48 hours. The reaction was concentrated under reduced pressure and partitioned between EtOAc (25 $\mathrm{mL}$ ) and saturated aqueous solution of sodium bicarbonate $(25 \mathrm{~mL})$. The layers were separated and the aqueous layer extracted with EtOAc $(25 \mathrm{~mL})$. The combined organic layers were washed with saturated brine $(25 \mathrm{~mL})$, dried over $\mathrm{Na}_{2} \mathrm{SO}_{4}$, filtered and concentrated under reduced pressure. The residue was purified by ion exchange chromatography, using an SCX column. The desired product was eluted from the column using $7 \mathrm{M} \mathrm{NH}_{3} / \mathrm{MeOH}$ to afford (R)-1-(3-fluoro-1H-indazol-4-yl)- $\mathrm{N}-(2,2,2-$ trifluoroethyl)propan-2-amine $(3.90 \mathrm{~g}, 94 \%)$ as a brown gum. ${ }^{1} \mathrm{H} N \mathrm{NMR}\left(500 \mathrm{MHz}, \mathrm{CDCl}_{3}, 27^{\circ} \mathrm{C}\right) 1.11(3 \mathrm{H}$, d), $1.37(1 \mathrm{H}, \mathrm{s}), 2.92(1 \mathrm{H}, \mathrm{dd}), 3.06-3.25(4 \mathrm{H}, \mathrm{m}), 6.93-6.97(1 \mathrm{H}, \mathrm{m}), 7.23-7.26(1 \mathrm{H}, \mathrm{m}), 7.35(1 \mathrm{H}$, dd), $9.45(1 \mathrm{H}, \mathrm{s}) ;{ }^{19} \mathrm{~F} \mathrm{NMR}\left(471 \mathrm{MHz}, \mathrm{CDCl}_{3}, 27^{\circ} \mathrm{C}\right)-130.06,-72.04 ; \mathrm{m} / \mathrm{z}$ : $\mathrm{ESI}+$ calcd $\mathrm{C}_{12} \mathrm{H}_{13} \mathrm{~F}_{4} \mathrm{~N}_{3}[\mathrm{M}+\mathrm{H}]+$ : 276; observed 276.

Preparation of (6S,8R)-6-(5-bromo-6-fluoropyridin-2-yl)-1-fluoro-8-methyl-7-(2,2,2-trifluoroethyl)6,7,8,9-tetrahydro-3H-pyrazolo[4,3-f]isoquinoline<smiles>C[C@H]1Cc2c(ccc3[nH]nc(F)c23)C(c2ccc(Br)c(F)n2)[C@@H]1CN(C)C(F)(F)F</smiles>

5-Bromo-6-fluoropicolinaldehyde (163 mg, $0.80 \mathrm{mmol}$ ) was added to a solution of $(R)$-1-(3-fluoro-1Hindazol-4-yl)-N-(2,2,2-trifluoroethyl)propan-2-amine (200 mg, $0.73 \mathrm{mmol})$ in toluene $(3.45 \mathrm{~mL}) / \mathrm{TFA}$ $(182 \mu \mathrm{L})$. The resultion solution was stirred at $90^{\circ} \mathrm{C}$ for 5 hours. The reaction mixture was cooled to room temperature and diluted with $\mathrm{DCM}(10 \mathrm{~mL})$ and washed with a saturated aqueous solution of $\mathrm{NaHCO}_{3}(10 \mathrm{~mL})$. The organic phase was dried over $\mathrm{Na}_{2} \mathrm{SO}_{4}$ and concentrated under reduced pressure. The residue was purified by flash silica chromatography, elution gradient 0 to $30 \%$ EtOAc in heptane to afford (65,8R)-6-(5-bromo-6-fluoropyridin-2-yl)-1-fluoro-8-methyl-7-(2,2,2-trifluoroethyl)-6,7,8,9tetrahydro-3H-pyrazolo[4,3-f] isoquinoline $(275 \mathrm{mg}, 82 \%)$ as a beige solid. NMR as a 93:7 ratio of trans to cis isomers. ${ }^{1} \mathrm{H}$ NMR $\left(500 \mathrm{MHz}, \mathrm{CDCl}_{3}, 27^{\circ} \mathrm{C}\right) 1.17(3 \mathrm{H}, \mathrm{d}), 2.91-3.03(2 \mathrm{H}, \mathrm{m}), 3.32(2 \mathrm{H}, \mathrm{tt}), 3.41-$ $3.58(1 \mathrm{H}, \mathrm{m}), 5.01(1 \mathrm{H}, \mathrm{s}), 7.06(1 \mathrm{H}, \mathrm{d}), 7.12(1 \mathrm{H}, \mathrm{dd}), 7.35(1 \mathrm{H}, \mathrm{dd}), 7.88-7.99(1 \mathrm{H}, \mathrm{m}), 9.10(1 \mathrm{H}, \mathrm{s})$; $\mathrm{m} / \mathrm{z}$ : ESI- calcd $\mathrm{C}_{18} \mathrm{H}_{14} \mathrm{BrF}_{5} \mathrm{~N}_{4}$ [M-H]-: 459; observed 459.

Preparation of (6S,8R)-6-(5-bromo-3-fluoropyridin-2-yl)-1-fluoro-8-methyl-7-(2,2,2-trifluoroethyl)6,7,8,9-tetrahydro-3H-pyrazolo[4,3-f]isoquinoline 
<smiles>C[C@H]1Cc2c(ccc3[nH]nc(F)c23)C(c2ncc(Br)cc2F)N1CC(F)(F)F</smiles>

Trifluoroacetic acid $(2.16 \mathrm{~mL})$ was added to a solution of $(R)$-1-(3-fluoro-1H-indazol-4-yl)-N-(2,2,2trifluoroethyl)propan-2-amine $(2.50 \mathrm{~g}, 9.08 \mathrm{mmol})$ in toluene $(90 \mathrm{~mL})$. The resulting solution was stirred at $90{ }^{\circ} \mathrm{C}$ for 90 minutes. The reaction mixture was allowed to cool to room temperature and was diluted with DCM $(50 \mathrm{~mL})$ and a saturated aqueous solution of sodium bicarbonate $(50 \mathrm{~mL})$. The layers were separated and the organic layer was concentrated reduced pressure. The residue was purified by flash silica chromatography, elution gradient $0-50 \%$ ethyl acetate in heptane to afford (6S,8R)-6-(5-bromo-3-fluoropyridin-2-yl)-1-fluoro-8-methyl-7-(2,2,2-trifluoroethyl)-6,7,8,9-

tetrahydro-3H-pyrazolo[4,3-f]isoquinoline $(2.90 \mathrm{~g}, 69 \%)$ as a white solid. ${ }^{1} \mathrm{H} \mathrm{NMR}\left(500 \mathrm{MHz}, \mathrm{CDCl}_{3}\right.$, $\left.27^{\circ} \mathrm{C}\right) 1.15(3 \mathrm{H}, \mathrm{d}), 2.88-3.04(2 \mathrm{H}, \mathrm{m}), 3.24-3.35(2 \mathrm{H}, \mathrm{m}), 3.63-3.71(1 \mathrm{H}, \mathrm{m}), 5.39(1 \mathrm{H}, \mathrm{s}), 6.83(1 \mathrm{H}$, d), $7.08(1 \mathrm{H}, \mathrm{dd}), 7.60(1 \mathrm{H}, \mathrm{dd}), 8.36(1 \mathrm{H}, \mathrm{dd}), 9.13(1 \mathrm{H}, \mathrm{s}) ;{ }^{19} \mathrm{~F} \mathrm{NMR}\left(471 \mathrm{MHz}, \mathrm{CDCl}_{3}, 27^{\circ} \mathrm{C}\right)-131.03,-$ $118.70(J=8.7),-71.33(J=9.2) ; \mathrm{m} / z$ : ESI- calcd $\mathrm{C}_{18} \mathrm{H}_{14} \mathrm{BrF}_{5} \mathrm{~N}_{4}[\mathrm{M}-\mathrm{H}]-:$ 459; observed 459.

Preparation of 2-fluoro-6-((6S,8R)-1-fluoro-8-methyl-7-(2,2,2-trifluoroethyl)-6,7,8,9-tetrahydro-3Hpyrazolo[4,3-flisoquinolin-6-yl)- $N$-(1-(3-fluoropropyl)azetidin-3-yl)pyridin-3-amine (8)<smiles>C[C@@H]1Cc2c(ccc3[nH]nc(F)c23)N(CC(F)(F)F)[C@@H]1c1ccc(NC2CN(CCCF)C2)c(F)n1</smiles>

1-(3-Fluoropropyl)azetidin-3-amine $(90 \mathrm{mg}, 0.68 \mathrm{mmol})$ was added to a degassed suspension of (6S,8R)-6-(5-bromo-6-fluoropyridin-2-yl)-1-fluoro-8-methyl-7-(2,2,2-trifluoroethyl)-6,7,8,9-

tetrahydro-3H-pyrazolo[4,3-f] isoquinoline ( $250 \mathrm{mg}, 0.54 \mathrm{mmol}$ ), sodium tert-butoxide (208 $\mathrm{mg}, 2.17$ $\mathrm{mmol})$ and brettphos $\mathrm{G} 3(25.9 \mathrm{mg}, 0.03 \mathrm{mmol})$ in 1,4-dioxane $(2.71 \mathrm{~mL})$. The resulting solution was stirred at $55{ }^{\circ} \mathrm{C}$ for 2 hours. The reaction mixture was cooled to room temperature and diluted with EtOAc $(10 \mathrm{~mL})$ and washed with saturated brine $(10 \mathrm{~mL})$. The aqueous layer was extracted with EtOAc $(10 \mathrm{~mL})$ and the combined organic layers were dried over $\mathrm{Na}_{2} \mathrm{SO}_{4}$ and concentrated under reduced pressure. The residue was purified by preparative HPLC (Waters SunFire column, $5 \mu$ silica, $19 \mathrm{~mm}$ diameter, $100 \mathrm{~mm}$ length), using decreasingly polar mixtures of water (containing $0.1 \% \mathrm{NH}_{3}$ ) and $\mathrm{MeCN}$ as eluents. Fractions containing the desired compound were evaporated to dryness to afford 2-fluoro-6-((6S,8R)-1-fluoro-8-methyl-7-(2,2,2-trifluoroethyl)-6,7,8,9-tetrahydro-3H-pyrazolo[4,3-

flisoquinolin-6-yl)- $N$-(1-(3-fluoropropyl)azetidin-3-yl)pyridin-3-amine 8 (162 $\mathrm{mg}, 58 \%)$ as a colourless solid. ${ }^{1} \mathrm{H}$ NMR $\left(500 \mathrm{MHz}, \mathrm{CDCl}_{3}, 27^{\circ} \mathrm{C}\right) 1.15(3 \mathrm{H}, \mathrm{d}), 1.60-1.88(2 \mathrm{H}, \mathrm{m}), 2.62(2 \mathrm{H}, \mathrm{t}), 2.80-3.09(4 \mathrm{H}$, $\mathrm{m}), 3.11-3.39(2 \mathrm{H}, \mathrm{m}), 3.51-3.60(1 \mathrm{H}, \mathrm{m}), 3.76(2 \mathrm{H}, \mathrm{q}), 4.09(1 \mathrm{H}, \mathrm{h}), 4.25(1 \mathrm{H}, \mathrm{d}), 4.44(1 \mathrm{H}, \mathrm{t}), 4.53$ $(1 \mathrm{H}, \mathrm{t}), 4.94(1 \mathrm{H}, \mathrm{s}), 6.83(1 \mathrm{H}, \mathrm{dd}), 6.96(1 \mathrm{H}, \mathrm{d}), 7.01(1 \mathrm{H}, \mathrm{dd}), 7.19(1 \mathrm{H}, \mathrm{d}), 9.57(1 \mathrm{H}, \mathrm{s}) ;{ }^{13} \mathrm{C}$ NMR $(126$ $\mathrm{MHz}$, DMSO- $\left.d_{6}, 27^{\circ} \mathrm{C}\right) 17.8,28.7,29.4,43.4,47.3,48.7,55.0,61.0,67.0,82.5(J=163.5 \mathrm{~Hz}), 106.8$, $108.8,120.4,122.5,126.7,126.7,126.9,129.8,130.3,141.0,145.2,150.9(J=228.1 \mathrm{~Hz}), 157.6(J=$ $240.6 \mathrm{~Hz}) ;{ }^{19} \mathrm{~F} \mathrm{NMR}\left(471 \mathrm{MHz}\right.$, DMSO- $\left.d_{6}, 27^{\circ} \mathrm{C}\right)-218.12(J=47.7,25.1),-134.40,-83.85(J=10.2),-69.95$ $(J=9.9) . \mathrm{m} / \mathrm{z}$ : $\mathrm{ESI}+$ calcd $\mathrm{C}_{24} \mathrm{H}_{26} \mathrm{~N}_{6} \mathrm{~F}_{6}[\mathrm{M}+\mathrm{H}]+: 513$; observed 513; HRMS (ESI $\left.{ }^{+}\right)$: Anal. calcd. For $\mathrm{C}_{24} \mathrm{H}_{26} \mathrm{~N}_{6} \mathrm{~F}_{6}$ $[\mathrm{M}+\mathrm{H}]+:$ 513.2201; observed 513.2214. 
Preparation of 5-fluoro-6-((6S,8R)-1-fluoro-8-methyl-7-(2,2,2-trifluoroethyl)-6,7,8,9-tetrahydro-3Hpyrazolo[4,3-flisoquinolin-6-yl)-N-(1-(3-fluoropropyl)azetidin-3-yl)pyridin-3-amine (9)<smiles>C[C@H]1Cc2c(ccc3[nH]nc(F)c23)N(CC(F)(F)F)[C@@H]1c1ncc(NC2CN(CCCF)C2)cc1F</smiles>

Sodium tert-butoxide $(3.12 \mathrm{~g}, 32.5 \mathrm{mmol})$ and BrettPhos $\mathrm{G} 3(245 \mathrm{mg}, 0.27 \mathrm{mmol})$ were added to a degassed solution of 1-(3-fluoropropyl)azetidin-3-amine $(1.08 \mathrm{~g}, 8.13 \mathrm{mmol})$ and 1-(3fluoropropyl)azetidin-3-amine $(1.075 \mathrm{~g}, 8.13 \mathrm{mmol})$ in 1,4-dioxane $(27.1 \mathrm{~mL})$. The resulting solution was stirred at $60{ }^{\circ} \mathrm{C}$ for 2 hours. The reaction mixtue was cooled to room temperature and diluted with EtOAc $(50 \mathrm{~mL})$ and water $(50 \mathrm{~mL})$, and the layers were separated. The aqueous layer was extracted with EtOAc $(50 \mathrm{~mL})$, and the combined organics were dried over $\mathrm{MgSO}_{4}$ and concentrated under reduced pressure. The residue was purified by flash silica chromatography, elution gradient $0-$ $10 \%$ methanol in ethyl acetate, to afford the crude product. This was further purified by preparative HPLC (Waters SunFire column, $5 \mu$ silica, $19 \mathrm{~mm}$ diameter, $100 \mathrm{~mm}$ length), using decreasingly polar mixtures of water (containing $0.1 \% \mathrm{NH}_{3}$ ) and $\mathrm{MeCN}$ as eluents. Fractions containing the desired compound were evaporated to dryness to give a mixture of epimers. The epimers were separated by SFC; the sample was dissolved in $\mathrm{MeOH}$ and separated using the following SFC conditions: Mobile phase: $25 \% \mathrm{MeOH}+0.1 \% \mathrm{NH}_{3}$, to give 5-fluoro-6-((6S,8R)-1-fluoro-8-methyl-7-(2,2,2-trifluoroethyl)6,7,8,9-tetrahydro-3H-pyrazolo[4,3-f]isoquinolin-6-yl)- $N$-(1-(3-fluoropropyl)azetidin-3-yl)pyridin-3amine $(1.780 \mathrm{~g}, 64 \%)$ as foam. ${ }^{1} \mathrm{H} \mathrm{NMR}\left(500 \mathrm{MHz}, \mathrm{CDCl}_{3}, 27^{\circ} \mathrm{C}\right) 1.15(3 \mathrm{H}, \mathrm{d}), 1.67-1.81(2 \mathrm{H}, \mathrm{m}), 2.59$ $(2 \mathrm{H}, \mathrm{t}), 2.81-3.03(4 \mathrm{H}, \mathrm{m}), 3.17-3.34(2 \mathrm{H}, \mathrm{m}), 3.70(3 \mathrm{H}, \mathrm{q}), 4.01-4.08(1 \mathrm{H}, \mathrm{m}), 4.20(1 \mathrm{H}, \mathrm{d}), 4.43$ $(1 \mathrm{H}, \mathrm{t}), 4.53(1 \mathrm{H}, \mathrm{t}), 5.32(1 \mathrm{H}, \mathrm{s}), 6.54(1 \mathrm{H}, \mathrm{dd}), 6.81(1 \mathrm{H}, \mathrm{d}), 6.95(1 \mathrm{H}, \mathrm{d}), 7.64-7.68(1 \mathrm{H}, \mathrm{m}), 9.46(1 \mathrm{H}$, s); ${ }^{13} \mathrm{C}$ NMR $\left(126 \mathrm{MHz}\right.$, DMSO- $\left.d_{6}, 27^{\circ} \mathrm{C}\right) 17.8,28.7,29.1,43.4,47.0,49.1,55.4,61.4,62.4,82.6(\mathrm{~J}=$ $165.6 \mathrm{~Hz}), 105.3,106.8,108.8,126.5,126.8,127.3,129.6,130.3,136.4,141.0,145.4,157.6(\mathrm{~J}=$ $244.5 \mathrm{~Hz}), 158.70(\mathrm{~J}=257.0 \mathrm{~Hz}) ;{ }^{19} \mathrm{~F}$ NMR $\left(471 \mathrm{MHz}\right.$, DMSO- $\left.d_{6}, 27^{\circ} \mathrm{C}\right)-218.16(J=47.6,25.2),-134.52,-$ $124.66(J=15.5,8.8,8.2),-70.01(J=9.4) . \mathrm{m} / \mathrm{z}$ : ESI+ calcd $\mathrm{C}_{24} \mathrm{H}_{26} \mathrm{~N}_{6} \mathrm{~F}_{6}[\mathrm{M}+\mathrm{H}]+:$ : 513; observed 513; HRMS $\left(\mathrm{ESI}^{+}\right)$: Anal. calcd. For $\mathrm{C}_{24} \mathrm{H}_{26} \mathrm{~N}_{6} \mathrm{~F}_{6}[\mathrm{M}+\mathrm{H}]+$ : 513.2201; obsevered 513.2214.

\section{Scheme 5}

\section{Preparation of 3-bromo-2-methylbenzaldehyde}<smiles>Cc1c(Br)cccc1C=O</smiles>

$n$-Butyllithium (1.6M in hexanes, $28.5 \mathrm{~mL}, 45.6 \mathrm{mmol}$ ) was added dropwise to a solution of 1,3dibromo-2-methylbenzene $(9.50 \mathrm{~g}, 38.0 \mathrm{mmol})$ in THF $(119 \mathrm{~mL})$ at $-78^{\circ} \mathrm{C}$. The resulting solution was stirred at this temperature for 30 minutes. $N, N$-Dimethylformamide $(4.41 \mathrm{~mL}, 57.0 \mathrm{mmol})$ was added and the reaction was stirred for a further 30 minutes, before being allowed to warm to $0{ }^{\circ} \mathrm{C}$ over 1 hour. The reaction was quenched by addition of water, then was extracted with EtOAc $(100 \mathrm{~mL})$. The organic phase was dried over $\mathrm{MgSO}_{4}$, filtered and concentrated under reduced pressure to afford 3bromo-2-methylbenzaldehyde $(7.19 \mathrm{~g}, 95 \%)$ as a straw coloured oil. ${ }^{1} \mathrm{H} \mathrm{NMR}\left(500 \mathrm{MHz}, \mathrm{CDCl}_{3}, 27^{\circ} \mathrm{C}\right)$ $2.75(3 \mathrm{H}, \mathrm{s}), 7.18-7.37(1 \mathrm{H}, \mathrm{m}), 7.78(2 \mathrm{H}, \mathrm{ddd}), 10.26(1 \mathrm{H}, \mathrm{s})$. 


\section{Preparation of (3-bromo-2-methylphenyl)methanol}<smiles>Cc1c(Br)cccc1CO</smiles>

Sodium borohydride $(1.78 \mathrm{~g}, 47.1 \mathrm{mmol})$ was added to a solution of 3-bromo-2-methylbenzaldehyde $(7.50 \mathrm{~g}, 37.7 \mathrm{mmol})$ in THF $(151 \mathrm{~mL})$. The resulting solution was stirred at room temperature for 2 hours. The reaction was cooled in an ice-bath to $0{ }^{\circ} \mathrm{C}$ and quenched by dropwise addition of $2 \mathrm{~N}$ aqueous $\mathrm{HCl}$ solution, then extracted with EtOAc $(2 \times 150 \mathrm{~mL})$. The combined organic layers were washed with saturated brine, dried over $\mathrm{MgSO}_{4}$ and concentrated under reduced pressure to afford (3-bromo-2-methylphenyl)methanol $(7.73 \mathrm{~g}, 100 \%)$ as a pale yellow solid. ${ }^{1} \mathrm{H} \mathrm{NMR}\left(500 \mathrm{MHz}, \mathrm{CDCl}_{3}\right.$, $\left.27^{\circ} \mathrm{C}\right) 1.99(1 \mathrm{H}, \mathrm{br} \mathrm{s}), 2.41(3 \mathrm{H}, \mathrm{s}), 4.70(2 \mathrm{H}, \mathrm{s}), 7.05(1 \mathrm{H}, \mathrm{t}), 7.30(1 \mathrm{H}, \mathrm{d}), 7.49-7.53(1 \mathrm{H}, \mathrm{m})$.

\section{Preparation of 1-bromo-3-(bromomethyl)-2-methylbenzene (28)}<smiles>Cc1c(Br)cccc1CBr</smiles>

Carbon tetrabromide (14.35 g, $43.3 \mathrm{mmol})$ was added portionwise to a solution of (3-bromo-2methylphenyl)methanol $(7.25 \mathrm{~g}, 36.1 \mathrm{mmol})$ and triphenylphosphine $(11.35 \mathrm{~g}, 43.27 \mathrm{mmol})$ in DCM $(120 \mathrm{~mL})$ (reaction exotherms to $\sim 40{ }^{\circ} \mathrm{C}$ ). The resultion solution was stirred at room temperature for 2 hours. The residue was passed through a pad of silica, eluting with DCM. The filtrate was concentrated under reduced pressure. The residue was purified by flash silica chromatography, elution gradient 0 to $25 \%$ EtOAc in heptane to afford 1-bromo-3-(bromomethyl)-2-methylbenzene $(8.52 \mathrm{~g}, 90 \%)$ as a colourless oil. ${ }^{1} \mathrm{H}$ NMR $\left(500 \mathrm{MHz}, \mathrm{CDCl}_{3}, 27^{\circ} \mathrm{C}\right) 2.48(3 \mathrm{H}, \mathrm{s}), 4.52(2 \mathrm{H}, \mathrm{s}), 6.99-7.05$ $(1 \mathrm{H}, \mathrm{m}), 7.22-7.27(1 \mathrm{H}, \mathrm{m}), 7.52(1 \mathrm{H}, \mathrm{dd})$.

\section{Preparation of tert-butyl (S)-3-(3-bromo-2-methylphenyl)-2-((diphenylmethylene)} amino)propanoate (29)<smiles>Cc1c(Br)cccc1C[C@H](N=C(c1ccccc1)c1ccccc1)C(=O)OC(C)(C)C</smiles>

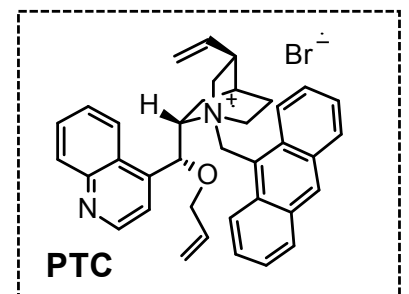

1-Bromo-3-(bromomethyl)-2-methylbenzene $(6.86 \mathrm{~g}, 26.0 \mathrm{mmol})$ was added to a solution of tert-butyl 2-((diphenylmethylene)amino)acetate $(7.68 \mathrm{~g}, 26 \mathrm{mmol})$ and $(1 S, 2 S, 4 S, 5 R)-2$-((R)-(allyloxy)(quinolin4-yl)methyl)-1-(anthracen-9-ylmethyl)-5-vinylquinuclidin-1-ium bromide PTC (1.58 g, $2.60 \mathrm{mmol})$ in toluene $(130 \mathrm{~mL})$ and $50 \%$ aq. $\mathrm{KOH}$ solution $(15.08 \mathrm{~g}, 130.0 \mathrm{mmol})$. The biphasic mixture was stirred vigourously at $0{ }^{\circ} \mathrm{C}$ (ice-bath) for 4 hours. The reaction was diluted by addition of water $(100 \mathrm{~mL})$, then extracted with EtOAc $(2 \times 100 \mathrm{~mL})$. The combined organics were washed with saturated brine, dried over $\mathrm{MgSO}_{4}$ and concentrated to dryness. The residue was purified by flash silica chromatography, elution gradient 0 to 50\% EtOAc in heptane to afford tert-butyl (S)-3-(3-bromo-2-methylphenyl)-2((diphenylmethylene)amino)propanoate $(9.96 \mathrm{~g}, 80 \%)$ as a pale yellow liquid. ${ }^{1} \mathrm{H}$ NMR $(500 \mathrm{MHz}$, $\left.\mathrm{CDCl}_{3}, 27^{\circ} \mathrm{C}\right) 1.46(9 \mathrm{H}, \mathrm{s}), 1.99(3 \mathrm{H}, \mathrm{s}), 3.17(1 \mathrm{H}, \mathrm{dd}), 3.34(1 \mathrm{H}, \mathrm{dd}), 4.12(1 \mathrm{H}, \mathrm{dd}), 6.48(2 \mathrm{H}, \mathrm{s}), 6.82-$ $6.89(1 \mathrm{H}, \mathrm{m}), 7.01(1 \mathrm{H}, \mathrm{dd}), 7.25-7.41(7 \mathrm{H}, \mathrm{m}), 7.53-7.59(2 \mathrm{H}, \mathrm{m}) . \mathrm{m} / \mathrm{z}$ : ESI+ calcd $\mathrm{C}_{27} \mathrm{H}_{28} \mathrm{BrNO}_{2}[\mathrm{M}+\mathrm{H}]+$ : 478; observed 478. Chiral analysis using analytical HPLC (Regis $(R, R)$ Whelk-O1 column, $5 \mu \mathrm{m}$ silica, 4.6 $\mathrm{mm}$ diameter, $250 \mathrm{~mm}$ length), using a 95/05 mixture of Heptane/EtOH as eluents at $2 \mathrm{~mL} / \mathrm{min}$ showed the product existed in a $98: 2$ ratio of isomers ( $96 \%$ ee). 
Chiral Analysis of tert-butyl (S)-3-(3-bromo-2-methylphenyl)-2-

((diphenylmethylene)amino)propanoate

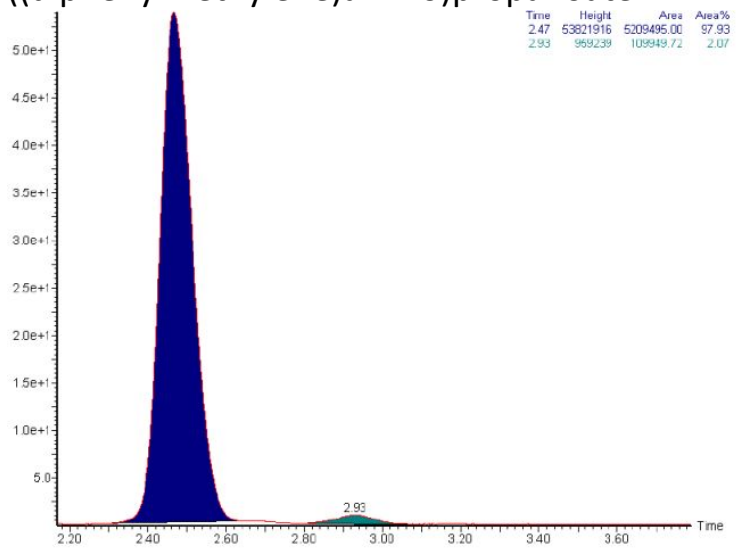

Preparation of tert-butyl (S)-2-amino-3-(3-bromo-2-methylphenyl)propanoate<smiles>Cc1c(Br)cccc1C[C@@H](N)C(=O)OC(C)(C)C</smiles>

tert-Butyl (S)-3-(3-bromo-2-methylphenyl)-2-((diphenylmethylene)amino)propanoate (9.00 g, 18.8 $\mathrm{mmol})$ was stirred in EtOAc $(63 \mathrm{~mL})$ and aqueous $\mathrm{HCl}(2 \mathrm{~N}, 31.5 \mathrm{~mL})$. The resulting biphasic solution was stirred at room temperature for 1 hour. The layers were seperated and the aqueous layer was basified by addition of $2 \mathrm{~N} \mathrm{NaOH}$ solution, then extracted with EtOAc $(2 \times 50 \mathrm{~mL})$. The combined organic layers were dried over $\mathrm{MgSO}_{4}$, filtered and concentrated under reduced pressure. The residue was purified by flash silica chromatography, elution gradient 0 to $100 \%$ EtOAc in heptane to afford tertbutyl (S)-2-amino-3-(3-bromo-2-methylphenyl)propanoate $(4.98 \mathrm{~g}, 84 \%)$ as a pale yellow oil. ${ }^{1} \mathrm{H}$ NMR $\left(500 \mathrm{MHz}, \mathrm{CDCl}_{3}, 27^{\circ} \mathrm{C}\right) 1.40(9 \mathrm{H}, \mathrm{s}), 2.44(3 \mathrm{H}, \mathrm{s}), 2.80(1 \mathrm{H}, \mathrm{dd}), 3.12(1 \mathrm{H}, \mathrm{dd}), 3.55(1 \mathrm{H}, \mathrm{dd}), 6.94-7.00$ $(1 \mathrm{H}, \mathrm{m}), 7.07-7.12(1 \mathrm{H}, \mathrm{m}), 7.45(1 \mathrm{H}, \mathrm{dd}) ; \mathrm{m} / z$ : $\mathrm{ESI}+$ calcd $\mathrm{C}_{14} \mathrm{H}_{20} \mathrm{BrNO}_{2}[\mathrm{M}+\mathrm{H}]+:$ : 314; observed 314.

\section{Preparation of (S)-2-amino-3-(3-bromo-2-methylphenyl)propan-1-ol (30)}<smiles>Cc1c(Br)cccc1C[C@@H](N)CO</smiles>

Lithium borohydride solution ( $2 \mathrm{M}$ in THF; $14.38 \mathrm{~mL}, 28.75 \mathrm{mmol}$ ) was added to a solution of tertbutyl (S)-2-amino-3-(3-bromo-2-methylphenyl)propanoate (7.23 g, $23.0 \mathrm{mmol}$ ) in THF (78 $\mathrm{mL})$. The resulting solution was stirred at $50{ }^{\circ} \mathrm{C}$ for 1 hour. After cooling in an ice-bath to $0{ }^{\circ} \mathrm{C}$, the reaction was quenched by addition of $1 \mathrm{~N} \mathrm{HCl}$ solution. The aqueous layer was then basified by addition of $2 \mathrm{~N}$ $\mathrm{NaOH}$ and extracted with EtOAc $(3 \times 100 \mathrm{~mL})$. The combined organic layers were dried over $\mathrm{MgSO}_{4}$, filtered and concentrated under reduced pressure to afford (S)-2-amino-3-(3-bromo-2methylphenyl)propan-1-ol $(5.93 \mathrm{~g}, 100 \%)$ as a straw coloured oil. ${ }^{1} \mathrm{H} \mathrm{NMR}\left(500 \mathrm{MHz}, \mathrm{CDCl}_{3}, 27^{\circ} \mathrm{C}\right)$ $1.91-2.04(2 \mathrm{H}, \mathrm{m}), 2.41(3 \mathrm{H}, \mathrm{s}), 2.60(1 \mathrm{H}, \mathrm{dd}), 2.88(1 \mathrm{H}, \mathrm{dd}), 3.01-3.14(1 \mathrm{H}, \mathrm{m}), 3.40(1 \mathrm{H}, \mathrm{dd}), 3.63$ $(1 \mathrm{H}, \mathrm{dd}), 6.94-7.01(1 \mathrm{H}, \mathrm{m}), 7.08(1 \mathrm{H}, \mathrm{dd}), 7.13(1 \mathrm{H}, \mathrm{dd}), 7.45(1 \mathrm{H}, \mathrm{dd}) ; \mathrm{m} / \mathrm{z}$ : $\mathrm{ESI}+$ calcd $\mathrm{C}_{10} \mathrm{H}_{14} \mathrm{BrNO}$ $[\mathrm{M}+\mathrm{H}]+:$ 244; observed 244. 
<smiles>Cc1c(Br)cccc1C[C@H](CO)NCC(F)F</smiles>

2,2-Difluoroethyl trifluoromethanesulfonate in DCM $(0.4 \mathrm{M}, 51.8 \mathrm{~mL}, 20.7 \mathrm{mmol})$ was added to a solution of (S)-2-amino-3-(3-bromo-2-methylphenyl)propan-1-ol (4.40 g, $18.02 \mathrm{mmol}$ ) and DIPEA (4.05 $\mathrm{mL}, 23.43 \mathrm{mmol})$ in 1,4-dioxane $(16.23 \mathrm{~mL}$ ). The resulting solution was stirred at room temperature for 2 hours. The reaction mixture was washed with saturated brine, then dried over $\mathrm{Na}_{2} \mathrm{SO}_{4}$, filtered and concentrated under reduced pressure. The residue was purified by flash silica chromatography, elution gradient 0 to $100 \%$ EtOAc in heptane to afford $(S)$-3-(3-bromo-2-methylphenyl)-2-((2,2difluoroethyl)amino)propan-1-ol (5.06 g, 91\%) as a pale yellow oil. ${ }^{1} \mathrm{H} \mathrm{NMR}\left(500 \mathrm{MHz}, \mathrm{CDCl}_{3}, 27^{\circ} \mathrm{C}\right)$ $2.42(3 \mathrm{H}, \mathrm{s}), 2.73-3.03(5 \mathrm{H}, \mathrm{m}), 3.34(1 \mathrm{H}, \mathrm{dd}), 3.60(1 \mathrm{H}, \mathrm{dd}), 5.54-6.10(1 \mathrm{H}, \mathrm{m}), 7.00(1 \mathrm{H}, \mathrm{d}), 7.07$ $(1 \mathrm{H}, \mathrm{dd}), 7.46(1 \mathrm{H}, \mathrm{dd}) ; \mathrm{m} / \mathrm{z}$ : $\mathrm{ESI}+$ calcd $\mathrm{C}_{12} \mathrm{H}_{16} \mathrm{BrF}_{2} \mathrm{NO}[\mathrm{M}+\mathrm{H}]+$ : 308; observed 308.

\section{Preparation of (S)-3-(3-amino-2-methylphenyl)-2-((2,2-difluoroethyl)amino)propan-1-ol (31)}<smiles>Cc1c(N)cccc1CC(CO)NCC(F)F</smiles>

$\mathrm{Pd}_{2}(\mathrm{dba})_{3}(0.267 \mathrm{~g}, 0.29 \mathrm{mmol})$ was added to a degassed suspension of $(\mathrm{S})$-3-(3-bromo-2methylphenyl)-2-((2,2-difluoroethyl)amino)propan-1-ol (4.50 g, $11.68 \mathrm{mmol})$, diphenylmethanimine $(1.960 \mathrm{~mL}, 11.68 \mathrm{mmol})$, sodium tert-butoxide $(1.684 \mathrm{~g}, 17.52 \mathrm{mmol})$ and rac-BINAP $(0.363 \mathrm{~g}, 0.58$ $\mathrm{mmol})$ in toluene $(56.4 \mathrm{~mL})$. The resulting solution was stirred at $90{ }^{\circ} \mathrm{C}$ for 2 hours. After the reaction mixture was cooled to room temperature, the solution was quenched with water $(50 \mathrm{~mL})$. The layers were seperated and the aqueous layer was extracted with EtOAc $(50 \mathrm{~mL})$. The combined organic layers were concentrated under reduced pressure. The residue was dissolved in EtOAc $(60 \mathrm{~mL})$ and $2 \mathrm{~N} \mathrm{HCl}$ $(30 \mathrm{~mL})$. The biphasic mixture was stirred at room temperature for 1 hour. The layers were separated, then the aqueous layer was extracted with EtOAc $(30 \mathrm{~mL})$. The organic layers were back-extracted with $2 \mathrm{~N} \mathrm{HCl}(50 \mathrm{~mL})$, then the combined aqueous phases were basified by addition of $2 \mathrm{~N} \mathrm{NaOH}$ solution. The basic aqueous phase was extracted with DCM $(3 \times 100 \mathrm{~mL})$, then the combined DCM extracts were dried over $\mathrm{Na}_{2} \mathrm{SO}_{4}$, filtered and concentrated under reduced pressure to afford (S)-3-(3amino-2-methylphenyl)-2-((2,2-difluoroethyl)amino)propan-1-ol (2.230 g, 78\%) as a brown oil, which solidified on standing. ${ }^{1} \mathrm{H}$ NMR $\left(500 \mathrm{MHz}, \mathrm{CDCl}_{3}, 27^{\circ} \mathrm{C}\right) 2.11(3 \mathrm{H}, \mathrm{s}), 2.69-3.06(6 \mathrm{H}, \mathrm{m}), 3.34(1 \mathrm{H}, \mathrm{dd})$, $3.60(1 \mathrm{H}, \mathrm{dd}), 5.75(1 \mathrm{H}, \mathrm{tdd}), 6.59(2 \mathrm{H}, \mathrm{t}), 6.96(1 \mathrm{H}, \mathrm{t}) ; \mathrm{m} / \mathrm{z}$ : $\mathrm{ESI}+$ calcd $\mathrm{C}_{12} \mathrm{H}_{18} \mathrm{~F}_{2} \mathrm{~N}_{2} \mathrm{O}[\mathrm{M}+\mathrm{H}]+:$ 245; observed 245.

Preparation of ((1S,3S)-6-amino-1-(5-bromopyridin-2-yl)-2-(2,2-difluoroethyl)-5-methyl-1,2,3,4tetrahydroisoquinolin-3-yl)methanol<smiles>Cc1ccc2c(c1)CN(C(O)CF)C2Cc1ccc(Br)cn1</smiles>

5-Bromopicolinaldehyde $(3.05 \mathrm{~g}, 16.37 \mathrm{mmol})$ was added to a solution of (S)-3-(3-amino-2methylphenyl)-2-((2,2-difluoroethyl)amino)propan-1-ol $(2.00 \mathrm{~g}, 8.19 \mathrm{mmol})$ in acetic acid $(32.0 \mathrm{~mL})$ and water $(0.737 \mathrm{~mL}, 40.94 \mathrm{mmol})$. The resuting solution was heated to $50^{\circ} \mathrm{C}$ for 1 hour. After cooling to room temperature, the solution was concentrated under reduced pressure. The residue was 
dissolved in $\mathrm{DCM}$ and washed with a saturated aqueous $\mathrm{NaHCO}_{3}$ solution. The aqueous was extracted with DCM, then the combined organics were concentrated under reduced pressure. The residue was dissolved in methanol $(30 \mathrm{~mL})$ then hydroxylamine hydrochloride $(1.138 \mathrm{~g}, 16.37 \mathrm{mmol})$ and potassium acetate $(2.009 \mathrm{~g}, 20.47 \mathrm{mmol})$ were added and the reaction was stirred at room temperature for 1 hour. The solution was concentrated under reduced pressure, then the residue was dissolved in DCM (100 mL) and washed with saturated brine $(100 \mathrm{~mL})$. The organic phase was dried over $\mathrm{Na}_{2} \mathrm{SO}_{4}$, filtered and concentrated under reduced pressure. The residue was purified by flash silica chromatography, elution gradient 0 to 50\% EtOAc in heptane to afford ((1S,3S)-6-amino-1-(5bromopyridin-2-yl)-2-(2,2-difluoroethyl)-5-methyl-1,2,3,4-tetrahydroisoquinolin-3-yl)methanol

$(2.140 \mathrm{~g}, 63 \%)$ as a beige solid as a $3.6: 1$ ratio of diastereoisomers. ${ }^{1} \mathrm{H}$ NMR $\left(500 \mathrm{MHz}, \mathrm{CDCl}_{3}, 27^{\circ} \mathrm{C}\right)$ $2.06(3 \mathrm{H}, \mathrm{s}), 2.46(1 \mathrm{H}, \mathrm{dd}), 2.57(1 \mathrm{H}, \mathrm{dd}), 2.76-2.87(1 \mathrm{H}, \mathrm{m}), 3.10(1 \mathrm{H}, \mathrm{dd}), 3.29(1 \mathrm{H}, \mathrm{ddt}), 3.52-3.67$ $(2 \mathrm{H}, \mathrm{m}), 5.03(1 \mathrm{H}, \mathrm{s}), 5.76-6.1(1 \mathrm{H}, \mathrm{m}), 6.58(1 \mathrm{H}, \mathrm{d}), 6.71(1 \mathrm{H}, \mathrm{d}), 7.23(1 \mathrm{H}, \mathrm{d}), 7.71(1 \mathrm{H}, \mathrm{dd}), 8.58(1 \mathrm{H}$, dd); $m / z$ : $\mathrm{ESI}+$ calcd $\mathrm{C}_{18} \mathrm{H}_{20} \mathrm{BrF}_{2} \mathrm{~N}_{3} \mathrm{O}[\mathrm{M}+\mathrm{H}]+:$ 412; observed 412 .

Preparation of ((6S,8S)-6-(5-bromopyridin-2-yl)-7-(2,2-difluoroethyl)-6,7,8,9-tetrahydro-3Hpyrazolo[4,3-f]isoquinolin-8-yl)methanol (32)<smiles>OCC(c1ccc(Br)cn1)N1CCc2[nH]ncc2C1CO</smiles>

Sodium nitrite $(0.34 \mathrm{~g}, 4.85 \mathrm{mmol})$ was added in water $(2.02 \mathrm{~mL})$ to a cooled solution of $((1 S, 3 S)-6$ amino-1-(5-bromopyridin-2-yl)-2-(2,2-difluoroethyl)-5-methyl-1,2,3,4-tetrahydroisoquinolin-3$\mathrm{yl})$ methanol $(2.00 \mathrm{~g}, 4.85 \mathrm{mmol})$ in propionic acid $(10.1 \mathrm{~mL})$ at $-15^{\circ} \mathrm{C}$. The resulting solution was stirred for 1 hour and ice-cold toluene $(80 \mathrm{~mL})$ was added to the reaction mixture and allowed to warm to room temperature over 1 hour. The reaction mixture was basified by washing with $2 \mathrm{~N} \mathrm{Na}_{2} \mathrm{CO}_{3}$ solution $(100 \mathrm{~mL})$ and extracted with EtOAc $(2 \times 100 \mathrm{~mL})$. The combined organic layers were dried over $\mathrm{Na}_{2} \mathrm{SO}_{4}$, filtered and concentrated under reduced pressure. The residue was purified by flash silica chromatography, elution gradient 0 to 100\% EtOAc in heptane to afford ((6S,8S)-6-(5-bromopyridin2-yl)-7-(2,2-difluoroethyl)-6,7,8,9-tetrahydro-3H-pyrazolo[4,3-f]isoquinolin-8-yl)methanol (706 mg, $34 \%)$ as a beige solid. ${ }^{1} \mathrm{H}$ NMR $\left(500 \mathrm{MHz}, \mathrm{CDCl}_{3}, 27^{\circ} \mathrm{C}\right) 2.37(1 \mathrm{H}, \mathrm{s}), 2.76-2.96(2 \mathrm{H}, \mathrm{m}), 3.01(1 \mathrm{H}, \mathrm{dd})$, $3.22(1 \mathrm{H}, \mathrm{qd}), 3.43-3.53(1 \mathrm{H}, \mathrm{m}), 3.64(1 \mathrm{H}, \mathrm{dd}), 3.73(1 \mathrm{H}, \mathrm{dd}), 5.22(1 \mathrm{H}, \mathrm{s}), 5.91(1 \mathrm{H}, \mathrm{tt}), 7.01(1 \mathrm{H}, \mathrm{d})$, $7.28(1 \mathrm{H}, \mathrm{d}), 7.33(1 \mathrm{H}, \mathrm{d}), 7.77(1 \mathrm{H}, \mathrm{dd}), 8.02(1 \mathrm{H}, \mathrm{s}), 8.57(1 \mathrm{H}, \mathrm{dd}), 10.46(1 \mathrm{H}, \mathrm{s}) ; \mathrm{m} / \mathrm{z}$ : ESI+ calcd $\mathrm{C}_{18} \mathrm{H}_{17} \mathrm{BrF}_{2} \mathrm{~N}_{4} \mathrm{O}[\mathrm{M}+\mathrm{H}]+:$ : 423; observed 423.

Preparation of (6S,8S)-6-(5-bromopyridin-2-yl)-7-(2,2-difluoroethyl)-6,7,8,9-tetrahydro-3Hpyrazolo[4,3-flisoquinoline-8-carbaldehyde<smiles>O=C[C@H]1Cc2c(ccc3[nH]ncc23)C(c2ccc(Br)cn2)N1CC(F)F</smiles>

Sulfur trioxide pyridine complex $(579 \mathrm{mg}, 3.64 \mathrm{mmol})$ was added in DMSO $(3.85 \mu \mathrm{L}$ ) to a cooled solution of ((6S,8S)-6-(5-bromopyridin-2-yl)-7-(2,2-difluoroethyl)-6,7,8,9-tetrahydro-3H-pyrazolo[4,3f]isoquinolin-8-yl)methanol (700 mg, $1.65 \mathrm{mmol}$ ) and triethylamine $(576 \mu \mathrm{l}, 4.13 \mathrm{mmol})$ in DCM (3.85 $\mathrm{mL}$ ) at $5{ }^{\circ} \mathrm{C}$ (ice-bath). The resulting solution was allowed to warm to room temperature and stirred 
for 2 hours. The reaction mixture was diluted with DCM $(10 \mathrm{~mL})$ and washed with water $(10 \mathrm{~mL})$ and saturated brine $(10 \mathrm{~mL})$. The organic phase was then dried over $\mathrm{Na}_{2} \mathrm{SO}_{4}$, filtered and concentrated. The residue was purified by flash silica chromatography, elution gradient 0 to $100 \%$ EtOAc in heptane to afford (6S,8S)-6-(5-bromopyridin-2-yl)-7-(2,2-difluoroethyl)-6,7,8,9-tetrahydro-3H-pyrazolo[4,3f]isoquinoline-8-carbaldehyde ( $443 \mathrm{mg}, 64 \%)$ as a beige solid which was used immediately in the next step. $\mathrm{m} / \mathrm{z}$ : $\mathrm{ESI}+$ calcd $\mathrm{C}_{18} \mathrm{H}_{15} \mathrm{BrF}_{2} \mathrm{~N}_{4} \mathrm{O}[\mathrm{M}+\mathrm{H}]+:$ : 421 ; observed 421.

Preparation of (6S,8S)-6-(5-bromopyridin-2-yl)-7-(2,2-difluoroethyl)-8-(difluoromethyl)-3(tetrahydro-2H-pyran-2-yl)-6,7,8,9-tetrahydro-3H-pyrazolo[4,3-f] isoquinoline<smiles></smiles>

PTSA hydrate $(0.032 \mathrm{~g}, 0.17 \mathrm{mmol})$ was added to a suspension of $(6 \mathrm{~S}, 8 \mathrm{~S})$-6-(5-bromopyridin-2-yl)-7(2,2-difluoroethyl)-6,7,8,9-tetrahydro-3H-pyrazolo[4,3-f]isoquinoline-8-carbaldehyde (350 mg, 0.83 $\mathrm{mmol})$ and PTSA hydrate $(0.032 \mathrm{~g}, 0.17 \mathrm{mmol})$ in DCM $(6.31 \mathrm{~mL})$. The resulting solution was stirred at $40{ }^{\circ} \mathrm{C}$ for 2 hours. After cooling to room temperature, the reaction mixture was washed with saturatered aqueous $\mathrm{NaHCO}_{3}$ solution, dried over $\mathrm{Na}_{2} \mathrm{SO}_{4}$, filtered and concentrated. The residue was dissolved in DCM $(6.31 \mathrm{~mL})$, then DAST $(0.243 \mathrm{~mL}, 1.83 \mathrm{mmol})$ was added and the reaction mixture was stirred at room temperature overnight. The reaction solution was diluted with $D C M(10 \mathrm{~mL})$ the reaction mixture was washed with saturatered aqueous $\mathrm{NaHCO}_{3}$ solution, dried over $\mathrm{Na}_{2} \mathrm{SO}_{4}$, filtered and concentrated. The residue was purified by flash silica chromatography, elution gradient 0 to $40 \%$ EtOAc in heptane to afford (6S,8S)-6-(5-bromopyridin-2-yl)-7-(2,2-difluoroethyl)-8-(difluoromethyl)-3(tetrahydro-2H-pyran-2-yl)-6,7,8,9-tetrahydro-3H-pyrazolo[4,3-f]isoquinoline (176 $\mathrm{mg}, 40 \%$ ) as a beige solid. ${ }^{1} \mathrm{H}$ NMR $\left(500 \mathrm{MHz}, \mathrm{CDCl}_{3}, 27^{\circ} \mathrm{C}\right) 1.62-1.82(2 \mathrm{H}, \mathrm{m}), 2.01-2.10(1 \mathrm{H}, \mathrm{m}), 2.14(1 \mathrm{H}, \mathrm{dt}), 2.54$ $(1 \mathrm{H}, \mathrm{dddd}), 2.99(1 \mathrm{H}, \mathrm{dddt}), 3.20-3.31(1 \mathrm{H}, \mathrm{m}), 3.35-3.54(2 \mathrm{H}, \mathrm{m}), 3.66-3.78(2 \mathrm{H}, \mathrm{m}), 3.96-4.05$ $(1 \mathrm{H}, \mathrm{m}), 5.29(1 \mathrm{H}, \mathrm{d}), 5.52(1 \mathrm{H}, \mathrm{dd}), 5.64-5.68(1 \mathrm{H}, \mathrm{m}), 5.67-5.96(1 \mathrm{H}, \mathrm{m}), 6.93(1 \mathrm{H}, \mathrm{dd}), 7.21(1 \mathrm{H}$, ddd), $7.36(1 \mathrm{H}, \mathrm{dd}), 7.72(1 \mathrm{H}, \mathrm{ddd}), 8.04(1 \mathrm{H}, \mathrm{s}), 8.59(1 \mathrm{H}, \mathrm{td}) ; \mathrm{m} / \mathrm{z}$ : $\mathrm{ESI}+$ calcd $\mathrm{C}_{23} \mathrm{H}_{23} \mathrm{BrF}_{4} \mathrm{~N}_{4} \mathrm{O}[\mathrm{M}+\mathrm{H}]+$ : 527; observed 527.

Preparation of 6-((6S,8S)-7-(2,2-difluoroethyl)-8-(difluoromethyl)-6,7,8,9-tetrahydro-3Hpyrazolo[4,3-flisoquinolin-6-yl)-N-(1-(3-fluoropropyl)azetidin-3-yl)pyridin-3-amine (11)<smiles>FCCCN1CC(Nc2ccc(C3CN(CC(F)F)[C@@H](C(F)F)Cc4c3ccc3[nH]ncc43)nc2)C1</smiles>

Brettphos G3 (12.9 mg, $0.01 \mathrm{mmol}$ ) was added to a degassed suspension of $(6 \mathrm{~S}, 8 \mathrm{~S})$-6-(5-bromopyridin2-yl)-7-(2,2-difluoroethyl)-8-(difluoromethyl)-3-(tetrahydro-2H-pyran-2-yl)-6,7,8,9-tetrahydro-3Hpyrazolo[4,3-f] isoquinoline (150 mg, $0.28 \mathrm{mmol})$, sodium tert-butoxide $(68.3 \mathrm{mg}, 0.71 \mathrm{mmol}$ ) and 1(3-fluoropropyl)azetidin-3-amine $(47.0 \mathrm{mg}, 0.36 \mathrm{mmol})$ in 1,4-dioxane $(2.28 \mathrm{~mL})$. The resulting solution was stirred at $70^{\circ} \mathrm{C}$ for 4 hours. After cooling to room temperature, the reaction mixture was diluted with $\mathrm{DCM}(10 \mathrm{~mL})$ and water $(10 \mathrm{~mL})$, and the layers were separated. The aqueous layer was extracted 
with DCM $(3 \times 10 \mathrm{~mL})$ and the combined organics were evaporated. The residue was dissolved in DCM $(2 \mathrm{~mL})$ and TFA $(1 \mathrm{~mL})$ was added. The reaction mixture was stirred at room temperature for 1 hour, then was diluted with DCM and washed with saturated aqueous $\mathrm{NaHCO}_{3}$ solution. The aqueous layer was extracted with $\mathrm{DCM}$, then the combined organic layers were dried over $\mathrm{Na}_{2} \mathrm{SO}_{4}$, filtered and concentrated under reduced pressure. The residue was purified by preparative HPLC (Waters SunFire column, $5 \mu$ silica, $19 \mathrm{~mm}$ diameter, $100 \mathrm{~mm}$ length), using decreasingly polar mixtures of water (containing $0.1 \% \mathrm{NH}_{3}$ ) and $\mathrm{MeCN}$ as eluents. Fractions containing the desired compound were evaporated to dryness to afford 6-((6S,8S)-7-(2,2-difluoroethyl)-8-(difluoromethyl)-6,7,8,9tetrahydro-3H-pyrazolo[4,3-f]isoquinolin-6-yl)- $\mathrm{N}$-(1-(3-fluoropropyl)azetidin-3-yl)pyridin-3-amine 11 (74.0 mg, 53\%) as a beige solid. ${ }^{1} \mathrm{H} \mathrm{NMR}\left(500 \mathrm{MHz}, \mathrm{CDCl}_{3}, 27^{\circ} \mathrm{C}\right) 1.68-1.86(2 \mathrm{H}, \mathrm{m}), 2.63(2 \mathrm{H}, \mathrm{dd}), 2.98$ $(2 \mathrm{H}, \mathrm{dd}), 3.00-3.07(1 \mathrm{H}, \mathrm{m}), 3.20(1 \mathrm{H}, \mathrm{dd}), 3.28-3.44(2 \mathrm{H}, \mathrm{m}), 3.70(3 \mathrm{H}, \mathrm{q}), 4.10(1 \mathrm{H}, \mathrm{dh}), 4.43(2 \mathrm{H}$, t), $4.52(1 \mathrm{H}, \mathrm{t}), 5.19(1 \mathrm{H}, \mathrm{s}), 5.43(1 \mathrm{H}, \mathrm{tdd}), 5.81(1 \mathrm{H}, \mathrm{td}), 6.77(1 \mathrm{H}, \mathrm{dd}), 6.84(1 \mathrm{H}, \mathrm{d}), 7.09(2 \mathrm{H}, \mathrm{t}), 7.86$ $(1 \mathrm{H}, \mathrm{d}), 8.00-8.02(1 \mathrm{H}, \mathrm{m})$, exchangeable $\mathrm{NH}$ not observed; ${ }^{13} \mathrm{C}$ NMR $\left(126 \mathrm{MHz}\right.$, DMSO- $\left.d_{6}, 27^{\circ} \mathrm{C}\right) 22.3$, $27.8,42.7,51.8,54.62,61.0,66.2,82.0(\mathrm{~J}=163.1 \mathrm{~Hz}), 107.7,115.8,116.9,118.6,122.1,123.5,124.1$, $126.7,127.0,131.6,133.0,138.4,142.4,149.7 ;{ }^{19} \mathrm{~F}$ NMR (471 MHz, DMSO- $\left.d_{6}, 27^{\circ} \mathrm{C}\right)-218.15,-120.91$ $(J=286.3),-120.55(J=280.4),-119.73(J=280.6) ; \mathrm{m} / \mathrm{z}$ : ESI+ calcd $\mathrm{C}_{24} \mathrm{H}_{27} \mathrm{~N}_{6} \mathrm{~F}_{5}[\mathrm{M}+\mathrm{H}]+:$ 495; observed 495; HRMS $\left(E S I^{+}\right)$: Anal. calcd. For $\mathrm{C}_{24} \mathrm{H}_{27} \mathrm{~N}_{6} \mathrm{~F}_{5}[\mathrm{M}+\mathrm{H}]+$ : 495.2296; observed 495.2293.

\section{Scheme 6}

\section{Preparation of 3-((tert-butyldiphenylsilyl)oxy)-2,2-difluoropropyl trifluoromethanesulfonate}<smiles>CC(C)(C)[Si](OCC(F)(F)COS(=O)(=O)C(F)(F)F)(c1ccccc1)c1ccccc1</smiles>

Trifluoromethanesulfonic anhydride $(4.93 \mathrm{~mL}, 29.13 \mathrm{mmol})$ was added dropwise to a stirred solution of 3-((tert-butyldiphenylsilyl)oxy)-2,2-difluoropropan-1-ol $(9.28 \mathrm{~g}, 26.5 \mathrm{mmol})$ and 2,6dimethylpyridine $(4.63 \mathrm{~mL}, 39.7 \mathrm{mmol})$ in $\mathrm{DCM}(96 \mathrm{~mL})$ at $-10^{\circ} \mathrm{C}$. The resulting solution was stirred at $-10{ }^{\circ} \mathrm{C}$ for 2 hours. The reaction mixture was quenched with water $(100 \mathrm{~mL})$ and the layers were seperated. The organc layer was washed with $\mathrm{HCl}(1 \mathrm{~N}, 100 \mathrm{~mL})$ solution and saturated aquous $\mathrm{NaHCO}_{3}$ solution $(100 \mathrm{~mL})$. The organic phase was dried over $\mathrm{MgSO}_{4}$, filtered and concentrated under reduced pressure to afford 3-((tert-butyldiphenylsilyl)oxy)-2,2-difluoropropyl trifluoromethanesulfonate $(12.77 \mathrm{~g}, 100 \%) .{ }^{1} \mathrm{H} \mathrm{NMR}\left(300 \mathrm{MHz}, \mathrm{CDCl}_{3}\right) 1.03-1.14(9 \mathrm{H}, \mathrm{s}), 3.90(2 \mathrm{H}, \mathrm{t}), 4.76(2 \mathrm{H}, \mathrm{t}), 7.39-7.56(6 \mathrm{H}$, $\mathrm{m}), 7.59-7.75(4 \mathrm{H}, \mathrm{m})$.

Preparation of $(R)-N$-(1-(1H-indazol-4-yl)propan-2-yl)-3-((tert-butyldiphenylsilyl)oxy)-2,2difluoropropan-1-amine (33)

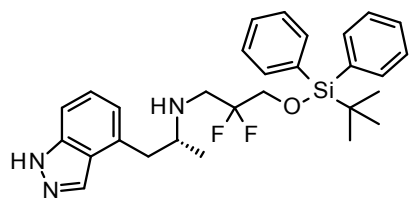

3-((tert-butyldiphenylsilyl)oxy)-2,2-difluoropropyl trifluoromethanesulfonate (2.59 g, $5.36 \mathrm{mmol})$ was added to a solution of $(R)-1$ - $(1 \mathrm{H}$-indazol-4-yl)propan-2-amine $(0.94 \mathrm{~g}, 5.36 \mathrm{mmol})$ and DIPEA (1.390 $\mathrm{mL}, 8.05 \mathrm{mmol})$ in 1,4-dioxane $(38.9 \mathrm{~mL})$. The resulting solution was stirred at $60^{\circ} \mathrm{C}$ for 18 hours. The reaction mixture was concentrated under reduced pressure. The residue was diluted with EtOAc (50 $\mathrm{mL}$ ) and washed with water $(50 \mathrm{~mL})$, the aqueous layer was further extracted with EtOAc $(3 \times 50 \mathrm{~mL})$. The combined organic layers were washed with saturated brine, dried over $\mathrm{MgSO}_{4}$, filtered and concentrated under reduced pressure. The residue was purified by flash silica (Puriflash, $120 \mathrm{~g}, \mathrm{HC}$, 
$50 \mu$ ) chromatography, elution gradient 0 to $50 \%$ EtOAc in heptane. Pure fractions were evaporated to dryness to afford (R)-N-(1-(1H-indazol-4-yl)propan-2-yl)-3-((tert-butyldiphenylsilyl)oxy)-2,2difluoropropan-1-amine $(1.52 \mathrm{~g}, 52 \%)$ as a colourless gum. ${ }^{1} \mathrm{H}$ NMR $\left(500 \mathrm{MHz}, \mathrm{DMSO}-d_{6}, 27^{\circ} \mathrm{C}\right) 0.92$ $(3 \mathrm{H}, \mathrm{d}), 0.97(9 \mathrm{H}, \mathrm{s}), 1.78-1.86(1 \mathrm{H}, \mathrm{m}), 2.73(1 \mathrm{H}, \mathrm{dd}), 2.98-3.14(4 \mathrm{H}, \mathrm{m}), 3.83(2 \mathrm{H}, \mathrm{td}), 6.85(1 \mathrm{H}, \mathrm{d})$, $7.20(1 \mathrm{H}, \mathrm{dd}), 7.34(1 \mathrm{H}, \mathrm{d}), 7.41-7.50(6 \mathrm{H}, \mathrm{m}), 7.58-7.64(4 \mathrm{H}, \mathrm{m}), 8.08(1 \mathrm{H}, \mathrm{s}), 12.98(1 \mathrm{H}, \mathrm{s}) ; \mathrm{m} / \mathrm{z}$ : $\mathrm{ESI}+$ calcd $\mathrm{C}_{29} \mathrm{H}_{35} \mathrm{~F}_{2} \mathrm{~N}_{3} \mathrm{OSi}[\mathrm{M}+\mathrm{H}]+$ : 508 ; observed 508 .

Preparation of $(6 S, 8 R)-6-(5-$ bromo-3-fluoropyridin-2-yl)-7-(3-((tert-butyldiphenylsilyl)oxy)-2,2difluoropropyl)-8-methyl-6,7,8,9-tetrahydro-3H-pyrazolo[4,3-f] isoquinoline<smiles>C[C@@H]1Cc2c(ccc3[nH]ncc23)[C@@H](c2ncc(Br)cc2F)N(CC(F)(F)CO[Si](c2ccccc2)(c2ccccc2)C(C)(C)C)[C@@H]1C</smiles>

Trifluoroacetic acid $(319 \mu \mathrm{l})$ was added to a solution of $(R)-N$-(1-(1H-indazol-4-yl)propan-2-yl)-3-((tertbutyldiphenylsilyl)oxy)-2,2-difluoropropan-1-amine $(681 \mathrm{mg}, 1.34 \mathrm{mmol})$ and 5-bromo-3fluoropicolinaldehyde $(287 \mathrm{mg}, 1.41 \mathrm{mmol})$ in toluene $(6387 \mu \mathrm{l})$. The resulting solution was stirred at $110^{\circ} \mathrm{C}$ for 1 hour. The reaction was allowed to cool to room temperature and was concentrated under reduced pressure. The residue was purified by Flash RP chromatography (100 g Redisep Rf C18 column), using decreasingly polar mixtures of water (containing $0.1 \%$ formic acid) and MeCN (60 $100 \%$ ) as eluents. Fractions containing the desired compound were combined and was isolated by ion exchange chromatography, using an $20 \mathrm{~g} \mathrm{SCX}-2$ column. The desired product was eluted from the column using $1 \mathrm{M} \mathrm{NH}_{3} / \mathrm{MeOH}$ and pure fractions were evaporated to dryness to afford $(6 S, 8 R)$-6-(5bromo-3-fluoropyridin-2-yl)-7-(3-((tert-butyldiphenylsilyl)oxy)-2,2-difluoropropyl)-8-methyl-6,7,8,9tetrahydro-3H-pyrazolo[4,3-f]isoquinoline (763 mg, 82\%) as an off-white solid. ${ }^{1} \mathrm{H}$ NMR $(500 \mathrm{MHz}$, DMSO- $\left.d_{6}, 27^{\circ} \mathrm{C}\right) 0.99(9 \mathrm{H}, \mathrm{s}), 1.04(3 \mathrm{H}, \mathrm{d}), 2.74-2.89(2 \mathrm{H}, \mathrm{m}), 2.97-3.04(1 \mathrm{H}, \mathrm{m}), 3.31(1 \mathrm{H}, \mathrm{s}), 3.54-$ $3.62(1 \mathrm{H}, \mathrm{m}), 3.78(1 \mathrm{H}, \mathrm{q}), 3.92-4.02(1 \mathrm{H}, \mathrm{m}), 5.36(1 \mathrm{H}, \mathrm{s}), 6.72(1 \mathrm{H}, \mathrm{d}), 7.23(1 \mathrm{H}, \mathrm{d}), 7.41-7.49(6 \mathrm{H}$, $\mathrm{m}), 7.57-7.61(4 \mathrm{H}, \mathrm{m}), 8.04(1 \mathrm{H}, \mathrm{dd}), 8.09(1 \mathrm{H}, \mathrm{s}), 8.38(1 \mathrm{H}, \mathrm{d}), 13.01(1 \mathrm{H}, \mathrm{s}) ; \mathrm{m} / \mathrm{z}$ : ESI+ calcd $\mathrm{C}_{35} \mathrm{H}_{36} \mathrm{BrF}_{3} \mathrm{~N}_{4} \mathrm{OSi}[\mathrm{M}+\mathrm{H}]+$ : 693; observed 693.

Preparation of (6S,8R)-6-(5-bromo-3-fluoropyridin-2-yl)-7-(3-((tert-butyldiphenylsilyl)oxy)-2,2difluoropropyl)-8-methyl-3-(tetrahydro-2H-pyran-2-yl)-6,7,8,9-tetrahydro-3H-pyrazolo[4,3flisoquinoline (34)

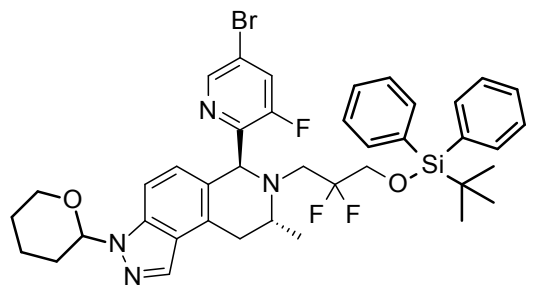

4-Methylbenzenesulfonic acid hydrate (143 $\mathrm{mg}, 0.75 \mathrm{mmol})$ was added to a solution of $(6 \mathrm{~S}, 8 R)$-6-(5bromo-3-fluoropyridin-2-yl)-7-(3-((tert-butyldiphenylsilyl)oxy)-2,2-difluoropropyl)-8-methyl-6,7,8,9tetrahydro-3H-pyrazolo[4,3-f]isoquinoline $(522 \mathrm{mg}, 0.75 \mathrm{mmol})$ and 3,4-dihydro-2H-pyran $(206 \mu \mathrm{l}$, $2.26 \mathrm{mmol})$ in DCM $(7.72 \mathrm{~mL})$. The resuting solution was stirred at $40{ }^{\circ} \mathrm{C}$ for 1 hour 45 minutes. The reaction mixture was allowed to cool to room temperature and diluted with EtOAc $(10 \mathrm{~mL})$ and washed with saturated aqueous $\mathrm{NaHCO}_{3}$ solution $(10 \mathrm{~mL})$ and saturated brine $(10 \mathrm{~mL})$. The organic layer was dried over $\mathrm{MgSO}_{4}$, filtered and concentrated under reduced pressure. The residue was 
purified by flash silica chromatography (40g, Puriflash, $\mathrm{HC}, 50 \mu)$, elution gradient 0 to $25 \%$ EtOAc in heptane to afford (6S,8R)-6-(5-bromo-3-fluoropyridin-2-yl)-7-(3-((tert-butyldiphenylsilyl)oxy)-2,2difluoropropyl)-8-methyl-3-(tetrahydro-2H-pyran-2-yl)-6,7,8,9-tetrahydro-3H-pyrazolo[4,3-

f]isoquinoline (400 mg, $68 \%$ ) as a gum. ${ }^{1} \mathrm{H}$ NMR $\left(500 \mathrm{MHz}, \mathrm{CDCl}_{3}, 27^{\circ} \mathrm{C}\right) 1.05(9 \mathrm{H}, \mathrm{d}), 1.12(3 \mathrm{H}, \mathrm{d}), 1.52$ $-1.80(1 \mathrm{H}, \mathrm{m}), 2.06(1 \mathrm{H}, \mathrm{d}), 2.15(1 \mathrm{H}, \mathrm{s}), 2.51-2.62(1 \mathrm{H}, \mathrm{m}), 2.79-2.89(2 \mathrm{H}, \mathrm{m}), 3.15(1 \mathrm{H}, \mathrm{ddd}), 3.24$ $-3.35(1 \mathrm{H}, \mathrm{m}), 3.67-3.76(3 \mathrm{H}, \mathrm{m}), 3.93-4.05(2 \mathrm{H}, \mathrm{m}), 5.41(1 \mathrm{H}, \mathrm{d}), 5.67(1 \mathrm{H}, \mathrm{ddd}), 6.78(1 \mathrm{H}, \mathrm{dd}), 7.31$ $(1 \mathrm{H}, \mathrm{dd}), 7.35-7.46(7 \mathrm{H}, \mathrm{m}), 7.61-7.67(4 \mathrm{H}, \mathrm{m}), 8.03(1 \mathrm{H}, \mathrm{dd}), 8.29-8.32(1 \mathrm{H}, \mathrm{m}) ; \mathrm{m} / \mathrm{z}$ : ESI+ calcd $\mathrm{C}_{40} \mathrm{H}_{44} \mathrm{BrF}_{3} \mathrm{~N}_{4} \mathrm{O}_{2} \mathrm{Si}[\mathrm{M}+\mathrm{H}]+:$ : 777; observed 777.

Preparation of 3-((6S,8R)-6-(5-bromo-3-fluoropyridin-2-yl)-8-methyl-3-(tetrahydro-2H-pyran-2-yl)3,6,8,9-tetrahydro-7H-pyrazolo[4,3-f]isoquinolin-7-yl)-2,2-difluoropropan-1-ol (35)

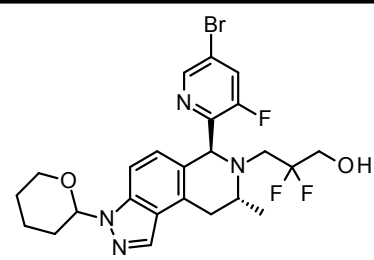

Tetrabutylammonium fluoride in THF $(1 \mathrm{M}, 560 \mu \mathrm{L}, 0.56 \mathrm{mmol})$ was added dropwise to $(6 \mathrm{~S}, 8 R)-6-(5-$ bromo-3-fluoropyridin-2-yl)-7-(3-((tert-butyldiphenylsilyl)oxy)-2,2-difluoropropyl)-8-methyl-3-

(tetrahydro-2H-pyran-2-yl)-6,7,8,9-tetrahydro-3H-pyrazolo[4,3-f]isoquinoline (396 mg, $0.51 \mathrm{mmol}$ ) in THF $(4.53 \mathrm{~mL})$. The resulting mixture was stirred at $25{ }^{\circ} \mathrm{C}$ for 1 hour. The reaction mixture was concentrated under reduced pressure. The residue was purified by flash silica $(25 \mathrm{~g}$, Puriflash, $50 \mu, \mathrm{HC})$ chromatography, elution gradient 0 to $50 \%$ EtOAc in heptane to afford 3-( $65,8 R)-6$-(5-bromo-3fluoropyridin-2-yl)-8-methyl-3-(tetrahydro-2H-pyran-2-yl)-3,6,8,9-tetrahydro-7H-pyrazolo[4,3-

f]isoquinolin-7-yl)-2,2-difluoropropan-1-ol (212 mg, $77 \%$ ) as a white solid. ${ }^{1} \mathrm{H}$ NMR (500 MHz, DMSO$\left.d_{6}, 27^{\circ} \mathrm{C}\right) 1.04(3 \mathrm{H}, \mathrm{d}), 1.56(2 \mathrm{H}, \mathrm{s}), 1.73(1 \mathrm{H}, \mathrm{s}), 1.94(1 \mathrm{H}, \mathrm{d}), 2.02(1 \mathrm{H}, \mathrm{d}), 2.36-2.43(1 \mathrm{H}, \mathrm{m}), 2.62-$ $2.72(1 \mathrm{H}, \mathrm{m}), 2.81-2.90(1 \mathrm{H}, \mathrm{m}), 2.99-3.06(1 \mathrm{H}, \mathrm{m}), 3.14-3.25(1 \mathrm{H}, \mathrm{m}), 3.50-3.74(4 \mathrm{H}, \mathrm{m}), 3.85$ $(1 \mathrm{H}, \mathrm{d}), 5.31(1 \mathrm{H}, \mathrm{t}), 5.37(1 \mathrm{H}, \mathrm{d}), 5.78(1 \mathrm{H}, \mathrm{ddd}), 6.82(1 \mathrm{H}, \mathrm{dd}), 7.41(1 \mathrm{H}, \mathrm{dd}), 8.09-8.13(2 \mathrm{H}, \mathrm{m}), 8.39$ $(1 \mathrm{H}, \mathrm{dd}) ; \mathrm{m} / \mathrm{z}$ : $\mathrm{ESI}+$ calcd $\mathrm{C}_{24} \mathrm{H}_{26} \mathrm{BrF}_{3} \mathrm{~N}_{4} \mathrm{O}_{2}[\mathrm{M}+\mathrm{H}]+:$ 539; observed 539.

Preparation of 3-((6S,8R)-6-(5-bromo-3-fluoropyridin-2-yl)-8-methyl-3-(tetrahydro-2H-pyran-2-yl)3,6,8,9-tetrahydro-7H-pyrazolo[4,3-f] isoquinolin-7-yl)-2,2-difluoropropyl trifluoromethanesulfonate<smiles>C[C@H]1Cc2c(ccc3c2cnn3C2CCCCO2)C(c2ncc(Br)cc2F)N1CC(F)(F)COS(=O)(=O)C(F)(F)F</smiles>

A solution of trifluoromethanesulfonic anhydride $(71.9 \mu \mathrm{L}, 0.43 \mathrm{mmol})$ in DCM $(279 \mu \mathrm{L})$ was added dropwise to a solution of 3-((6S,8R)-6-(5-bromo-3-fluoropyridin-2-yl)-8-methyl-3-(tetrahydro-2Hpyran-2-yl)-3,6,8,9-tetrahydro-7H-pyrazolo[4,3-f]isoquinolin-7-yl)-2,2-difluoropropan-1-ol (210 mg, $0.39 \mathrm{mmol})$ and 2,6-dimethylpyridine $(136 \mu \mathrm{L}, 1.17 \mathrm{mmol})$ in DCM $(1.68 \mathrm{~mL})$ at $-5^{\circ} \mathrm{C}$ under nitrogen. The resulting solution was stirred for 65 minutes at $-5{ }^{\circ} \mathrm{C}$. The reaction mixture was concentrated under reduced pressure to dryness at $15^{\circ} \mathrm{C}$ on buchi rotary evaporator to afford 3-( $\left.6 S, 8 R\right)-6-(5-$ bromo-3-fluoropyridin-2-yl)-8-methyl-3-(tetrahydro-2H-pyran-2-yl)-3,6,8,9-tetrahydro-7H- 
pyrazolo[4,3-f]isoquinolin-7-yl)-2,2-difluoropropyl trifluoromethanesulfonate which was used directly in the next reaction without further purification.

Preparation of (6S,8R)-6-(5-bromo-3-fluoropyridin-2-yl)-8-methyl-3-(tetrahydro-2H-pyran-2-yl)-7(2,2,3-trifluoropropyl)-6,7,8,9-tetrahydro-3H-pyrazolo[4,3-flisoquinoline (36)<smiles>C[C@@H]1Cc2c(ccc3c2cnn3C2CCCCO2)N(CC(F)(F)CF)C1c1ncc(Br)cc1F</smiles>

Tetrabutylammonium fluoride in THF (1M, $1.95 \mathrm{~mL}, 1.95 \mathrm{mmol})$ was added in one portion to 3((6S,8R)-6-(5-bromo-3-fluoropyridin-2-yl)-8-methyl-3-(tetrahydro-2H-pyran-2-yl)-3,6,8,9-tetrahydro7H-pyrazolo[4,3-f] isoquinolin-7-yl)-2,2-difluoropropyl trifluoromethanesulfonate (262 $\mathrm{mg}, 0.39$ $\mathrm{mmol})$ in THF $(1.95 \mathrm{~mL})$ under nitrogen. The resulting solution was stirred at room temperature for 90 minutes. The reaction mixture was concentrated under reduced pressure. The residue was purified by Flash RP chromatography (100g Redisep, C18 column), using decreasingly polar mixtures of water (containing $1 \% \mathrm{NH}_{3}$ ) and $\mathrm{MeCN}(50 \%-95 \%$ gradient) as eluents. Fractions containing the desired compound were evaporated to dryness to afford $(6 S, 8 R)-6$-(5-bromo-3-fluoropyridin-2-yl)-8-methyl3-(tetrahydro-2H-pyran-2-yl)-7-(2,2,3-trifluoropropyl)-6,7,8,9-tetrahydro-3H-pyrazolo[4,3f]isoquinoline (146 mg, 69\%) as an off-white solid. $\mathrm{m} / \mathrm{z}$ : $\mathrm{ESI}+$ calcd $\mathrm{C}_{24} \mathrm{H}_{25} \mathrm{BrF}_{4} \mathrm{~N}_{4} \mathrm{O}[\mathrm{M}+\mathrm{H}]+$ : 541 ; observed 541.

Preparation of (6S,8R)-6-(5-bromo-3-fluoropyridin-2-yl)-8-methyl-7-(2,2,3-trifluoropropyl)-6,7,8,9tetrahydro-3H-pyrazolo[4,3-flisoquinoline (37)<smiles>C[C@@H]1Cc2c(ccc3[nH]ncc23)C(c2ncc(Br)cc2F)N1CC(F)(F)CF</smiles>

Trifluoroacetic acid $(407 \mu \mathrm{l}, 5.32 \mathrm{mmol})$ was added dropwise to $(65,8 R)$-6-(5-bromo-3-fluoropyridin-2yl)-8-methyl-3-(tetrahydro-2H-pyran-2-yl)-7-(2,2,3-trifluoropropyl)-6,7,8,9-tetrahydro-3H-

pyrazolo[4,3-f]isoquinoline $(144 \mathrm{mg}, 0.27 \mathrm{mmol})$ in $\mathrm{DCM}(2.25 \mathrm{~mL})$ under nitrogen. The resulting solution was stirred at room temperature for 2.5 hours. The reaction mixture was concentrated under reduced pressure. The residue was purified by ion exchange chromatography, using an $5 \mathrm{~g}$ SCX-2 column. The desired product was eluted from the column using $1 \mathrm{M} \mathrm{NH}_{3} / \mathrm{MeOH}$ to afford $(6 S, 8 R)-6-(5-$ bromo-3-fluoropyridin-2-yl)-8-methyl-7-(2,2,3-trifluoropropyl)-6,7,8,9-tetrahydro-3H-pyrazolo[4,3f]isoquinoline (100 mg, 82\%) as a beige solid. $\mathrm{m} / \mathrm{z}$ : $\mathrm{ESI}+$ calcd $\mathrm{C}_{19} \mathrm{H}_{17} \mathrm{BrF}_{4} \mathrm{~N}_{4}[\mathrm{M}+\mathrm{H}]+: 457$; observed 457.

Preparation of 5-fluoro-N-(1-(3-fluoropropyl)azetidin-3-yl)-6-((6S,8R)-8-methyl-7-(2,2,3trifluoropropyl)-6,7,8,9-tetrahydro-3H-pyrazolo[4,3-f] isoquinolin-6-yl)pyridin-3-amine (12) 
<smiles></smiles>

Brettphos $3 \mathrm{G}$ precatalyst (19.43 $\mathrm{mg}, 0.02 \mathrm{mmol}$ ) was added to a solution of 1-(3-fluoropropyl)azetidin3-amine $\quad(56.7 \mathrm{mg}, \quad 0.43 \mathrm{mmol}), \quad(6 S, 8 R)-6$-(5-bromo-3-fluoropyridin-2-yl)-8-methyl-7-(2,2,3trifluoropropyl)-6,7,8,9-tetrahydro-3H-pyrazolo[4,3-f]isoquinoline (98 $\mathrm{mg}, 0.21 \mathrm{mmol}$ ) and sodium tert-butoxide $(82 \mathrm{mg}, 0.86 \mathrm{mmol})$ in degassed 1,4-dioxane $(2.38 \mathrm{~mL})$. The resulting mixture was evacuated and purged with nitrogen and stirred at $60^{\circ} \mathrm{C}$ for 100 minutes. The reaction mixture was cooled to room temperature, diluted with EtOAc $(10 \mathrm{~mL})$ and washed with water $(10 \mathrm{~mL})$. The layers were seperated and the aqueous layer was further extracted with EtOAc $(3 \times 10 \mathrm{~mL})$. The combined organic layers were washed with saturated brine, dried over $\mathrm{MgSO}_{4}$, filtered and concentrated under reduced pressure. The residue was purified by flash RP (Puriflash, C18, HC, 15 $\mu$ column), using decreasingly polar mixtures of water (containing $0.1 \%$ formic acid) and MeCN (10-30\% gradient) as eluents. Fractions containing the desired compound were isolated via ion exchange chromatography, using an $5 \mathrm{~g}$ SCX-2 column. The desired product was eluted from the column using $1 \mathrm{M} \mathrm{NH}_{3} / \mathrm{MeOH}$ and pure fractions were evaporated to dryness to afford 5-fluoro- $N$-(1-(3-fluoropropyl)azetidin-3-yl)-6((6S,8R)-8-methyl-7-(2,2,3-trifluoropropyl)-6,7,8,9-tetrahydro-3H-pyrazolo[4,3-f]isoquinolin-6yl)pyridin-3-amine $12(41.3 \mathrm{mg}, 37 \%)$ as a white solid. ${ }^{1} \mathrm{H}$ NMR $\left(500 \mathrm{MHz}\right.$, DMSO- $\left.d_{6} 27^{\circ} \mathrm{C}\right) 1.04(3 \mathrm{H}, \mathrm{d})$, $1.64(2 \mathrm{H}, \mathrm{dq}), 2.44(2 \mathrm{H}, \mathrm{t}), 2.66-2.84(4 \mathrm{H}, \mathrm{m}), 2.97(1 \mathrm{H}, \mathrm{dd}), 3.15-3.26(1 \mathrm{H}, \mathrm{m}), 3.56-3.64(3 \mathrm{H}, \mathrm{m})$, $3.94(1 \mathrm{H}, \mathrm{h}), 4.39(1 \mathrm{H}, \mathrm{t}), 4.48(1 \mathrm{H}, \mathrm{t}), 4.56-4.82(2 \mathrm{H}, \mathrm{m}), 5.19(1 \mathrm{H}, \mathrm{s}), 6.61(1 \mathrm{H}, \mathrm{d}), 6.66-6.73(2 \mathrm{H}$, m), $7.20(1 \mathrm{H}, \mathrm{d}), 7.55(1 \mathrm{H}, \mathrm{dd}), 8.04(1 \mathrm{H}, \mathrm{s}), 12.95(1 \mathrm{H}, \mathrm{s}) ;{ }^{13} \mathrm{C}$ NMR $\left(126 \mathrm{MHz}, \mathrm{DMSO}-d_{6} 27^{\circ} \mathrm{C}\right) 17.4$, 28.7, 29.7, 43.4, 47.3, 48.7, 55.4, 61.4, 62.1, $80.2(J=172.7 \mathrm{~Hz}), 82.5(J=162.2 \mathrm{~Hz}), 105.3,108.1,122.1$, $122.9,125.5,12756,127.7,130.3,132.0,136.8,139.1,145.4,158.7(J=260.1 \mathrm{~Hz}) ;{ }^{19} \mathrm{~F} \mathrm{NMR}(471 \mathrm{MHz}$, DMSO- $\left.d_{6} 27^{\circ} \mathrm{C}\right)-238.81(J=46.1,14.1),-218.16(J=47.7,25.2),-124.84,-110.70(J=22.7,14.9,8.4)$. $\mathrm{m} / \mathrm{z}$ : $\mathrm{ESI}+$ calcd $\mathrm{C}_{25} \mathrm{H}_{29} \mathrm{~N}_{6} \mathrm{~F}_{5}[\mathrm{M}+\mathrm{H}]+:$ 509; observed 509; HRMS $\left(E S I^{+}\right)$: Anal. calcd. For $\mathrm{C}_{25} \mathrm{H}_{29} \mathrm{~N}_{6} \mathrm{~F}_{5}$ $[\mathrm{M}+\mathrm{H}]+$ : 509.2452; observed 509.2462. 


\section{Biochemical and in vitro cell assays:}

Assays were run as per Callis R.; Rabow A.; Tonge M.; Bradbury R.; Challinor M.; Roberts K.; Jones K.; Walker G. A Screening Assay Cascade to Identify and Characterize Novel Selective Estrogen Receptor Downregulators (SERDs). J. Biomol. Screen. 2015, 20(6),748-759 and are fully described below

\section{ER $\alpha$ binding assay}

The ability of compounds to bind to isolated Estrogen Receptor Alpha Ligand binding domain (ER alpha - LBD (GST)) was assessed in competition assays using a LanthaScreen ${ }^{\text {TM }}$ Time-Resolved Fluorescence Resonance Energy Transfer (TR-FRET) detection end-point. For the LanthaScreen TR-FRET endpoint, a suitable fluorophore (Fluormone ES2, Product code P2645) and recombinant human Estrogen Receptor alpha ligand binding domain (Product code PV4543) were purchased from Invitrogen and used to measure compound binding. The assay principle is that ER alpha -LBD (GST) is added to a fluorescent ligand to form a receptor/fluorophore complex. A terbium-labelled anti-GST antibody (Product code PV3551) is used to indirectly label the receptor by binding to its GST tag, and competitive binding is detected by a test compounds' ability to displace the fluorescent ligand resulting in a loss of TR-FRET signal between the Tb-anti-GST antibody and the tracer. The assay was performed as follows with all reagent additions carried out using the Beckman Coulter BioRAPTR FRD microfluidic workstation:-

1. Acoustic dispense $120 \mathrm{nl}$ of the test compound into a black low volume 384 well assay plates.

2. Prepare $1 x$ ER alpha -LBD/Tb-antiGST Ab in ES2 screening buffer and incubate for 20 minutes.

3. Add $1 x$ fluorophore to the ER alpha -LBD/Tb-antiGST Ab solution prior to use.

4. Dispense $12 \mu \mathrm{l}$ of the $1 \times$ AR-LBD/Tb-anti-GST Ab/Fluorophore reagent into each well of the assay plate

5. Cover the assay plate to protect the reagents from light and evaporation, and incubate at room temperature for 1 hour.

6. Excite at $337 \mathrm{~nm}$ and measure the fluorescent emission signal of each well at $490 \mathrm{~nm}$ and 520 $\mathrm{nm}$ using the BMG PheraSTAR.

Compounds were dosed directly from a compound source microplate containing serially diluted compound (4 wells containing $10 \mathrm{mM}, 0.1 \mathrm{mM}, 1 \mu \mathrm{M}$ and $10 \mathrm{nM}$ final compound respectively) to an assay microplate using the Labcyte Echo 550. The Echo 550 is a liquid handler that uses acoustic technology to perform direct microplate-to-microplate transfers of DMSO compound solutions and the system can be programmed to transfer multiple small $\mathrm{nL}$ volumes of compound from the different source plate wells to give the desired serial dilution of compound in the assay which is then back-filled to normalise the DMSO concentration across the dilution range. In total $120 \mathrm{~nL}$ of compound plus DMSO is added to each well and compounds were tested in a 12-point concentration response format over a final compound concentration range of 100, 29.17, 10.42, 2.083, 1, 0.292, 0.104, 0.02083, 0.01, $0.002917,0.001042,0.0001 \mu \mathrm{M}$, respectively. TR-FRET dose response data obtained with each compound was exported into a suitable software package (such as Origin or Genedata) to perform curve fitting analysis. Competitive ER alpha binding was expressed as an $\mathrm{IC}_{50}$ value. This was determined by calculation of the concentration of compound that was required to give a $50 \%$ reduction in tracer compound binding to ER alpha-LBD.

\section{MCF-7 ER degradation assay}

The ability of compounds to down-regulate Estrogen Receptor (ER) numbers was assessed in a cell based immuno-fluorescence assay using the MCF-7 human ductal carcinoma breast cell line. MCF-7 cells were revived directly from a cryovial (approx $5 \times 10^{6}$ cells) in Assay Medium (phenol red free Dulbecco's Modified Eagle's medium (DMEM) (Sigma D5921) containing 2mM L-Glutamine and $5 \%(\mathrm{v} / \mathrm{v})$ Charcoal/Dextran treated foetal calf serum Cells were syringed once using a sterile $18 \mathrm{G} \mathrm{x}$ 1.5inch $(1.2 \times 40 \mathrm{~mm})$ broad gauge needle and cell density was measured using a Coulter Counter (Beckman). Cells were further diluted in Assay Medium to a density of $3.75 \times 10^{4}$ cells per $\mathrm{ml}$ and $40 \mathrm{\mu l}$ per well added to transparent bottomed, black, tissue culture treated 384 well plates (Costar, No. 
3712) using a Thermo Scientific Matrix WellMate or Thermo Multidrop. Following cell seeding, plates were incubated overnight at $37^{\circ} \mathrm{C}, 5 \% \mathrm{CO}_{2}$ (Liconic carousel incubator). Test data was generated using the LabCyte Echo ${ }^{\circledR}$ model 555 compound reformatter which is part of an automated workcell (Integrated Echo 2 workcell). $10 \mathrm{mM}$ compound stock solutions of the test compounds were used to generate a 384 well compound dosing plate (Labcyte P-05525-CV1). 40 ?al of each of the $10 \mathrm{mM}$ compound stock solutions was dispensed into the first quadrant well and then 1:100 step-wise serial dilutions in DMSO were performed using a Hydra II (MATRIX UK) liquid handling unit to give 40ul of diluted compound into quadrant wells $2(0.1 \mathrm{mM}), 3(1 \mathrm{lM})$ and $4(0.01 \mathrm{lM})$, respectively. 40? DMSO added to wells in row $\mathrm{P}$ on the source plate allow for DMSO normalisation across the dose range. To dose the control wells 40 ?] of DMSO was added to row 01 and 40 ?] of $100 \mu \mathrm{M}$ Faslodex ${ }^{\circledR}$ in DMSO was added to row $\mathrm{O} 3$ on the compound source plate. The Echo uses acoustic technology to perform direct microplate-to-microplate transfers of DMSO compound solutions to assay plates. The system can be programmed to transfer volumes as low as $2.5 \mathrm{~nL}$ in multiple increments between microplates and in so doing generates a serial dilution of compound in the assay plate which is then back-filled to normalise the DMSO concentration across the dilution range. Compounds were dispensed onto the cell plates with a compound source plate prepared as above producing a $12 \mathrm{pt}$ duplicate $3 \mu \mathrm{M}$ to $3 \mathrm{pM}$ dose range with 3 fold dilutions and one final 10 fold dilution using the Integrated Echo 2 workcell. The maximum signal control wells were dosed with DMSO to give a final concentration of $0.3 \%$ and the minimum signal control wells were dosed with Faslodex ${ }^{\circledR}$ to give a final concentration of $100 \mathrm{nM}$ accordingly. Plates were further incubated for $18-22$ hours at $37{ }^{\circ} \mathrm{C}, 5 \% \mathrm{CO}_{2}$ and then fixed by the addition of $20 \mu \mathrm{l}$ of $11.1 \%(\mathrm{v} / \mathrm{v})$ formaldehyde solution (in phosphate buffered saline (PBS)) giving a final formaldehyde concentration of $3.7 \%(\mathrm{v} / \mathrm{v})$. Cells were fixed at room temperature for 20 mins before being washed two times with 250 $\mu$ PBS/Proclin (PBS with a Biocide preservative) using a BioTek platewasher, $40 \mu \mathrm{l}$ of PBS/Proclin was then added to all wells and the plates stored at $4{ }^{\circ} \mathrm{C}$. The fixing method described above was carried out on the Integrated Echo 2 workcell. Immunostaining was performed using an automated AutoElisa workcell. The PBS/Proclin was aspirated from all wells and the cells permeabilised with $40 \mu \mathrm{l}$ PBS containing $0.5 \%$ Tween $^{\mathrm{TM}} 20$ $(\mathrm{v} / \mathrm{v})$ for 1 hour at room temperature. The plates were washed three times in $250 \mu \mathrm{l}$ of PBS/0.05\% $(\mathrm{v} / \mathrm{v})$ Tween 20 with Proclin (PBST with a Biocide preservative) and then $20 \mu \mathrm{l}$ of ER $\alpha$ (SP1) Rabbit monoclonal antibody (Thermofisher) 1:1000 in PBS/Tween ${ }^{\mathrm{TM}} / 3 \%(\mathrm{w} / \mathrm{v})$ Bovine Serum Albumin was added. The plates were incubated overnight at $4{ }^{\circ} \mathrm{C}$ (Liconic carousel incubator) and then washed three times in $250 \mu \mathrm{l}$ of PBS/0.05\% (v/v) Tween ${ }^{\text {TM }} 20$ with Proclin (PBST). The plates were then incubated with $20 \mu \mathrm{l} /$ well of a goat anti-rabbit IgG AlexaFluor 594 or goat anti-rabbit AlexaFluor 488 antibody (Molecular Probes) with Hoechst at 1:5000 in PBS/Tween ${ }^{\mathrm{TM}} / 3 \%(\mathrm{w} / \mathrm{v})$ Bovine Serum Albumin for $1 \mathrm{hr}$ at room temperature. The plates were then washed three times in $250 \mu \mathrm{l}$ of PBS/0.05\% (v/v) Tween $^{\mathrm{TM}} 20$ with Proclin (PBST with a Biocide preservative). $20 \mu \mathrm{l}$ of PBS was added to each well and the plates covered with a black plate seal and stored at $4{ }^{\circ} \mathrm{C}$ before being read. Plates were read using a Cellomics Arrayscan reading the $594 \mathrm{~nm}$ ( $24 \mathrm{hr}$ time point) or $488 \mathrm{~nm}$ ( $5 \mathrm{hr}$ timepoint) fluorescence to measure the ER $\alpha$ receptor level in each well. The mean total intensity was normalized for cell number giving the total intensity per cell. The data was exported into a suitable software package (such as Origin) to perform curve fitting analysis. Down-regulation of the ER $\alpha$ receptor was expressed as an $\mathrm{IC}_{50}$ value and was determined by calculation of the concentration of compound that was required to give a $50 \%$ reduction of the average maximum Total Intensity signal. $\mathrm{S}_{\text {inf }}$ is reported as a $\%$ reduction relative to fulvestrant as a standard.

Results are tabulated below for both assays together with number of test results ( $n$ ) and standard error of the mean (SEM)

ER binding and ER degradation assay: Values \& Errors

\begin{tabular}{|c|c|c|c|c|c|c|c|c|}
\hline Cpd No & $\begin{array}{c}\text { ER bind } \\
\mathrm{pIC}_{50}\end{array}$ & pIC $_{50} \mathrm{SD}$ & $\begin{array}{c}\mathrm{pIC}_{50} \\
\mathrm{SEM}\end{array}$ & $\mathrm{n}$ & $\mathrm{ER}$ & $\mathrm{pIC}_{50} \mathrm{SD}$ & $\mathrm{pIC}_{50}$ & $\mathrm{n}$ \\
$\mathrm{SR}$ & & & $\mathrm{SEM}$ & \\
\hline
\end{tabular}




\begin{tabular}{|c|c|c|c|c|c|c|c|c|}
\hline & & & & & $\mathrm{plC}_{50}$ & & & \\
\hline $\mathbf{1}$ & 8.6 & 0.54 & 0.11 & 22 & 9.8 & 0.16 & 0.04 & 17 \\
\hline $\mathbf{2}$ & 8.8 & 0.54 & 0.27 & 4 & 9.7 & 0.24 & 0.17 & 2 \\
\hline $\mathbf{3}$ & 8.7 & 0.47 & 0.21 & 5 & 9.6 & 0.05 & 0.03 & 3 \\
\hline $\mathbf{4}$ & 9.3 & 0.29 & 0.15 & 4 & 9.7 & 0.25 & 0.15 & 3 \\
\hline $\mathbf{5}$ & 7.8 & 0.27 & 0.14 & 4 & 8.3 & 0.12 & 0.07 & 3 \\
\hline $\mathbf{6}$ & 6.3 & 1.37 & 0.79 & 3 & 8.6 & 0.11 & 0.08 & 2 \\
\hline $\mathbf{7}$ & 7.4 & 0.29 & 0.17 & 3 & 6.9 & 0.1 & 0.07 & 2 \\
\hline $\mathbf{8}$ & 9.0 & 0.69 & 0.34 & 4 & 10.3 & 0.29 & 0.17 & 3 \\
\hline $\mathbf{9}$ & 8.9 & 0.65 & 0.27 & 6 & 10.0 & 0.27 & 0.16 & 3 \\
\hline $\mathbf{1 0}$ & 8.4 & 0.60 & 0.23 & 7 & 9.5 & 0.13 & 0.07 & 4 \\
\hline $\mathbf{1 1}$ & 8.6 & 0.40 & 0.20 & 4 & 9.3 & 0.19 & 0.11 & 3 \\
\hline $\mathbf{1 2}$ & 8.7 & 0.64 & 0.32 & 4 & 9.9 & 0.25 & 0.15 & 3 \\
\hline
\end{tabular}

Western blotting: Expression levels of protein were assessed using standard Western blotting techniques (NuPAGE Novex 4\%-12\% Bis-Tris gels). Cells were lysed in $25 \mathrm{mmol} / \mathrm{L}$ Tris/HCL pH 6.8, 3 $\mathrm{mmol} / \mathrm{L}$ EDTA, $3 \mathrm{mmol} / \mathrm{L}$ EGTA, $50 \mathrm{mmol} / \mathrm{L} \mathrm{NaF}, 2 \mathrm{mmol} / \mathrm{L}$ sodium orthovanadate, $270 \mathrm{mmol} / \mathrm{L}$ sucrose, $10 \mathrm{mmol} / \mathrm{L} \beta$-glycerophosphate, $5 \mathrm{mmol} / \mathrm{L}$ sodium pyrophosphate and $0.5 \%$ Triton $\mathrm{X}-100$ supplemented with protease inhibitors (Roche) and phosphatase inhibitors (Pierce). Antibodies to ER (SP1, Thermo) or $\beta$ Actin (4970, CST) were diluted in 5\% milk-PBS-0.05\% Tween and signal detected using SuperSignal West Dura HRP substrate followed by visualization on a Syngene ChemiGenius Imager.

\begin{tabular}{|c|c|c|c|c|}
\hline Cpd No & $\begin{array}{c}\text { \% deg vs Fv } \\
\text { MCF-7 }\end{array}$ & $\mathrm{n}$ & $\begin{array}{c}\text { \% deg vs Fv } \\
\text { CAMA-1 }\end{array}$ & $\mathrm{n}$ \\
\hline $\mathbf{1}$ & 95 & 28 & 98 & 17 \\
\hline $\mathbf{2}$ & 93 & 2 & 106 & 2 \\
\hline $\mathbf{3}$ & 96 & 2 & 98 & 2 \\
\hline $\mathbf{4}$ & 98 & 1 & 97 & 2 \\
\hline $\mathbf{9}$ & 96 & 2 & 100 & 2 \\
\hline $\mathbf{1 0}$ & 95 & 1 & 98 & 2 \\
\hline
\end{tabular}




\section{PAINS screening}

Compounds were screened for known PAINS substructures, using SMARTS definitions curated by OpenEye Scientific and adapted from the SLN patterns from Baell and Holloway. ${ }^{1}$ All compounds were found to be clean against all filters.

1. Baell, J. B.; Holloway, G. A. New Substructure Filters for Removal of Pan Assay Interference Compounds (PAINS) from Screening Libraries and for Their Exclusion in Bioassays J. Med. Chem., 2010, 53(7), 2719-2740.

\section{Molecular Formula Strings}

\begin{tabular}{|c|c|}
\hline 1 & C[C@@ @ $] 1 \mathrm{Cc} 2 \mathrm{c}(\mathrm{ccc} 3 \mathrm{c} 2 \mathrm{cn}[\mathrm{nH}] 3)[\mathrm{C} @ \mathrm{H}](\mathrm{N} 1 \mathrm{CC}(\mathrm{F})(\mathrm{F}) \mathrm{F}) \mathrm{c} 4 \mathrm{ccc}(\mathrm{cn} 4) \mathrm{NC5CN}(\mathrm{C} 5) \mathrm{CCCF}$ \\
\hline 2 & C[C@@ $@] 1 C c 2 c(c c c 3 c 2 c n[n H] 3)[C @ H](N 1 C C(F)(F) F) c 4 c c c(c(n 4) F) N C 5 C N(C 5) C C C F$ \\
\hline 3 & $\mathrm{C}[\mathrm{C} @ @ \mathrm{H}] 1 \mathrm{Cc} 2 \mathrm{c}(\mathrm{ccc} 3 \mathrm{c} 2 \mathrm{cn}[\mathrm{nH}] 3)[\mathrm{C} @ \mathrm{H}](\mathrm{N} 1 \mathrm{CC}(\mathrm{F})(\mathrm{F}) \mathrm{F}) \mathrm{c} 4 \mathrm{c}(\mathrm{cc}(\mathrm{cn} 4) \mathrm{NC} 5 \mathrm{CN}(\mathrm{C} 5) \mathrm{CCCF}) \mathrm{F}$ \\
\hline 4 & $\mathrm{C}[\mathrm{C} @ @ \mathrm{H}] 1 \mathrm{Cc} 2 \mathrm{c}(\mathrm{cc}(\mathrm{c} 3 \mathrm{c} 2 \mathrm{cn}[\mathrm{nH}] 3) \mathrm{F})[\mathrm{C} @ \mathrm{H}](\mathrm{N} 1 \mathrm{CC}(\mathrm{F})(\mathrm{F}) \mathrm{F}) \mathrm{c} 4 \mathrm{ccc}(\mathrm{cn} 4) \mathrm{NC} 5 \mathrm{CN}(\mathrm{C} 5) \mathrm{CCCF}$ \\
\hline 5 & $\mathrm{C}[\mathrm{C} @ @ \mathrm{H}] 1 \mathrm{Cc} 2 \mathrm{c3cn}[\mathrm{nH}] \mathrm{c3cc}(\mathrm{c} 2[\mathrm{C} @ \mathrm{H}](\mathrm{N} 1 \mathrm{CC}(\mathrm{F})(\mathrm{F}) \mathrm{F}) \mathrm{c} 4 \mathrm{ccc}(\mathrm{cn} 4) \mathrm{NC}$ CNN(C5)CCCF)F \\
\hline 6 & C[C@@ @ $] 1 \mathrm{Cc} 2 \mathrm{c} 3 \mathrm{cn}[\mathrm{nH}] \mathrm{c3cc}(\mathrm{c} 2[\mathrm{C} @ \mathrm{H}](\mathrm{N} 1 \mathrm{CC}(\mathrm{F})(\mathrm{F}) \mathrm{F}) \mathrm{c} 4 \mathrm{ccc}(\mathrm{cn} 4) \mathrm{NC} 5 \mathrm{CN}(\mathrm{C} 5) \mathrm{CCCF}) \mathrm{OC}$ \\
\hline 7 & C[C@@H]1Cc2c3cn[nH]c3cc(c2[C@H](N1CC(F)(F)F)c4ccc(cn4)NC5CN(C5)CCCF)O \\
\hline 8 & $\mathrm{C}[\mathrm{C} @ @ \mathrm{H}] 1 \mathrm{Cc} 2 \mathrm{c}(\mathrm{ccc} 3 \mathrm{c} 2 \mathrm{c}(\mathrm{n}[\mathrm{nH}] 3) \mathrm{F})[\mathrm{C} @ \mathrm{H}](\mathrm{N} 1 \mathrm{CC}(\mathrm{F})(\mathrm{F}) \mathrm{F}) \mathrm{c} 4 \mathrm{ccc}(\mathrm{c}(\mathrm{n} 4) \mathrm{F}) \mathrm{NC} 5 \mathrm{CN}(\mathrm{C} 5) \mathrm{CCCF}$ \\
\hline 9 & $\mathrm{C}[\mathrm{C} @ @ \mathrm{H}] 1 \mathrm{Cc} 2 \mathrm{c}(\mathrm{ccc} 3 \mathrm{c} 2 \mathrm{c}(\mathrm{n}[\mathrm{nH}] 3) \mathrm{F})[\mathrm{C} @ \mathrm{H}](\mathrm{N} 1 \mathrm{CC}(\mathrm{F})(\mathrm{F}) \mathrm{F}) \mathrm{c} 4 \mathrm{c}(\mathrm{cc}(\mathrm{cn} 4) \mathrm{NC} 5 \mathrm{CN}(\mathrm{C} 5) \mathrm{CCCF}) \mathrm{F}$ \\
\hline 10 & C[C@@ @ $] 1 C c 2 c(c c c 3 c 2 c n[n H] 3)[C @ H](N 1 C C(F) F) c 4 c c c(c n 4) N C 5 C N(C 5) C C C F$ \\
\hline 11 & c1cc(ncc1NC2CN(C2)CCCF)[C@@H]3c4ccc5c(c4C[C@H](N3CC(F)F)C(F)F)cn[nH]5 \\
\hline 12 & $\mathrm{C}[\mathrm{C} @ @ \mathrm{H}] 1 \mathrm{Cc} 2 \mathrm{c}(\mathrm{ccc} 3 \mathrm{c} 2 \mathrm{cn}[\mathrm{nH}] 3)[\mathrm{C} @ \mathrm{H}](\mathrm{N} 1 \mathrm{CC}(\mathrm{CF})(\mathrm{F}) \mathrm{F}) \mathrm{c} 4 \mathrm{c}(\mathrm{cc}(\mathrm{cn} 4) \mathrm{NC} 5 \mathrm{CN}(\mathrm{C} 5) \mathrm{CCCF}) \mathrm{F}$ \\
\hline
\end{tabular}

